Distribution Category:

Environmental Control Technology and Earth Sciences (UC-11)

ANL-80-115

Part III

ARGONNE NATIONAL LABORATORY

9700 South Cass Avenue

Argonne, Illinois 60439

RADIOLOGICAL AND ENVIRONMENTAL RESEARCH DIVISION ANNUAL REPORT

Ecology

January-December 1980

R. E. Rowland, Division Director

W. R. Penrose, Section Head

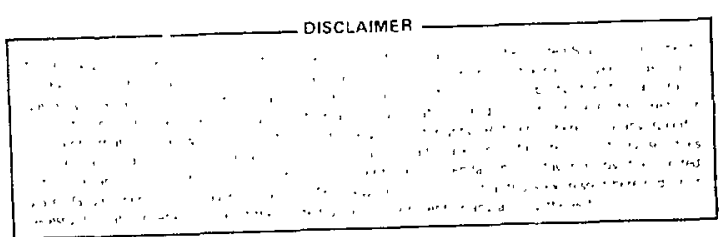

July 1981

\title{
Preceding Report
}

ANL-79-65 Part III

January-December 1979 
The year 1980 will stand as one of the most productive in the recent history of the Ecological sciences section, as many long-term research programs bore fruit. In addition, several new programs were begun, including a development project for microcosm screening systems, two initiatives in ecological modeling, and a program of field experiments for a national assessment of crop losses due to air pollution.

The microcosm project exploited recent developments of the Great Lakes Research program, namely two techniques for maintaining simulations of the euphotic and bentric zones of lakes in the laboratory. A proposal to develop these procedures into screening protocols for newly-manufactured chemicals as required by the Toxic Substances control Act was generated and funded. This research has been highly productive to date, and it continues into 1981.

Numerical modeling of ecological systems offers the potential for integrating and explaining complex sets of field data, and perhaps even for prediction. For example, this year simple models of pollutant uptake by Lake Michigan fish were expanded to include bioenergetic terms, and a substantial amount of outwardly disparate data from both our own experiments and the literature has thus been explained. Further, a lake eutrophication model has been implemented for the National Great Lakes Program office, EPA Region V, to simulate the effects of phosphorus control on Lake Michigan.

The National Crop Loss Assessment Network is an EPA program being conducted at five sites across the nation, selected to represent economicallyimportant crops. Argonne, as the only site in the Midwest, occupies a.l important position in the program. Results measured in terms of productivity can be linked directly to air pollution effects assessments in economic terms.

Long-term work on two different problems came together this year to produce a significant, and perhaps alarming, prediction of the effects of zinc in Lake Michigan. Experiments in enclosures in both lake and laboratory demonstrated a dramatic sensitivity of Lake Michigan plankton to zinc at ievels well below those permitted by published EPA criteria. At the same time, mass budget calculations predicted that zinc concentrations high enough to inhibit primary productivity in the lake would be attained as early as 1995. Proposed revision of the Clean Air Act and projected increases in coal 
combustion could bring about these changes sooner.

Dissolved organic carbon appears to play a significant role in the aquatic chemistry of plutonium, essentially competing with sediment particles for the element. Recognition of the role of this water quality parameter rationalizes a substantial body of formerly contradictory data on plutonium chemistry in natural aquatic systems.

The new Section Head, Dr. William Penrose, joined Argonne in February. A biochemist formerly with Canada Fisheries in St. John's, Newfoundland, he has been involved in environmental research for eight years. Other new members of the Section are Lance Kress, who heads the Argonne Regional crop Loss Assessment Project; Greeneville B. Hall and Chi-Hsiang Lei, postdoctoral appointees with the biology group; and Donald Metta and Patricia SzczepanikVan leeuwen, who transferred from other Divisions. Prof. Alvin Jensen, a Faculty Research Leave Appointee from the University of Michigan, has lent valuable assistance in the initiation of our ecological modeling projects.

We look forward to an active and prosperous 1981. 
Effect on the Productivity of Field-Grown Soybeans by Combinations

of Sulfur Dioxide and Nitrogen Dioxide

P. M. IRVING, P. B. XERIKOS, and J. E. MILLER

Effect of $\mathrm{H}^{+}, \mathrm{SO}_{4}{ }^{-}, \mathrm{NO}_{3}^{-}$, and $\mathrm{NH}_{4}^{-}$Concentrations and Ratios in Precipitation Applied to Greenhouse-Grown Soybeans

P. M. IRVING and D. A. SOWINSKI

Impact of Ozone on Soybean Yield

L. W. KRESS and J. E. MILLER

Variability of the Yield Response of Field-Grown Soybean Cultivars to $\mathrm{SO}_{2}$

J. E. MILLER, H. J. SMITH, and P. B. XERIKOS

Influence of Dissolved Organic Carbon on the sorption of Plutonium to Natural Sediments

D. M. NELSON, J. O. KAKTTUNEN, K. A. ORLANDINI, and R. P. LARSEN

Oxidation State Distribution of Plutonium in Marine Waters

D. M. NELLSON, D. N. METTA, and R. P. LARSEN

Comparison of the Geochemical Behavior of Plutonium, Thorium, and Uranium in Selected North American Lakes

M. A. WAHLGREN and K. A. ORLANDINI

R/N Ekos, A Research Tool

R. M. WILLIAMS and R. W. DANA

A Note on the Use of Box Models for Estimating Dry Deposition Velocity

R. M. WILLIAMS

A Model for the Dry Deposition of Particles on Natural Water Surfaces
R. M. WILLIAMS

Air quality Changes over Southern Lake Michigan: 1973-1974 Compared With 1978-1979

G. T. TISUE, D. J. FINGLETON, J. A. ROBBINS, R. ALLISON, and S. BARR

Results of Lab and Field Tests of an Organics Air Sampler R. J. WINGENDER

Sediment Resuspension Processes in the Great Lakes B. M. LESHT, R. M. WILLIAMS, and R. V. WHITE.

Lake Mi.chigan Database Analysis and Model Development B. M. LESHT 
Concentrations of Dissolved and Particulate Forms of Trace Elements in Lake Michigan's Major Tributaries G. T. TISUE, C. A. SEILS, and D. A. WARNER

Lake Water Chemistry and Zinc Toxicity to Plankton Communities - A

J. S. MARSHALL, D. M. NELSON, D. L. MELTINGER, C. LEI, S. G. LAWRENCE, and D. F. MALLEY

Sorption of ${ }^{65} \mathrm{Zn}$ and ${ }^{109} \mathrm{Cd}$ by Seston in Southern Lake Michigan

J. I. PARKER, K. A. STANLAW, and C. W. KENNEDY

A Three-Year Study on the Effects of Enclosure on Zooplankton in a Large, Curtained Bay of ELA Lake 382

D. L. MELLINGER, J. S. MARSHALL, and D. F. MALLEY

Measurement of the spatial and Temporal Distributions of Cllorophyll and Total Suspended Solids in Southern Lake Michigan by Fluorometer and Nephelometry, Respectively

J. I. PARKER, C. W. KENNEDY, and K. A. STANLAW

Plankton Microcosm Research. Response of Natural Phytoplankton Communities to Zinc Toxicity - A Preliminary Report

G. B. HALL

Use of a Coulter Counter for Seston Analysis in Plankton Microcosm Research

C. LEI and J. S. MARSHALL

A Laboratory Incubator for Plankton Microcosm Research

W. PREPEJCHAL, J. S. MARSHALL, G. B. HALL, and M. M. THOMMES

Construction of a Portable Incubator for Phytoplankton Primary Productivity Studies

W. PREPEJCHAL and G. B. HALL

Heterotrophy in a Sediment-water Microcosm

P. A. SZCZEPANIK-VAN LEEUWEN and W. R. PENROSE

Effects of Zinc and Cadmium on Phytoplankton Primary Productivity in Souchern Lake Michigan

J. I. PARKER, K. A. STANLAW, and C. H. BELTMAN

Thermal Experience of Brown Trout Residing Near Heated Discharges S. A. SPIGARELLI, M. M. THOMMES, W. PREPEJCHAL, and R. M. GOLDSTEIN

Effects of Constant and Fluctuating Temperatures on Ectotherms

S. A. SPIGAREILI, M. M. THOMMES, W. PREPEJCHAL, and A. JENSEN

Modelling Growth and PCB Uptake of Brown Trout (Salmo trutta)

A. L. JENSEN, S. A. SPIGARELLI, and M. M. THOMMES

Publications 
EFFECT (NN THE PRODUCTIVITY OF FIELD-GROWN SOYBEANS BY COMBINATIONS OF SULFUR DIOXIDE AIND NITROGEN DIOXIDE

P. M. Irving, P. B. Xerikos, and J. E. Miller

Background and scope

Most of the combustion processes which generate sulfur dioxide $\left(\mathrm{SO}_{2}\right)$ also produce a mixture of nitrogen oxiaes $\left(\mathrm{NO}_{\mathbf{x}}\right)$ because the associated high temperatures cause atmospheric $\mathrm{O}_{2}$ and $\mathrm{N}_{2}$ to combine to form No, which is then oxidized to $\mathrm{NO}_{2}$. We have previously shown significant reduction in yield of field-grown soybeans after chronic and acute $\mathrm{SO}_{2}$ exposures. ${ }^{1}$ While single pollutant studies are numerous and useful to determine phytotoxicity, research on the effects of pollutant combinations are necessary to estimate air pollutant damage to plants realistically in order to establi-h air quality standards. Several researchers have reported non-additive (synergistic or antagonistic) responses of plants to combinations of air pollutants. ${ }^{-4}$ Most of these studies, however, were done in chambers or greenhouses using potted plants and were not typical of field conditions. Our purpose was to determine the effects of $\mathrm{SO}_{2}$ and $\mathrm{NO}_{2}$ in combination on a field-grown crop in the presence of ambient concentrations of ozone $\left(\mathrm{O}_{3}\right)$.

\section{Progress in 1980}

Three experimental areas within a field plot of soybeans were selected for pollutant exposures to: (1) $\mathrm{SO}_{2}$ alone, (2) $\mathrm{NO}_{2}$ alone, and (3) $\mathrm{SO}_{2}$ and $\mathrm{NO}_{2}$ combined. Control plots were established 1 to 5 meters upwind of treated plots. Fumigation apparatus of the ZAPS (Zonal Air Pollution System) design, 5 was used to achieve the desired $\mathrm{SO}_{2}$ and $\mathrm{NO}_{2}$ concentrations. The same aluminum pipe was used to transport both the diluted $\mathrm{SO}_{2}$ and $\mathrm{NO}_{2}$ gases to the combired pollutant field plot. However, separate pipes will be used in future experiments since the combination of the two gases was corrosive to the aluminum pipe.

The plots were fumigated on 10 occasions between 30 July and 30 August 1980, with an average exposure time per fumigation of $2.5 \mathrm{hr}$ for $\mathrm{SO}_{2}$ anc 2.9 $\mathrm{hr}$ for $\mathrm{NO}_{2}$. The average concentrations during fumigations were 0.41 to 0.13 $\mathrm{ppm}$ of $\mathrm{SO}_{2}$ and 0.37 to $0.12 \mathrm{ppm}$ of $\mathrm{NO}_{2} \cdot$ Average ambient $\mathrm{SO}_{2}$ and $\mathrm{MO}_{2}$ concentrations were $<0.01 \mathrm{ppm}$. Twelve hour mean concentrations of ambient 
ozone ranged from 0.02 to 0.09 ppm with peaks exceeding 0.1 ppm on 6 occasions. The 12-hr average $\mathrm{O}_{3}$ concentration during July and August was 0.05 ppm.

Combinations of $\mathrm{SO}_{2}$ and $\mathrm{NO}_{2}$ decreased seed yield by 9.3 to 17.88 at concentrations causing no decreases when they occurred alone (Table 1 ). Analysis of variance indicated an interactive effect on yield when $\mathrm{SO}_{2}$ and $\mathrm{NO}_{2}$ occurred in combination and in the presence of ambient $\mathrm{O}_{3}$. Closer examination of the results in the combined plot suggest another interesting effect: Among plots having similar $\mathrm{SO}_{2}$ concentrations, those with lower $\mathrm{SO}_{2}: \mathrm{NO}_{2}$ ratios $(0.8$ and 0.7$)$ have less effect on yield than those with higher ratios $(1.8$ and 1.3).

The positive effects on yield at the low single pollutant concentrations (7.18 tigher at $3.5 \mathrm{ppm}^{\circ} \mathrm{hr} \mathrm{SO}_{2}$ and 7.58 higher at $3.5 \mathrm{ppm}{ }^{\circ} \mathrm{hr} \mathrm{NO}_{2}$ ) suggest a fertilizer response through additions of small amounts of $S$ or $N$. These positive effects are apparently outweighed by the negative effects of higher pollutant concentrations and by the synergistic effect of the pollutant combination. Increased biomass of tomato plants after exposure to low concentrations of $\mathrm{NO}_{2}$ have been reported. ${ }^{6}$ Positive effects on yield after exposure to low doses of $\mathrm{SO}_{2}$ have also been observed by a number of researchers. 7,8

When examined on 29 August 1980, a yreater number of plan's in the combined plot exhibited interveinal necrosis than in the single pollutant plots. It should also be noted that leaf bronzing at the sixth node and below was observed in untreated and fumigated plots and was apparently the result of ozone injury. Chlorophyll extraction of leaves collected on 3 september 1980 , indicated no significant effect from $\mathrm{SO}_{2}$ alone, little or no effect from $\mathrm{NO}_{2}$, and approximately a $23 \%$ decrease from the combination of $\mathrm{SO}_{2}$ and $\mathrm{NO}_{2}$ (Table 2). These results suggest that the yield decreases resulting from exposure to $\mathrm{SO}_{2}$ and $\mathrm{NO}_{2}$ combined may have been caused by accelerated senescence. A greater degree of chlorosis was visibly evident in the combined plots compared to the control and single pollutant plots in early september. Several investigators have reported visible injury to plants following exposure to combinations of $\mathrm{SO}_{2}$ and $\mathrm{NO}_{2}$ when no such injury occurred at similar concentrations of the pollutants alone. 3,9 
Table 1. Yield of soybeanc after 10 field exposures of sulfur dioxide, nitrogen dioxide, and combinations of the two in the presence of ambient ozone. ${ }^{a}$

\begin{tabular}{|c|c|c|c|c|c|c|}
\hline $\mathrm{ppm}^{\mathrm{e}}$ & $\mathrm{SO}_{2}^{\mathrm{b}} \mathrm{ppm} \cdot \mathrm{hr}{ }^{\mathrm{F}}$ & $\mathrm{ppm}^{\mathrm{e}}$ & $\mathrm{NO}_{2}^{\mathrm{C}} \mathrm{ppm} \cdot \mathrm{hr} \mathrm{r}^{\mathrm{F}}$ & $\begin{array}{ll} & \text { Yie } \\
8 \text { of }\end{array}$ & $\begin{array}{l}1 \mathrm{~d}, \mathrm{~d} \\
\text { control }\end{array}$ & $\mathrm{SO}_{2}: \mathrm{NO}_{2}$ \\
\hline$<0.01$ & $<0.25$ & $<0.01$ & $<0.29$ & 100.0 & \multicolumn{2}{|c|}{ bcd (contro:.) } \\
\hline 0.32 & 8.1 & & & 104.6 & $a b$ & \\
\hline 0.26 & 6.5 & & & 101.0 & $a b c d$ & \\
\hline U.20 & 5.0 & & & 104.9 & $a b$ & \\
\hline 0.14 & 3.5 & & & 107.1 & $a$ & \\
\hline 0.42 & 10.6 & & & 98.8 & bcde & \\
\hline 0.36 & 9.3 & & & 98.9 & bcde & \\
\hline 0.31 & 8.0 & & & 105.0 & $a b$ & \\
\hline \multirow[t]{9}{*}{0.25} & 6.6 & & & 98.7 & bcde & \\
\hline & & 0.37 & 10.2 & 97.4 & bcde & \\
\hline & & 0.31 & 8.9 & 97.4 & cde & \\
\hline & & 0.27 & 7.6 & 94.2 & de & \\
\hline & & 0.23 & 6.4 & 98.8 & bcde & \\
\hline & & 0.15 & 4.2 & 103.6 & $a b c$ & \\
\hline & & 0.14 & 3.9 & 104.5 & $a b c$ & \\
\hline & & 0.13 & 3.5 & 107.5 & a & \\
\hline & & 0.12 & 3.3 & 98.5 & bcde & \\
\hline 0.24 & 5.8 & 0.30 & 8.6 & 90.7 & ef & 0.8 \\
\hline 0.21 & 5.1 & 0.28 & 7.8 & 86.5 & $\mathrm{fgh}$ & 0.8 \\
\hline 0.18 & 4.4 & 0.25 & 6.9 & 86.0 & fgh & 0.7 \\
\hline 0.15 & 3.7 & 0.22 & 6.1 & 89.1 & fg & 0.7 \\
\hline 0.40 & 10.1 & 0.16 & 4.4 & 84.8 & gh & 2.5 \\
\hline 0.33 & 8.1 & 0.15 & 4.1 & 83.6 & gh & 2.2 \\
\hline 0.25 & 6.2 & 0.14 & 3.8 & 83.1 & $\mathrm{~h}$ & 1.8 \\
\hline 0.17 & 4.3 & 0.13 & 3.5 & 82.2 & $\mathrm{~h}$ & 1.3 \\
\hline
\end{tabular}

a 0.05 ppm mean 12-hr $\mathrm{O}_{3}$ concentration.

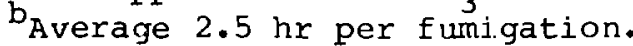

$C_{\text {Average } 2.9}$ hr per fumigation.

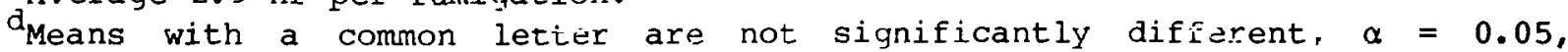
according to Duncan's multiple range test.

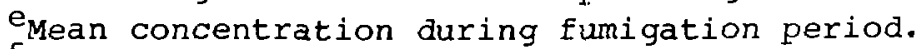

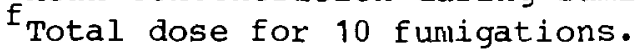

Our results and those of others make it clear that research on the effects of air polluiion should address the issue of multiple pollutant interactions at various concentrations and ratios before damage assessments are made. 
Table 2. Effect of $\mathrm{SO}_{2}, \mathrm{NO}_{2}$, and combinations of the two on leaf chlorophyll content.a

\begin{tabular}{rcc}
\multicolumn{1}{c}{$\mathrm{SO}_{2}$} & $\mathrm{NO}_{2}$ & $\begin{array}{c}\text { Total chlorophyll } \\
\text { of of control }\end{array}$ \\
\hline 8.07 & & 106.1 \\
10.59 & 10.18 & 105.7 \\
& 4.20 & 101.7 \\
5.80 & 8.63 & $93.9^{\mathrm{b}}$ \\
10.08 & 4.39 & $77.3^{\mathrm{b}}$ \\
& & $76.3^{\mathrm{b}}$ \\
\hline
\end{tabular}

a Leaves at fifth node from abtx, sampled on 3 Septemb in 1980, $\mathrm{n}=20$.

$b_{\text {Effect }}$ is statistically significant at 0.05 level.

\section{Prospects}

Field studies will be continued to generate additional dose-response information on exposure of soybeans to $\mathrm{SO}_{2}-\mathrm{NO}_{2}$. Effects on other crop species will also be investigated. Laboratory studies are being planned on plant enzyme systems to investigate possible mechanisms involved in the synergistic -ffects of $\mathrm{SO}_{2}$ and $\mathrm{NO}_{2}$.

\section{Ref erences}

1. Miller, J. E., H. J. Smith, P. B. Xerikos, and P. M. Irving, $\mathrm{SO}_{2}$ effects on soybean yield: Dose-response relations from 1979 field studies, Radiological and Environmental Research Division Annual Report, JanuaryDecember 1979, ANL-79-65, Part III, pp. 49-51.

2. White, K. L., A. C. Hill, and J, H. Bennett, Synergistic inhibition of apparent photosynthesis rate of alfalfa by combinations of sulfur dioxide and nitrogen dioxide, Environ. Sci. Technol. 8, 574-576 (1974).

3. Tingey, D. T., R. A. Reinert, J. A. Dunning, and W. W. Heck, Vegetation injury from the interation of nitrogen dioxide and sulfur dioxide, Phytopathology 61, 1506-1511 (1971).

4. Ashenden, T. W. and I. A. D. Williams, Growth reductions in Iolium multiflorum lam. and Phleum pratense L. as a result of $\mathrm{SO}_{2}$ and $\mathrm{NO}_{2}$ pollution, Environ. Pollut. 21, 131-139 (1980).

5. Miller, J. E., D. G. Sprugel, R. N. Muller, H. J. Smith, and P. B. 
Xerikos, Open-air fumigation system for investigating sulfur dioxide effects on crops, Phytopathology 70, 1124-1128 (1980).

6. Troiano, J. J. and I. A. Leone, Changes in growth rate and nitrogen content of tomato plants afer exposure to $\mathrm{NO}_{2}$, Phytopathology $67,1130-$ 1133 (1977).

7. Cowling, D. W., R. H. Jones, and D. R. Lockyer, Increased yield through correction of sulfur deficiency in ryegrass exposd to sulfur dioxide, Nature $\underline{243}, 479-480$ (1973).

8. Noggle, J. C. and H. C. Jones, Accumulation of atmospheric sulfur by plants and sulfur-supplying capacity of soils, U.S. Environmental Protection Agency Publ. EPA-60017-79-109 (1979).

9. Bennett, J. H., A. C. Hill, A. Soleimani, and W. H. Edwards, Acute effects of the combination of sulfur dioxide and nitrogen dioxide on plants, Environ. Pollut. $\underline{9}, 127-132$ (1975). 
EFFECT OF $\mathrm{H}^{+}, \mathrm{SO}_{4}{ }^{=}, \mathrm{NO}_{3}^{-}$, AND $\mathrm{NH}_{4}^{+}$CONCENTRATIONS AND RATIOS IN PRECIPITATION APPLIED TO GREENHOUSE-GROWN SOYBEANS

P. M. Irving and D. A. Sowinski*

\section{Background and Scope}

Pollutant gases and their transformation products affect precipitation chemistry in many regions of the U.S. However, the actual ionic composition of precipitation with simjlar mean $\mathrm{H}^{+}$concentrations (pH) may differ considerably among regions.1,2 The chemistry of precipitation may also vary considerably between individual events within a particular region. 3,4 The widely expressed concern about the effects of acid precipitation should direct research efforts to the investigation of the effects of all the major ions, in precipitation, rather than acidity alone. Previous research at Argonne has suggested that in addition to hydrogen ions, concentrations of $\mathrm{SO}_{4}=$ and $^{\mathrm{NO}_{3}}{ }^{-}$ in precipitation may affect plant response. An examination of the 1979 National Atmospheric Deposition Program (NADP) report on precipitation chemistry indicates regional variation in seasonal averages of some ions. We chose three sites from the NADP network in the northeast, midwest, and west (Cornell, New York; Bondville, Illinois; and Manitou, Colorado) regions of the U.S. to compare sulfate $\left(\mathrm{SO}_{4}{ }^{-}\right.$) and nitrate ( $\mathrm{NO}_{3}{ }^{-}$) ratios during the growing season (June, July and August) and found the $\mathrm{SO}_{4}$ : $\mathrm{NO}_{3}$ ratio to be approximately 3:1, $2: 1$ and $1: 1$ in the northeast, midwest and west, respectively. It was also determined thai $\mathrm{H}^{+}$and $\mathrm{NH}^{+}$were positively correlated with $\mathrm{so}_{4}=$ and $\mathrm{NO}_{3}{ }^{-}$. Because of the possibility that these ions, as well as $\mathrm{H}^{+}$, may be important factors affecting plant response to acid rain, we decided to examine in more detail the effects on crop plants of precipitation simulants having various chemistries.

\section{Progress in 1980}

Since $S$ and $N$ nutrition in plants is interrelated, we suspected their concentrations and ratios in precipitation could affect growth, and thus designed the experiment to include 3 ratios of $\mathrm{SO}_{4}=$ and $\mathrm{NO}_{3}{ }^{-}$and $3 \mathrm{pH}$ levels in the 9 simulant treatments (Table 1).

*Undergraduate Research Participant, Argonne's Division of Educatisnal Programs, University of Rhode Island. 
Table 1. Concentration of ions in precipitation simulants.a

\begin{tabular}{llllll}
\hline $\mathrm{pH}$ & $\mathrm{SO}_{4}: \mathrm{NO}_{3}$ & $\mathrm{H}^{+}$ & $\mathrm{SO}_{4}=$ & $\begin{array}{c}\mathrm{NO}_{3}{ }^{-} \\
\mathrm{mg} / \mathrm{L}\end{array}$ & $\mathrm{NH}_{4}^{+}$ \\
\hline \multirow{3}{*}{3.0} & $1: 1$ & 1.0 & 29.36 & 26.5 & 0.54 \\
& $2: 1$ & 1.0 & 36.45 & 18.32 & 1.04 \\
3.8 & $3: 1$ & 1.0 & 42.00 & 14.00 & 1.80 \\
& $1: 1$ & 0.15 & 5.34 & 5.33 & 0.54 \\
& $2: 1$ & 0.15 & 7.09 & 3.55 & 0.66 \\
& $3: 1 \mathrm{~b}$ & 0.15 & 8.00 & 5.165 & 1.47 \\
& $1: 1$ & 0 & 0.95 & 1.03 & 0.37 \\
& $2: 1$ & 0 & 1.40 & 0.70 & 0.30 \\
& $3: 1$ & 0 & 1.59 & 0.53 & 0.37 \\
\hline
\end{tabular}

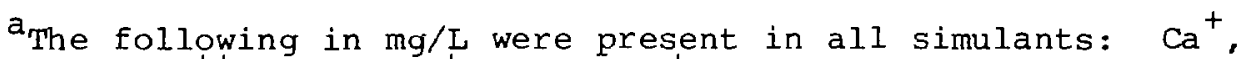
$0.22 ; \mathrm{Mg}^{++}, 0.027 ; \mathrm{K}^{+}, 0.04 ; \mathrm{Na}^{+}, 0.114 ; \mathrm{Cl}^{-}, 0.122$.

$\mathrm{b}_{\text {With this simulant formula, the ratio is actually } 1.5: 1 .}$

Greenhouse-grown soybean plants were sprayed with the precipitation simulants weekly, beginning one week after germination and continuing for 10 weeks, at which time seed set was nearly completed. Plants were harvested in two groups of five plants per group: (1) after completion of seed set, for measurements of biomass and rhizobium nodulation; and (2) after normal senescence, leaf fall and drying, for seed yield determinations. Regression analyses, testing for main effects and interactions, were used to determine whether any independent variable or combination of variables $\left(\mathrm{H}^{+}, \mathrm{NH}_{4}^{+}, \mathrm{SO}_{4}=\right.$, $\mathrm{NO}_{3}{ }^{-}$) significantly affected the dependent variables. Duncan's multiple range test was then used to compare means.

Results from the first harvest indicated that $\mathrm{H}^{+}, \mathrm{SO}_{4}=\mathrm{NO}_{3}^{-}$, and $\mathrm{NH}_{4}^{+}$in rain simulants affect shoot weight significantly (Table 2). The dry weight of root nodules is significantly affected by the interaction of $\mathrm{H}^{+}, \mathrm{SO}_{4}=\mathrm{NO}_{3}{ }^{-}$, and $\mathrm{NH}_{4}^{+}$(Table 2$)$.

Analysis of the second harvest indicated that the number of pods per plant, pod dry weight, and stod dry weight were significantly affected by the precipitation chemistry (Tab'e 3). The treatment group that received the highest dose of $\mathrm{H}^{+}$and $\mathrm{SO}_{4}=$ had the greatest pod and seed wejght. Lowest seed weights, however, occurred at the intermediate dose levels of $\mathrm{H}^{+}$and $\mathrm{so}_{4}=$. 
Tahle 2. Dry weight of soybean shoots and nodules as a function of $\mathrm{H}^{+}, \mathrm{SO}_{4}{ }^{+}, \mathrm{NO}_{3}{ }^{-}$, and $\mathrm{NH}_{4}^{+}$in applied precipitation.

\begin{tabular}{|c|c|c|c|}
\hline $\mathrm{pH}$ & $\mathrm{SO}_{4}=\mathrm{NO}_{3}{ }^{-}$ & Shoot & $\mathrm{g}^{\text {a }}$ \\
\hline \multirow[t]{3}{*}{3.0} & $1: 1$ & $8.586 a$ & $0.187 \mathrm{abc}$ \\
\hline & $2: 1$ & $7.674 \mathrm{ab}$ & $0.141 \mathrm{bc}$ \\
\hline & $3: 1$ & $8.310 a$ & $0.225 \mathrm{a}$ \\
\hline \multirow[t]{3}{*}{3.8} & $1: 1$ & $8.878 \mathrm{a}$ & $0.132 \mathrm{bc}$ \\
\hline & $2: 1$ & $7.266 \mathrm{ab}$ & $0.126 \mathrm{bc}$ \\
\hline & $1.5: 1$ & $7.382 \mathrm{ab}$ & $0 . \therefore 2$ bc \\
\hline \multirow[t]{3}{*}{5.6} & $1: 1$ & $8.214 \mathrm{a}$ & $0.127 \mathrm{bc}$ \\
\hline & $2: 1$ & $6.472 \quad b$ & $0.117 \quad \mathrm{c}$ \\
\hline & $3: 1$ & $7.706 \mathrm{ab}$ & $0.204 \mathrm{ab}$ \\
\hline
\end{tabular}

a Means with a common letter are not significantly different, $a=0.05, \mathrm{n}=5$.

Table 3. Pods, pod weight, and seed weicht of soybeans as a function of $\mathrm{H}^{+}, \mathrm{SO}_{4}{ }^{=}$, and $\mathrm{NO}_{3}=$ in applied precipitation.

\begin{tabular}{|c|c|c|c|c|c|}
\hline $\mathrm{H}^{+}$ & $\begin{array}{c}\mathrm{SO}_{4}= \\
\mathrm{mg} / \mathrm{L}\end{array}$ & $\mathrm{NO}_{3}^{-}$ & Pods per plant & Pod wt, $g^{a}$ & Seed $w t, g^{a}$ \\
\hline 1.0 & 29.36 & 26.50 & 19.8 & $6.69 \mathrm{ab}$ & $4.82 \mathrm{ab}$ \\
\hline 1.0 & 36.45 & 18.32 & $24.0 \mathrm{abc}$ & $7.07 \mathrm{ab}$ & $5.05 \mathrm{ab}$ \\
\hline 1.0 & 42.00 & 14.00 & $25.6 \mathrm{ab}$ & $7.77 \mathrm{a}$ & $5.58 \mathrm{a}$ \\
\hline 0.15 & 5.34 & 5.33 & $25.75 \mathrm{ab}$ & $6.55 \quad b$ & $4.42 \quad \mathrm{~b}$ \\
\hline 0.15 & 7.09 & 3.55 & $26.0 \quad a$ & $6.56 \quad b$ & $4.43 \quad \mathrm{~b}$ \\
\hline 0.15 & 8.00 & 5.165 & $26.2 \quad a$ & $6.90 \mathrm{ab}$ & $4.59 \quad \mathrm{~b}$ \\
\hline 0 & 0.955 & 1.03 & 20.6 & $6.33 \mathrm{~b}$ & $4.46 \quad b$ \\
\hline 0 & 1.40 & 0.70 & $21.75 \mathrm{abc}$ & $6.66 \mathrm{ab}$ & $4.68 \mathrm{ab}$ \\
\hline 0 & 1.59 & 0.53 & 21.8 abc & $7.40 \mathrm{ab}$ & $5.24 \mathrm{ab}$ \\
\hline
\end{tabular}

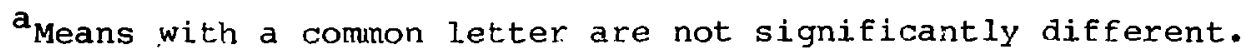

Because of the number of independent variables associated with this experiment, the only generalization possible from the results is that $\mathrm{H}^{+}$, $\mathrm{NH}_{4}{ }^{+}, \mathrm{SO}_{4}=$, and $\mathrm{NO}_{3}^{-}$in precipitation affect soybean productivity. Certain 
trends, however, are evident. For example, within each pH group, shoot weight and nodule weight were lowest as a result of the $2 \mathrm{sO}_{4}: 1 \mathrm{NO}_{3}$ ratio in applied precipitation. Seed weight and pods per plant were greatest at the highest $\mathrm{SO}_{4}=$ concentrations within each $\mathrm{pH}$ group. Within each $\mathrm{SO}_{4}{ }^{=}: \mathrm{NO}_{3}{ }^{-}$ratio, pod and seed weight.s followed the trend according to $\mathrm{pH}$ where $3.0>5.6>3.8$. Although the high concentrations of hydrogen ions used in the low $\mathrm{pH}$ treatments in this experiment caused visible injury no deleterious effects on soybean productivity was cbserved. Plant response appeared to be principally affected by the ratios of ions in the precipitation simulants.

\section{Prospects}

It is possible that the visible injury and negative effects on plantproductivity reported by some researchexs as a result of acid rain exposure may have been due to salt or acid stress from the high ionic strength solutions that comprise the acid simulants. There are probably different plant response curves for the various doses of acidity, sulfur, nitrogen and other components in precipitation. It is the interaction of precipitation components producing stress with those producing stimulation that will influence plant physiology and the ultimate growth response. The investigation and identification of these stress/stimulant factors and their interactions is a goal of our future effects research.

\section{References}

1. Andersson, T., Smal1-scale variations of the contamination of rain caused by washout from the low layers of the atmoshere, Tellus 21, 685-692 (1967).

2. Gorham, E., Acidic preciitation and its influence upon aquatic ecosystems - an overview, Water, Ajr, Soil Pollut. 6, 457-479 (1976).

3. Dawson, G. A., Ionic composition of rain during sixteen convective showers, Atmos. Environ. 12, 1991-1999 (1978).

4. Gorham, E., The influence and importance of daily weather conditions in the supply of chloride, sulphate, and other ions to fresh wacers from atinosheric precipitation, Philos. Trans. R. Soc. London, Ser. B. 247, 147173 (1958).

5. Irving, P. M. and J. E. Miller, The effects of acid precipitation alone and in combination with sulfur dioxide on field-grown soybeans, 
Radiological and Environmental Research Division Annual Report, JanuaryDecember 1978, ANL-78-65, Part III, pp. 17-20. 
IMPACT OF OZONE ON SOYBEAN YIELD

L. W. Kress and J. E. Miller

\section{Background and Scope}

Soybeans are a major crop in the world and one of the leading cash crops in the midwestern United States. Ozone $\left(\mathrm{O}_{3}\right)$, the primary photochemical oxidant and most important air pollutant worldwide, impinges upon soybeans to some extent wherever they are grown. Soybeans are sensitive to $O_{3}$, and yield reductions have been demonstrated under ambient field conditions.1,2 Heagle et $a 1 .{ }^{3}$ have reported the only field generated dose-response information. They found soybean yield reductions of $6,14,22$, and 308 associated with seasonal $7 \mathrm{hr} /$ day mean $\mathrm{O}_{3}$ concentrations of $0.07,0.08,0.09$, and $0.10 \mathrm{ppm}$, respectively.

Since it is known that greenhouse or growth chamber grown plants respond differently to stress from plants in their natural environment, it was decided that field evaluations, where all factors except air pollution are maintained as close to ambient as possible, were necessary to produce meaningful yield effect estimates. For the study of the impact of $o_{3}$, open-top field chambers utilizing charcoal-filtered air and unfiltered air, as well as air wi.th various amounts of $\mathrm{O}_{3}$ added, was deemed the best experimental approach. These chambers and methods have been used successfully for several years.1.4-6 The chambers are $2.4 \mathrm{~m}$ high and $3 \mathrm{~m}$ in diameter. An aluminum frame is covered with a clear polyvinyl chloride plastic. The bottom portion of the plastic has a double wall with perforations on the inner wall. A fan blows air into the double-walled plastic panel; the air goes into the bottom half of the chamber uniformly around its circumference and exits through the open top. The incoming air may be charcoal-filtered, unfiltered, or have various concentrations of pollutants added to it before it enters the chamber.

This repo." reflects a portion of the research conducted at Argonne for its part in the National Crop Loss Assessment Network (NCLAN). The objective of the study is to evaluate the impact of current and increased $\mathrm{O}_{3}$ concentrations on crop yield.

\section{Progress in 1980}

In 1980 a randomized block design incorporating four replicates of six 
treatments was used. Thr treרtments wer: AA, no chamber; CF, charcoal Eiltered air chamber; NF-1, unfiltered alr (1) 3 conventration equal to that $1 \mathrm{n}$ ambient air); NF-2, unflitered air plus 0.03 pom $j_{3}$ above ambient; NF-3, unfiltered air plus 0.06 ppm $3_{3}$ above ambient: NF-4, unfiltered air plus 0.09 pprn $C_{3}$ above ambient. Ozone was aried tu the chambers from 0900 to 1600 cST daily. Ozone was not added on rainy days, tius the actuai o 3 concentrations were somewhat less than 0.03, 0.05, anj 0.09 pon above arabent in those respective treatments (Table 1). The Growing perior for the soybeans (Giycine max Merr., cv. Corsoy) was approxlinately 1 July-1 orijer. The experimental treatments began on $\varepsilon$ sugust (the time of plant Eloweing) and coritined until 30 september. Snybean pols were harvester (alin 50 cm-row samples/plot)

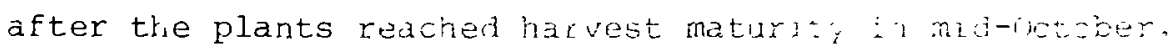

Twenty to thlety-two percent of the plarts ir each plot weze affected oy viruses. The virus-affecteri pionts were mostly atunted, rema nto green afier the other plants serescei, and pr bused ro or fin sesis, The seed

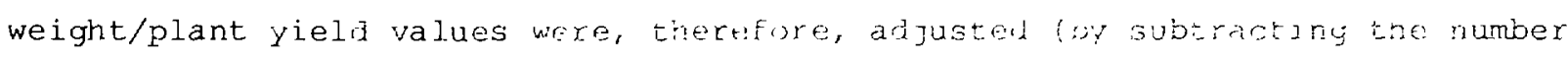

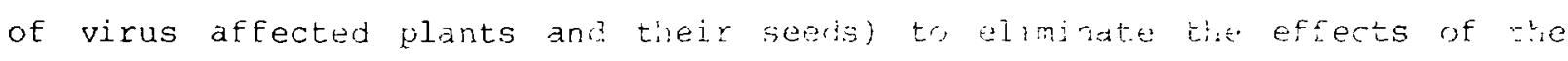

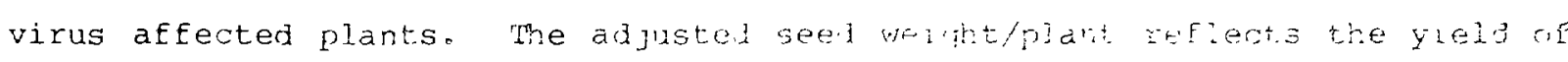
only the apparently healtiny plants.

The yield data demonstrated that as 0.3 pocertatimn iacreased, seed number and weight decreased (Table 1). Tiere were no sugnieicani differences between the AA plots and the NF-1 plots Eor any parameter. The wiohtiseed from the AA plots was significantly less thar that For the ch plots and the adjusted seed weight/plant for the NG-î plots was sjignílicantiy lesis than that for the CF plots. At an average $\mathrm{O}_{3}$ concentration of 0.065 ppm $\mathrm{O}_{3}$ ( $\mathrm{Ni}-2$; there was significantly less weight/seed than in the CF plots and loss seed weight/plant than in the NF-1 plots. The NF-3 (0.089 ppm O 3 ) plot vield was significantly less than the $\mathrm{NF}-2$ plot yield for seed neight, seed weight/plant, and weight/seed. The Ni-1 yields were sigrificartiy less than the NF-3 yields for total seed weight and weight/seed. The Ni-4 value for percent oil content was significantly less than, and that for percent protein content was significantly greater than the values for the CF, AA, and NF-i plots.

The $\mathrm{O}_{3}$ concentrations used in this experiment had significant impact on the yield of soybeans. As $\mathrm{O}_{3}$ increased there were fewer, smaller seeds rith a 
Table 1. Yield parameters of Corsoy soybeans exposed to charcoal-filtered air (CF), ambient air (AA) open plot, and (NF-1) unfiltered chamber, and ambient air plus $O_{3}$ during the 1980 growth period.

Yield per $50 \mathrm{~cm}$ row segment

\begin{tabular}{|c|c|c|c|c|c|c|c|c|c|c|c|c|c|}
\hline \multirow[b]{2}{*}{ Treatment } & \multicolumn{2}{|c|}{ ppm Ozone* } & \multirow[b]{2}{*}{ Plants } & \multirow{2}{*}{\multicolumn{2}{|c|}{$\begin{array}{l}\text { Seed } \\
\text { weight, } \\
g\end{array}$}} & \multirow{2}{*}{\multicolumn{2}{|c|}{$\begin{array}{c}\text { Seed } \\
\text { weight/plant, } \\
g\end{array}$}} & \multirow{2}{*}{\multicolumn{2}{|c|}{$\begin{array}{l}\text { Adjusted seed } \\
\text { weight/plant, } \\
\qquad\end{array}$}} & \multirow{2}{*}{\multicolumn{2}{|c|}{$\begin{array}{c}\text { Weight/seed, } \\
g\end{array}$}} & \multirow[b]{2}{*}{$80 i 1$} & \multirow[b]{2}{*}{$\%$ Protein } \\
\hline & $7 / 1-9 / 30$ & $8 / 6-9 / 30$ & & & & & & & & & & & \\
\hline$C F$ & 0.037 & 0.021 & 7.8 a & 109 & $\mathbf{a}$ & 14.2 & $a b$ & 22.0 & $\mathbf{a}$ & 0.149 & a & $19.5 \mathrm{a}$ & $38.9 \quad \mathrm{~b}$ \\
\hline$A A$ & 0.050 & 0.045 & $7.7 \mathrm{a}$ & 106 & a & 14.1 & $a b$ & 19.8 & $a b$ & 0.141 & b & $19.2 \mathrm{a}$ & $38.9 \quad b$ \\
\hline $\mathrm{NF}-1$ & 0.050 & 0.043 & $8.0 \mathrm{a}$ & 113 & $\mathbf{a}$ & 14.5 & a & 18.9 & $\mathrm{~b}$ & 0.143 & $a b$ & $19.2 \mathrm{a}$ & $38.3 \mathrm{~b}$ \\
\hline $\mathrm{NF}-2$ & 0.064 & 0.065 & $8.4 a$ & 96 & a & 11.8 & $\mathrm{~b}$ & 15.2 & $\mathrm{C}$ & 0.137 & $b$ & $18.9 \mathrm{ab}$ & $39.6 \mathrm{ab}$ \\
\hline $\mathrm{NF}-3$ & 0.079 & 0.089 & $8.2 a$ & 77 & b & 9.4 & C & 12.0 & d & 0.126 & c & $19.0 \mathrm{ab}$ & $39.5 \mathrm{ab}$ \\
\hline $\mathrm{NF}-4$ & 0.094 & 0.115 & $8.4 \mathrm{a}$ & 59 & C & 7.2 & C & 9.6 & $d$ & 0.115 & d & $18.2 \mathrm{~b}$ & $40.6 \mathrm{a}$ \\
\hline
\end{tabular}

*7/1-9/30, entire groi ing period for the soybeans; 8/6-9/30, duration of chamber treatments.

+ Seed weight/healthy plants, values adjusted to compensate for effects of virus infected plants which

¥ $\begin{aligned} & \text { produced little or no seed. } \\ & \text { Values in a column followed by the same letter are not significantly different at } P=0.05 \text {. }\end{aligned}$ 
lower oil content. The adaition of 0.014 to $0.022 \mathrm{ppm} \mathrm{O}_{3}$ above ambient (NF-2) caused a significant reduction in seed weight per plant. There were indications that even the ambient $O_{3}$ concentrations may have significantly suppressed the yield in terms of adjusted seed weight per plant. The yield reduction values generated in this experiment appear to be very compatible with experimental results collected for soybeans in North Carolina over the past three years. 1,4

A comiarison of the $F_{1}$ plot with the NF-1 plots revealed no significant chamber eifect for any of the mazsured parameters. Significantly less growth in chamters compared to open plots has been reported, 3 and significant differences in oil and protein content have also been reported. 7 The lack of any chamber effect in this study supports other research utilizing similar chamber designs. $2,5,6$

\section{Referances}

1. Heagle, A. S., A. J. Riordan, and W. W. Heck, Field mechods to assess the impact of air pollutants un crop yields, Pro'. 72nd Ann. Mtg. Air Pollution Control Assoce, Cincinnati, 24-29 Ju:e 19:9, Paper 79, p. 45.6 (1979).

2. Howell, R. K., E. J. Koch, and L. P. Rose, Jr., Fi.eld assessment of $\bar{c}$.ir pollution induced soybean yield losses, Agron. J. $71,285-288$ (1979).

3. Howell, R. K., Effects of air pollution on fcod production, Proc. 3Jth Ann. Mtg. Soil Conservation Soc. Ar.,. San Antonio, Texas, 10-13 August 1975, pp. 61-67.

4. Heagle, A. S., SEA, USDA, North Carolind State University, personal communication (1981).

5. Heagle, A. S., S. Spencer, and M. B. Letchworth, Yield response of winter wheat to chronic doses of ozone, ian. J. Bot. 57, 1999-2005 (1979).

6. Heggestad, H. E., A. S. Heagle, J. H. Bennett, and E. J. Koch, The effects of photochemical oxidants on the yield of snap beans, Atmos. Environ. 14, $317-326(1980)$

7. Howell, R. K. and L. P. Rose, Jr., Residual air pollution effects on soybean seed quality, Plant Disease $64,335-386$ (1980). 
VARIABILITY OF THE YIELD RESPONSE OF FIELD-GROWN SOYBEAN CULTIVARS TO SO 2

J. E. Miller, H. J. Smith, and P. B. Xerikos

Background and Scope

Projected increases in coal-fired electrical power generation have caused renewed concern regarding the impact of sulfur dioxide $\left(\mathrm{SO}_{2}\right)$ emissions on agricultural productivity. Although numerous studies have related elevated $\mathrm{SO}_{2}$ concentrations to plant injury and growth reductions, few of the available data can be used to define $\mathrm{SO}_{2}$ concentrations that cause economically significant yield reductions. To date, most experimental work of this kind has been carried out in laboratory or greenhouse growth chambers where it is difficult to grow most comnon crop plants to harvest maturity. As a result, the effects of $\mathrm{SO}_{2}$ at the seedling ard early vegetative stages have been emphasized. These results usually cannot be related to yield, especially in grain crops, since plants often componsate for injury that occurs early in their life cycles and do not exhibit significant yield reductions at harvest. In addition, pollutant-plant interactions in most growth chambers or greenhouses should not be used to predict field behavior, since the rate of pollutant uptake and the sensitivity of the plants to the pollutant are likely to be different in the field. For these reasons the Terrestrial Ecology research group hes been conducting field studies for the past four years on the effects of $\mathrm{SO}_{2}$ on the productivity of different soybean cultivars.

As in previous years, the studies utilized a modified zonal air pollution system (ZAPS) for delivering the $\mathrm{SO}_{2}$ gas.l The delivery system was further mod:fied in 1980 to consist of a single $\mathrm{SO}_{2}$ release pipe (Figure 1). An $\mathrm{SO}_{2}$ gradient hich occurred downwind of the release pipe was characterized by monitoring at the designated locations in the field plots. Each row of soybeans is considered to be a separate treatment and each of the four 5-m row segments a sample. Control plots were established on the prevailing upwind side of the pipe and the $\mathrm{SO}_{2}$ gas was released only when the wind direction assured the fumigation of only the treated plots. Nineteen $\mathrm{SO}_{2}$ furnigations of the soybeans were conducted between $16 \mathrm{July}$ and 24 september. The fumigations averaged $2 \mathrm{hr}$ and $34 \mathrm{~min}$ and were administered between the hours of 0900 and 1600 CDT. 


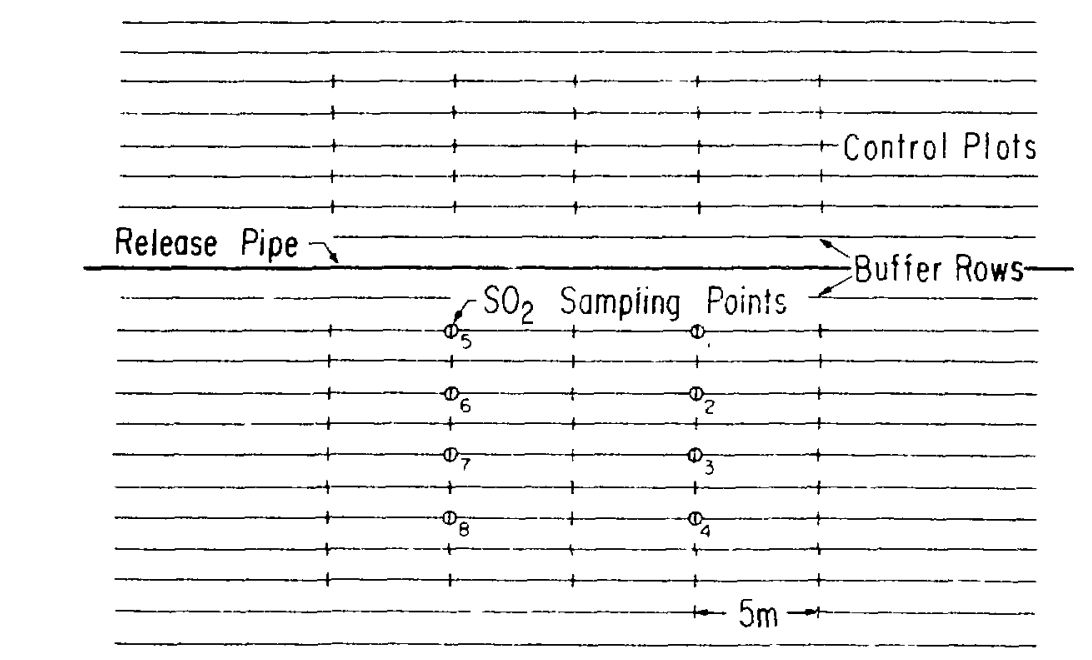

Eigure 1. Diagrammatic representation of the single release pipe fumigation unit used in 1980.

\section{Progress in 1980}

In 1980 two cultivars of soybeans (Glycine max Merr, w. Corsoy and Williams) were studied. The only visible symptoms of $\mathrm{SO}_{2}$ injury detected in either soybean cultivar was chlorosis which occurred primarily in the upper two-thirds of $\mathrm{tr}$. canopy. In the williams plot in late Augusti the chlorosis was guite obvious and extensive in the rows recelving the two highest $\mathrm{SO}_{2}$ concentrations $(0.4 \mathrm{C}$ and $0.31 \mathrm{ppm})$ becoming very mild at 0.18 rpir and undetectable at concentrations of $0.14 \mathrm{ppm}$ and lower. As the same time the Corsny soybeans showed milder chlorosis which was detectable only in the rows with mean $\mathrm{SO}_{2}$ concentrations of $0.24 \mathrm{ppm}$ and greater. In both cultivars senescence of the plants occurred sooner in the 3 rows receiving the highest $\mathrm{SO}_{2}$ concentrations.

The $\mathrm{SO}_{2}$ treatments elicited somewhat different yield responses from the two soybean cultivars (Table 1). At the lower $\mathrm{SO}_{2}$ concentrations $(0.16 \mathrm{ppm}$ or less) the yield of Corsoy soybeans was typically enhanced, while with willian's soybeans an apparent stimulation of yield was szen in only one set of samples and was not statistically significant. Despite the apparent difference in the response of the two cultivars to the lower $\mathrm{SO}_{2}$ concentrations, the response at concentrations of $0.2 \mathrm{ppm}$ and greater was similar (an average yield decrease of 118 anc 148 for Corsoy and Williams, respectivelyj. The reasons for the dissimilarity of the response curves of the two cultivars is not immediately 
apparent ard could be related to a number of factors such as possible differences in sulfur requirements or differences in the stage of development during $\mathrm{SO}_{2}$ t.reatments (the Williams cultivar matured more slowly). Another obvious factor which might explain the response of the two cultivars to $\mathrm{SO}_{2}$ is a difference in the level of soil sulfur in the two experimental plots. While soil sulfur analyses are not available at this writing, past analyses of the field have indicated that soil sulfur is adequate and not highly variable.

Table 1. Summary of the 1980 yield data for the Corsoy and williams soybean plots by row.

\begin{tabular}{|c|c|c|c|c|c|c|c|c|c|}
\hline \multirow[b]{2}{*}{ Row $^{a}$} & \multicolumn{4}{|c|}{ Corsoy } & \multicolumn{5}{|c|}{ Williams } \\
\hline & {$\left[\mathrm{SO}_{2}\right]^{\mathrm{b}}$} & Yield & & ( 8 of control) & {$\left[\mathrm{SO}_{2}\right]^{b}$} & Yield & & 18 & of control) \\
\hline 1 & 0.38 & 846 & $\star \star$ & (87) & 0.40 & 828 & $\star \star$ & & $(80)$ \\
\hline 2 & 0.31 & 805 & $\star \star$ & $(82)$ & 0.31 & 892 & $\star$ & & $(86)$ \\
\hline 3 & 0.24 & 858 & $\star \star$ & $(88)$ & 0.22 & 947 & $\star$ & & $(91)$ \\
\hline 4 & 0.20 & 963 & & (99) & 0.18 & 921 & $\star$ & & (89) \\
\hline 5 & 0.16 & 1050 & * & $(108)$ & 0.14 & 892 & $\star \star$ & & $(86)$ \\
\hline 6 & 0.13 & 1091 & * & $(112)$ & 0.12 & 985 & & & (95) \\
\hline 7 & 0.11 & 963 & & $(99)$ & 0.11 & 1063 & $\star$ & & $(102)$ \\
\hline 8 & 0.09 & 979 & & $(100)$ & 0.09 & 897 & $* *$ & & $(86)$ \\
\hline 9 & 0.08 & 1058 & * & $(1,18)$ & 0.08 & 990 & & & (95) \\
\hline Control & $<0.01$ & 976 & & -- & $<0.01$ & 1038 & & & -- \\
\hline
\end{tabular}

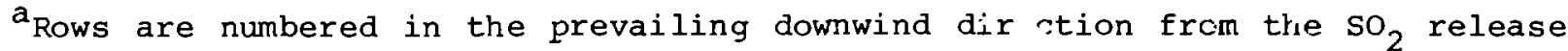
pipe.

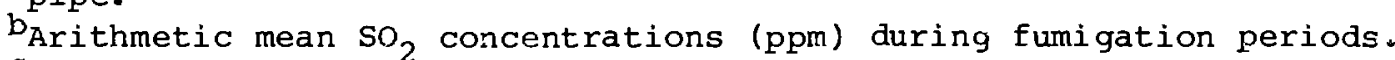

CValues are the mean driad bean $w$ ights of four $5-\mathrm{m}$ row segments in grams. Control values are the nein of sixteen $5-m$ row segments.

*, * Significant at the 55 and 18 level, respectively.

The yield response of all soybean cultivars studied by cur research group is summarized as a function of applied $\mathrm{SO}_{2}$ dose in Figure 2. These doses were all generated with chronic $\mathrm{SO}_{2}$ treatments having concentrations ranging $f$ rom 0.08 to $0.44 \mathrm{ppm} \mathrm{SO}_{2}$ and total houss of treatment of apprcximately 10 to 117. While $\mathrm{SO}_{2}$ dose is not a perfect parameter to use for quantifying $\mathrm{SO}_{2}$ exposures, we have found it to be the most useful in summarizing the results of experiments using maltiple $\mathrm{SO}_{2}$ exposures at subacute concentrations. It 
can be seen that the yield response to doses of $10 \mathrm{ppm}$ "hr and less is highly variable and apparently very specific for a cultivar, although year to year variation in the response of a given cultivar cannot be ruled out. At $\mathrm{SO}_{2}$ doses of greater than $10 \mathrm{ppm}{ }^{\circ} \mathrm{nr}$ there is some variability in the magnitude of the response, but the yields were consistently reduced. This summary emphasizes the importance of studying more than one cultivar of the major crop species if crop loss to air pollutants is to be quantified with any degree of assurance.

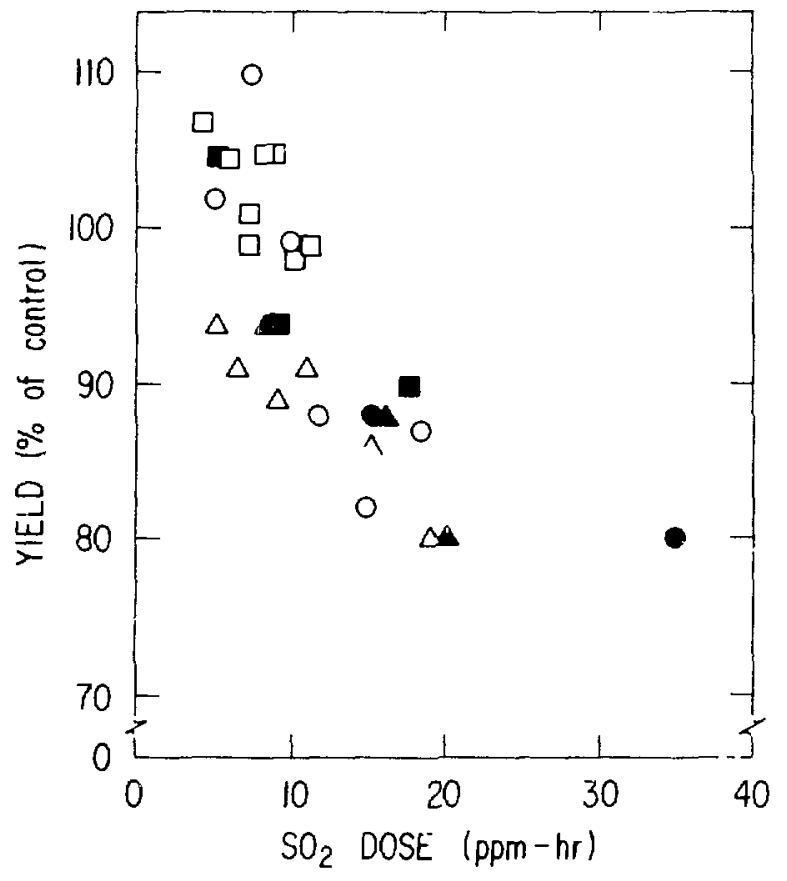

Figure 2. Summary of four years of $\mathrm{SO}_{2}$-soybean yield data. $\quad 1977$ (Welis); 4, 1978 (Wells);, 1979 $(\mathrm{NK}-1492) ; 0,1980$ (Corso: $) ; \Delta, 1980$ (Williams); 0,1980 (NK-1492).

\section{Reference}

1. Miller, J. E., D. G. Sprugel, R。 N. Muller, H. J. Smith, and P. B. Xerikos, Open-air fumigation system for investigating sulfur dioxide efiects on crops, Phytopathology 70, 1124-1128 (1980). 
INFLUENCE OF DISSOLVED ORGANIC CARBON ON THE SORPTION OF PLUTONIUM TO NATURAL SEDIMENTS

D. M. Nelson, J. O. Karttunen, K. A. Orlandini, and R. P. Larsen

\section{Background and Scope}

One prominent aspect of the environmental behavior of plutonium is a tendency for strong, though not complete, association with soil and sediments. The nature of this association is not well understood, and the water quality parameters which may affect it have not been identified. It is assumed that adsorption is dependent upon the chemical species present (oxidation state and complex ion associations) and that the uncomplexed form of $\mathrm{Pu}(I V)$ is the one that is most highly sorbed.

We have found that in certain oligotrophic waters the dissolved plutonium is primarily in the oxidized form (presumably as Pu(V)), a form that is weakly sorbed. This could account for its solubility. In all waters, however, soine of the dissolved plutonium is present in the reduced form (presumably as Pu(IV)). The apparent solubility of this reduced form, as measured by a sediment concentration factor, varies markedly among the lakes. This suggests that the reduced plutonium is present as a complex ion and that the degree or complexation varies among the lakes, presunably, in response to varying concentrations of the complexant. The concentration factors do not appe ir to be related to the concentrations of inorganic constituents of the waters, suggesting that the active complexing agent is organic in nature. Organic compounds, particularly the humic and fulvic acids, are recognized as being important complexing agents for many metals. Their importance as complexants for reduced plutonium in natural waters has often been suggested but never demonstrated.

Progress in 1980

The concentrations of dissolved organic carbon (DOC) have now been measured in the waters from a number of lakes and a general deperdence of the sediment concentration factor $\left(K_{D}\right)$ for $P u(I V)$ upon DOC has become evident (see Figure 1). These concentration factors were calculated by dividing the measured concentrations of ambient $239,240 \mathrm{Pu}$ sorbed to suspended solids $(\mathrm{fCi} / \mathrm{kg}$ ) by the measured concentrations of $239.240 \mathrm{Pu}(\mathrm{IV})$ in solution 
(fCi/L). The second set of points in Figure 1 was derived from the results of laboratery experiments in which various natural waters were spiked with $237 \mathrm{Pu}$ and equilibrated with aliquots of a single sediment type. The good agreement between the results of these Eield and laboratory experiments convinced us that (1) our laboratory experiments are useful apprcximations of the natural adsorption process, (2) the sediment chosen is representative of those present in a range of lakes, and '3) some organic constituent is indeed complexing the plutonium and hence affecting the concentration factor.

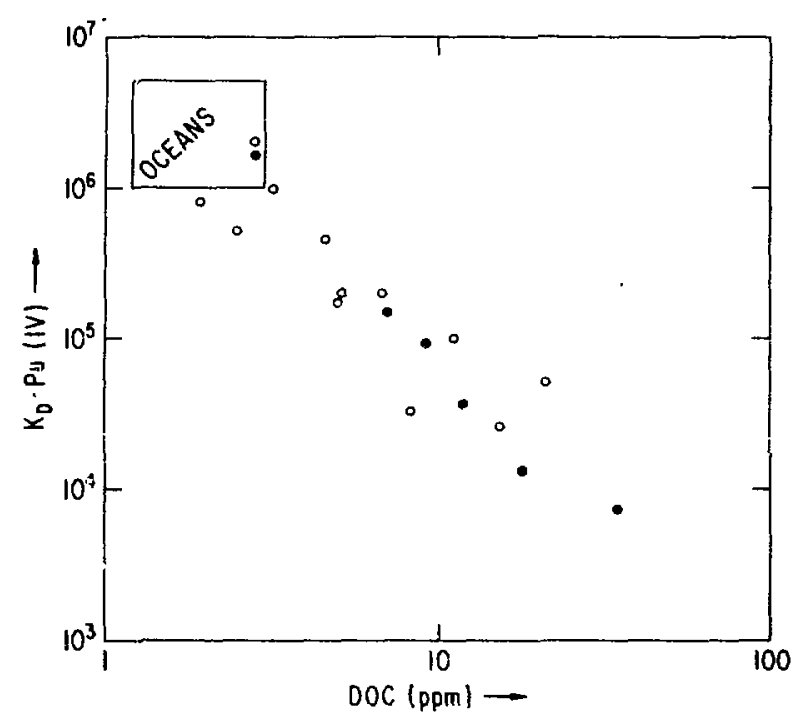

Figure 1. Variation of $k_{\mathrm{p}}$ as a function of ambient. dissolved crganic carbon (DOC) concentration for several natural waters (o represents field measurements, - represents results of laboratory equilibrations).

In orcier to study the nature of this plutonium-organic comlex in more detail several experiments were conducted in which the sediment concentration zactur was measured as a function of DOC concentration. The organic carbon used in these experiments was collected from natural waters by ultrafiltration usin membranes having a nominal molecular weight cutoff of 1000 . Portions of each of these organic concentrates were then ccinbined with the corresponaing ultrafiltered waters to produce a series of waters Jiffering from the original waters only in their DOC concentrations. These solutions wero then spiked with ${ }^{237} \mathrm{Pu}$ tracer, an aliquot of sediment $(\sim 40 \mathrm{mg} / \mathrm{L})$ was added, the systems were equilibrated for one week, and the concentration factor for reduced plutonium was determined. The results of an experiment in which the organic concentrate and ultrafiltered water were from the Okeefenokee swamp are presented in Figure 2a. The dependence of concentration factor on the 
concentration of added DOC is unmistakeable. It is apparent that the DOC has a pronounced effect on the adsorption of $\mathrm{Fu}(\mathrm{IV})$, even at DOC concentrations which are much lower than the ambient concentration, 35 ppm.

In contrast to these results, those obtained from an experiment using Lake Michigan water showed that the DOC in this lake is not an important complexer for $\mathrm{Pu}(\mathrm{IV})$ at ambient concentrations. As shown in Figure $2 \mathrm{~b}, \mathrm{a}$ decrease in $K_{D}$ occurs only at DOC concentrations that are well above the ambient level of $1 \mathrm{ppm}$.

Other water bodies have been investigated with the results being intermediate between those For Okeefenokee Swamp and Lake Michigan. Data from ELA 239 and from a smal? pond on the Argonne site are presented in Figures 2C and $2 \mathrm{~d}$. At their ambient DOC concenrations of 5 and $9 \mathrm{ppm}$, respectively, the $D O C$ in each of these lakes is effective in reducing the adsorption of plutonium to sediments.

These experiments have investigated two competative equilibria: between dissolved Pu(IV) and a soluble complexing ligand, and between dissolved Pu(IV) and a sclid adsorber. If these equilibria follow the usual mass action laws and a single complex is formed, the functional form of the dependence of $K_{D}$ upon ligand concentration, $[L]$, is given by the equation,

$$
K_{D}=\frac{K_{D}^{\circ}}{1+\frac{K_{1}}{K_{2}} K_{D}^{\circ}[L]^{n}}
$$

Here $\mathrm{K}_{1}$ and $\mathrm{K}_{2}$ are the stability constants describing the association of plutonium with the solid adsorber and the complexing ligand, respectively, $n$ is the number of ligands per plutonium atom in the complex and $K_{D}{ }^{\circ}$ is the value of $\mathrm{K}_{\mathrm{D}}$ at zero ligand concentration.

The data from the four previously described experiments were fitted to this equation using a non-linear least squares curve fitting program. The estimated values of the parameters $K_{D}{ }^{\circ}, K_{1} / K_{2}$, and $n$ are presented in Table 1 and the curves derived using these paraneter values are presented in Figure 2. The general agreement between the data and these theoretical curves lover a four order of magnitude range of DOC concentration) supports the original 

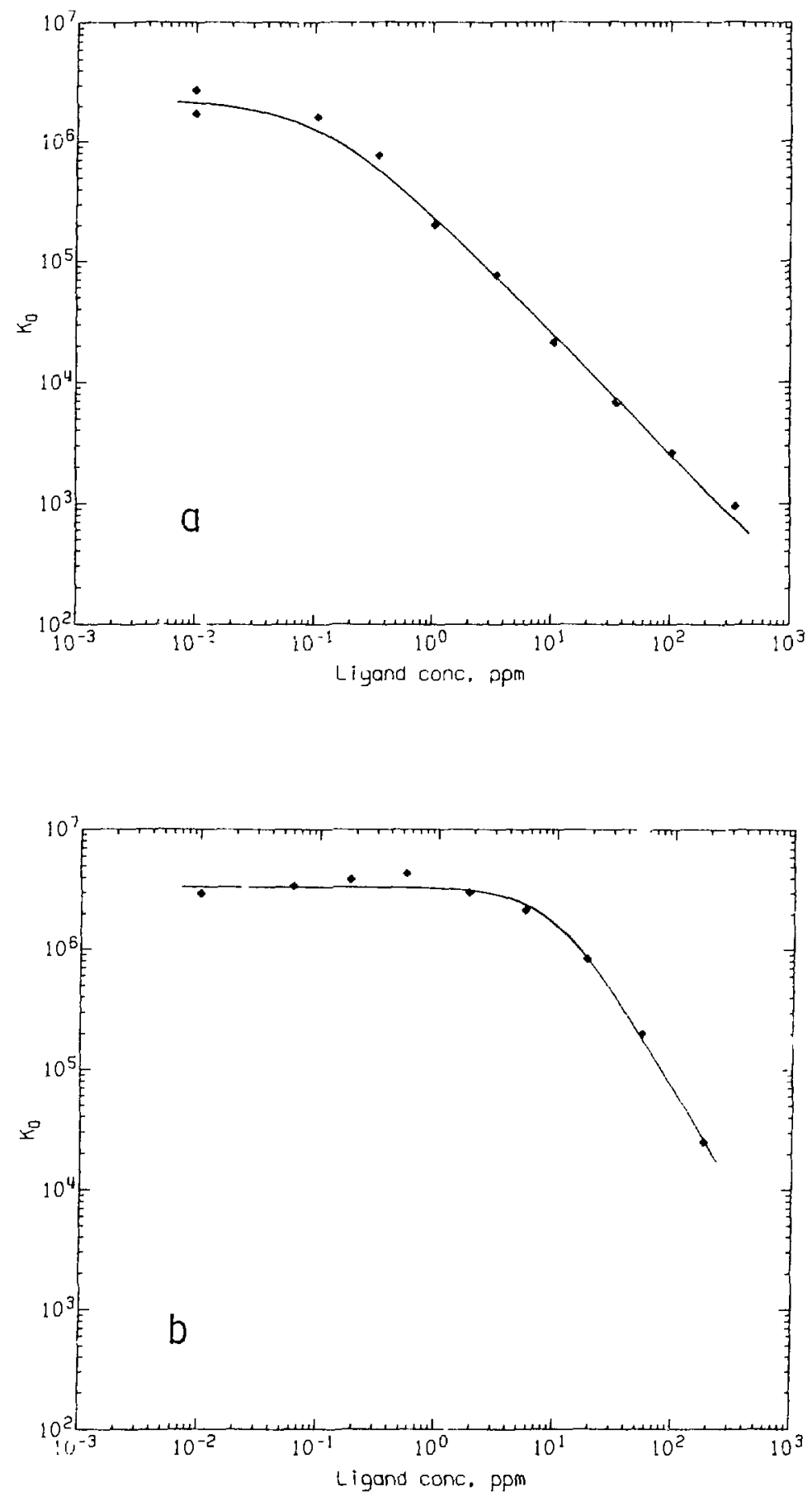

Figure 2. Variation of $\mathrm{K}_{\mathrm{D}}$ as a function of dissolved organic carbon concentration for individual lakes (a) Okeefenokee swamp, and (b) Lake Michigan. 

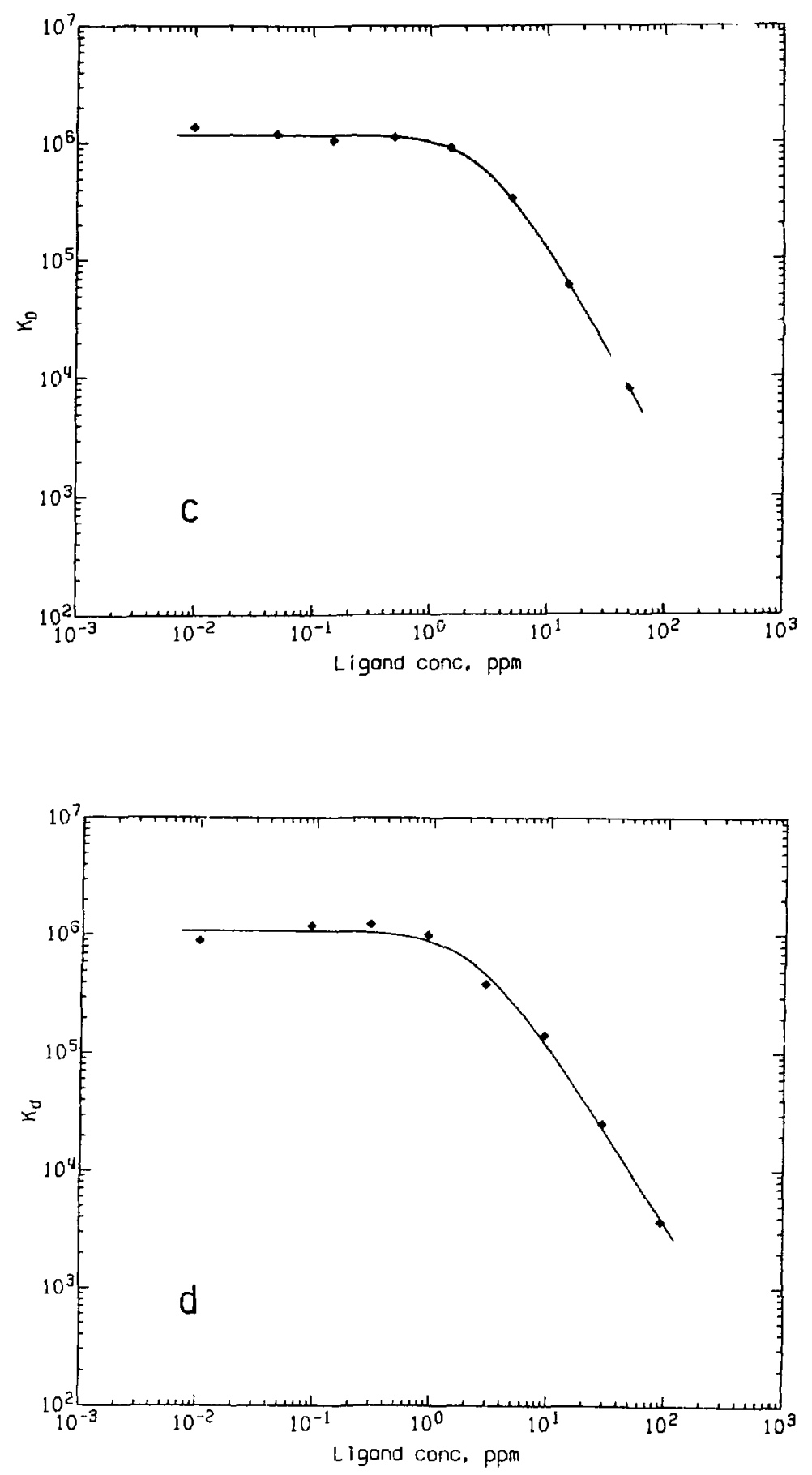

Figure 2. Continued. (c) ELA 239 and (d) small ponds on ANL site. 
premise that both the adsorption to sediments and the complexation by the organic ligand are equilibrium processes following the appropriaie laws of mass action. The values of $\mathrm{k}_{\mathrm{D}}{ }^{\circ}$ indicate that in the absence of organic complexing ligands, the adsorption of reduced plutonium to sediments is uniformly high.

Table 1. Estimated values for the parameters of Eq. 1 in several natural waters.

\begin{tabular}{llll}
\hline & $K_{D}{ }^{\circ}$ & $K_{1} / K_{2}$ & $n$ \\
\hline Okeefenokee Swamp & $2.3 \times 10^{6}$ & 3.8 & 1.01 \\
ANL pond & $1.0 \times 10^{6}$ & 0.24 & 1.54 \\
ELA 239 & $1.2 \times 10^{6}$ & 0.13 & 1.75 \\
Lake Michigan & $2.5 \times 10^{6}$ & 0.005 & 1.71 \\
\hline
\end{tabular}

Although the organic matter in each lake is capable of complexing plutonium, as evidenced by the decrease in $\mathrm{K}_{\mathrm{D}}$ at high DOC concentrations, there is a wide range in stability constants. For example, if it is assumed that $\mathrm{K}_{2}$ (which measures the strength of the association of uncomplexed Pu(IV) with the solid adsorber) does not vary between lakes, then $\mathrm{k}_{1}$ (which measures the stability of the organic complex of $P u(I V))$ is almost 1000 times higher for Okeefenokee Swamp than it is for Lake Michigan.

The value of $\mathrm{n}$ in Okeefenokee Swamp indicates that one organic molecula complexes one plutonium atom. In the other lakes, where $n$ is not an integer, the physical interpretation is not clear. It appears that the assumption that Pu(IV) reacts with the organic molecules to form just one complex is not realistic. The functional relationship vill have to be expanded to allow for several types of organic complexes.

\section{Prospects}

We feel that the knowledge gained during the course of this investigation has significantly expanded our understanding of the role organic complexants play in the environmental chemistry of plutonium. Since only a limited number of water types have been examined to date, the study will be expanded to include some major river systems as well as the ocean. The initial 
experiments were conducted at very low plutonium concentrations, those where the capacity (equivalents per liter) of the organic ligands to form complexes far exceeds the concentration of plutonium. Additional experiments must be done at higher plutonium concentrations to determine the comlexing capacity (i.e., equivalent weight) of this organic matter. Also the effects of inorganic variables such as $\mathrm{pH}$, ionic strength, and the presence of competing cations and anions must be examined in detail.

The experimental techniques developed in this study can be applied to other related problems. For example, biological uptake (and hence toxicity) rather than adsorption to sediments could be studied as a function of Doc concentration for plutonium or other toxic trace elements. 
OXIDATIDN STATE DISTRIBUTION OF PLUTONIUM IN MARINE WATERS

D. M. Nelson, D. N. Metta, and R. P. Larsen

Background ani scope

Our previous measurements ${ }^{l}$ have demonstrated that the disisolved plutonium in sea water exists as a mixture of two forms. The reduced form, probably $\mathrm{Pu}$ (IV), is strongly sorbed to suspended particulate matter while the oxidized form, probably $\mathrm{Pu}(\mathrm{V}), 2$ is not. The distribution of plutonium between these forms will consequently be very important in determining the fate of plutoniam added to the oceans.

The earlier measurements showed 70 to $95 \%$ of the dissolved plutonium to be in the oxidized form, however the measurements were confined to samples collected in shallow coastal environments (the Irish Sea and the Pacific test sites). A few samples collected elsewhere around the British Isles indicated that outside the Irish sea substantially less of the dissolred plutonium was in the oxidized form. No measurements of plutonium oxidation state distribution have been reported from waters of the deep ocean.

Measurements of total plutonium concentration, but not oxidation state have been reported from the Pacific Ocean by Bowen et $a,^{3}$ and have revealed a plutonium concentration maximum at $\sim 500 \mathrm{~m}$ below the surface. Little change in the vertical position of this maximum occurred between 1968 and 1978. Since this plutonium was presumably introduced at the sea surface in fallout from nuclear weapons testing, its existence at this depth almost certainly resulted from downward transport via settling particles. The difference in sorption between the two forms of plutonium could be responsible for the formation and maintenance of this subsurface concentration maximum if substantial differences in oxidation state distribution occur with depth in the ocean. This area of the Pacific Dcean is, therefore, an excellent location in which to continue our investigations of the oxidation state characterization of plutonium.

\section{Progress in 1980}

Samples of water from the Pacific Ocean north of Hawaii were collected during May of 1980 and have been analyzed for plutonium concencration and oxidation state using the lanthanum fluoride coprecipitation method. The 
samples were collected with the assistance of scientists from the Woods Hole Oceanographic Institute (WHOI) and the Scripps Institute of Oceanography aboard the research vessel Thomas Washington.

The results of our measurements of total plutonium, i.e., Pu(III,IV) plus $\mathrm{Pu}(\mathrm{V}, \mathrm{VI})$, which are shown in Figure $1 \mathrm{~A}$ are consistent with the earlier measurements, in both the position and magnitude of the subsurface plutonium maximum. Our measurements were done on unfiltered samples; concurrent filtration experiments by wHOI scientists indicated almost all of this plutonium is in solution.
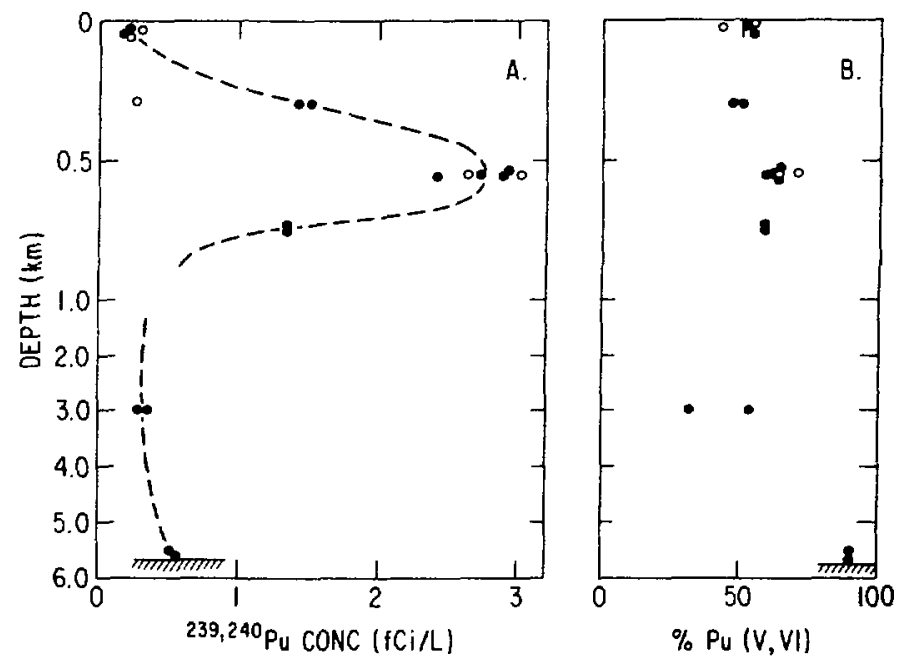

Figure $1 . \quad$ The dependance of
$239,240 \mathrm{Pu}$ concentration and
oxidation state on depth in the
North Central Pacific Oceun.
station located at $30^{\circ}$
latitude; $\mathrm{N}$
$24^{\circ} \mathrm{N}$. station located at

The distribution of oxidation states, presented in Figure $1 B$, shows that both oxidation state groups are present, as was observed in the Irish Sea, but in these samples the oxidized form is only slightly more abundant than the reduced. This lower fractional abundance of the oxidized form is consistent with the previous observations made around Great Britian outside the Irish Sea. The oxidation state distribution found in the near bottom sample is similar to those found in the Irish sea and at the Pacific test sites. This suggests that periodic contact with bottom sediments may be important in determining the oxidation state distribution.

The presence of the oxidized form at all depths suggests that interconversion of the two forms occurs even in water having very little particulate matter. Since the downward transport is most likely via the strongly sorbed reduced form, the oxidized plutonium found below 200 to $300 \mathrm{~m}$ 
(the depth to which ${ }^{137} \mathrm{Cs}$ and ${ }^{90} \mathrm{Sr}$ have penetrated) was presumably generated at depth by the oxidation of the reduced form.

Although oxidized plutonium apparently constitutes a lower percentage of the dissolved plutonium in the open Pacific Ocean than in the Irish Sea, it constitutes a far higher percentage of the total input. In the shallow Irish Sea $\sim 958$ of the input resides in the sediments, as Pu(IV), with $\sim 58$ remaining in solution primarily as Pu(V). In contrast, little of the plutonium input to the Pacific has been transferred to the sediments and consequently at least 508 of the total input exists as $\mathrm{Pu}(\mathrm{V})$ in solution.

\section{Prospects}

An adequate understanding of the geochemical behavior of plutonium in the marine environment certainly requires a knowledge of plutonium's chemical speciation including its oxidation state(s). Our measurements indicate that substantial differences in oxidation state distribution occur between areas and suggest that this distribution is influenced by contact with particulate matter. These observations need to be verified in other areas of the world's oceans. In doing this the chemical form of dissolved plutonium that is in the reducer state needs to be identified, the mechanism responsible for the formation and maintenance of the subsurface concentration maxinum needs to be investigated, the relative bioavailability of the two oxidation states need to be measured, and the rates and mechanisms of the oxidation and reduction reactions responsible for the maintenance of the apparent steady-state distributions need to be studied.

\section{References}

1. Nelson, D. M. and M. B. Lovett, The oxidation state of plutonium in the Irish Sea, Nature $276,599-601$ (1978).

2. Nelson, D. M. and K. A. Orlandini, Identification of $P u(V)$ in natural waters, Radiological and Environmental Research Division Annual Report, January-Docember 1979, ANL-79-65, Part III, pp. 57-59.

3. Bowen, V. T., V. E. Nnshkin, H. D. Livingston, and H. L. Volchok, Fallout radionuclides in the Pacific Ocean: Vertical and horizontal distriubtions largely from GEOSECS stations, Earth Planet. Sci. Lett. 49, 411-434 $(1980)$. 
COMPARISON OF THE GEOCHEMICAL GEHAVIOR OF PLUTONIUM, THORIUM, AND URANIUM IN SELECTED NORTH AMERICAN LAKES*

M. A. Wahlgren ${ }^{\dagger}$ and K. A. Orlandini

The distribution of fallout $239,240 \mathrm{Pu}$ between dissolved and suspended particulate phases has been determined in two groups of North American lakes. The lakes of the first group represent a variety of watershed conditions, ranging from an acidic bog ( $\mathrm{pH} 4.8$ ) to a highly saline lake $(\mathrm{pH}$ 8.7). Those of the second group have a common granitic environment and a limited $\mathrm{pH}$ range, but the chemical parameters of several have been significantly modified during the course of whole-lake fertilization and acidification experiments. Concurrent measurements of naturally occurring $232 \mathrm{Th}$ and $238_{\mathrm{U}}$ have permitted comparisons to be made between the geochemical behavior of $\mathrm{Pu}(\mathrm{IV})$ and $\mathrm{Pu}(\mathrm{VI})$ and that of their natural analogs, Th(IV) and $\mathrm{U}(\mathrm{VI})$.

The water samples were filtered immediately after collection, spiked with yield monitors for $\mathrm{Pu}$, Th and $\mathrm{U}$, or subjected to a sequential ultrafiltrationion exchange procedure ${ }^{l}$ prior to spiking. These treatments yield operationally defined fractions for comparison of $\mathrm{P} u$, Th and $U$ concentrations present as particulate, total dissolved, colloidal-sized and subcolloidalionic phases. Additional filtered water samples were spiked with yield monitors for measurement of the $\mathrm{Pu}(\mathrm{III+IV)}$ and $\mathrm{Pu}(\mathrm{V}+\mathrm{VI})$ oxidation state groups. ${ }^{2}$

The concentrations of total dissolved $239.240 \mathrm{Pu}$ were found to fall within the ranges of 1 to $3 \times 10^{-17} \mathrm{M}$ in 13 of the lakes, 3 to $10 \times 10^{-17} \mathrm{M}$ in 3 lakes, and 10 to $33 \times 10^{-17}$ in 5 other lakes. In the higher oxidation state group $239.240 \mathrm{Pu}(\mathrm{V}+\mathrm{VI})$ was present at measurable levels in 18 of the lakes, but in no case exceeded a concentration of $3 \times 10^{-17} \mathrm{M}$. The relatively wide range of observed concentration of total dissolved plutonium is, therefore, primarily due to that present in the lower (III+IV) oxidation state group. Further, the dissolved ${ }^{232} \mathrm{Th}$ exhibited a similarly wide range of

*Paper submitted to IAEA Symposium on Migration in the Terrestrial Environment of Long-Lived Radionuclides from the Nuclear Fuel Cycle, Knoxville, Tennessee, 27-31 July 1981. tChemical Engineering Division, Argonne National Laboratory. 
concentrations, with the absolute concercration of 232 Th $\left(1\right.$ to $\left.60 \times 10^{-11} \mathrm{M}\right)$ veing ca. 6 orders of magnitude high'sr than that of $239.240 \mathrm{Pu}$. The higher concentration of dissolved ${ }^{232}$ Th was foun.1 in the same lakes which had a high concentration of $239.240 \mathrm{Pu}$ (correlation coefficient $r \sim 0.7$ ); a similar correlation was found when the concentrations of $239.240 \mathrm{PL}$ and $232 \mathrm{Th}$ in particulate or ultrafilterea-ion exchanged fractions were compared. In contrast, no correlation between the concentrations of $238 \mathrm{U}$ (range 40 to 3500 $\left.\times 10^{-11} \mathrm{M}\right)$ and those of either the lower or higher oxidation state groups of 239.240 Pu was observed.

From the measured data on the concentration of plutonium, thorium, and uranium in particulate and dissolved phases, empirical descriptive characterizations, such as partition and distribution coefficients, were derived and regressed against morphological and chemical parameters, such as mean depth, flushing time, pH, and alkalinity of the lakes. On the basis of data obtained from the first group of lakes, the concentration of dissolved ${ }^{238} \mathrm{U}$ appeared to vary directly with the alkalinity of the water, that of $239.240 \mathrm{Pu}(\mathrm{V}+\mathrm{VI})$ was relatively invariant among the lakes studied, and that of $239.240 \mathrm{Pu}(\mathrm{III}+\mathrm{IV})$ and $232 \mathrm{Th}$ appeared to depend on the $\mathrm{pH}$ and alkalinity. However, data from the second group of lakes, which had only small differences in $\mathrm{pH}$, showed an unexpectedly wide range of both $239.240 \mathrm{Pu}$ (III+IV) and $232 \mathrm{Th}$ distribution ratios, and therefore invaidated the third of the preceding conclusions. Subsequent acquisition of data on the concentration of dissolved organic carbon in a number of the lakes shows that the distribution ratios of $239.240 \mathrm{Pu}(\mathrm{III}+\mathrm{IV})$ and $232 \mathrm{Th}$ are better correlated with this parameter than with any other available at present.

The foregoing results show that the fallout $239.240 \mathrm{Pu}$ now in lakes has, within little more than a decade, entered geochemical cycles similar to those of naturally occurring 232 Th. Thus, it appears that characterization of the chemical properties of natural water bodies may be utilized for prediction of the behavior of inputs of dissolved forms of plutonium. Laboratory studies under conditions that closely simulate those found in the environment are required to delineate the mechanisms which control the concentration of plutonium in surface waters. 


\section{References}

1. Alberts, J. J., M. A. Wahlgren, D. M. Nelson, and P. J. Jehn, Submicron particle size and charge characteristics of $239,240 \mathrm{Pu}$ il natural waters, Environ. Sci. Technol. 11, 673-676 (1977).

2. Nelson, D. M. and M. B. Lovett, The oxidation state of plutoniun in the Irish Sea, Nature 276, 599-601 (1978). 
$\mathrm{R} / \mathrm{V}$ EKOS, A RESEARCH TOOL

R. M. Williams and R. W. Dana

Background and scope

The 58 foot research vessel Ekos was purchased in 1978 to increase the interdisciplinary effectiveness of our Great lakes research programs. Design specifications of the vessel were the result of tradeoffs between available money and the desj.res of the research scientists. The initial report on the vessel's capabilities, including specifications, can be found in the 1978 Annual Report.l

\section{Progress in 1980}

This year saw increased use of the Ekos, with nearly 100 days of both winter and summer operation. Several extended cruises were completed, including a two-week trip to the northern basin of Lake Michigan for collection of water and sediment samples. Biological and chemical samples were also collected from stations accessible on day trips from Chicago. Instruments located at the 68 th street water intake and at a research tower on the Indiana Shoals were regularly serviced, and two overnight micrometeorological experiments were conducted using the Ekos as a data gathering laboratory and power source for instruments.

\section{Reference}

1. Romberg, G. P., R. W. Dana, and R. M. Williams, The new research vessel Ekos, Radiological and Environmental Research Division Annual Report, January-December 1978, ANL-78-65, Part III, Pp. 29-32. 
A NOTE ON THE USE OF BOX MODELS FOR ESTIMATING DRY DEPOSITION VELOCITY

R. M. Williams

\section{Background and Scope}

Recent papers by Delumyea and Petel 1,2 and Fingleton and Fobbins ${ }^{3}$ have made use of so-called "box models" for estimating the dry deposition velocity (or inversely the residence time) of atmospheric contaminants over the Great Lakes. The purpose of this note is to show that these models should be applied with caution to the short-fetch conditions existing over the Great Lakes because of the large inherent uncertainties involved.

In these models the box consists of a well-mixed region of the atmosphere bounded on the bottom by the earth's surface (either land or water) and on the top by the atmospheric inversion layer. Measurements of the contaminant concentration at the upwind $\left(C_{0}\right)$ and downwind $\left(C_{L}\right)$ sides of the box, the wind speed $(U)$, the fetch $(L)$ or distance between the upwind and downwind concentration measurements, and the height of the mixed region $(H)$ can be used to evaluate the dry deposition velocity from:

$$
v_{\mathrm{d}}=-\frac{\mathrm{UH}}{\mathrm{L}} \ln \left(\mathrm{C}_{\mathrm{L}} / \mathrm{C}_{\mathrm{o}}\right)
$$

In practice the average wind speed is used, and the mixing layer height is assumed to be some average inversion layer height (approximately $1 \mathrm{~km}$ ). Uncertainties in the values of these parameters can produce significant uncertainties in the resulting deposition velocity estimate. However, even greater uncertainty in the deposition velocity estimate arises from uncertainty in the concentration measurements when the fetch is limited.

\section{Progress in 1980}

If we assume that $U, H$ and $L$ are precise but allow for imprecise sampling and analysis in the concentration measurements, we can evaluate the resulting uncertainty in the deposition velocity estimate. Let the fractional concentration measurement uncertainty be $\alpha$ (independent for the upwind and downwind measurement) and the resulting fractional deposition velocity uncertainty be $\beta$. Ther, 


$$
\begin{aligned}
v_{d}(1 \pm \beta) & =-\frac{U H}{L} \ln \left(C_{L}\left(1 \pm \alpha_{L}\right) / C_{0}\left(1 \pm \alpha_{0}\right)\right), \\
& =-\left(\frac{U H}{L} \ln \left(C_{L} / C_{0}\right)\right)\left(1+\frac{\ln \left(\left(1 \pm \alpha_{L}\right) /\left(1 \pm \alpha_{0}\right)\right)}{\ln \left(C_{L} / C_{0}\right)}\right) .
\end{aligned}
$$

Therefore,

$$
\beta=\ln \left(\left(1 \pm \alpha_{L}\right) /\left(1 \pm \alpha_{0}\right)\right) / \ln \left(C_{L} / C_{0}\right)
$$

The turbulent transfer ccefficient can be used as an upper limit for the deposition velocity $\left(v_{d t}=C_{D} U\right)$ so that we can relate the concentration ratio t:o the fetch:

$$
\left(C_{L} / C_{0}\right)=\exp \left(-C_{D} L / H\right)
$$

where $C_{D}$ is the turbulent drag coefficient $\approx 0.0013$. Combining $\mathrm{Eg} \cdot 4$ and 5 yields,

$$
\beta=-\ln \left(\left(1 \pm \alpha_{L}\right) /\left(1 \pm \alpha_{0}\right)\right) / C_{D}(L / H),
$$

which for small $\alpha$ (less than $* 0.2$ ) becomes

$$
\beta=1538 \alpha /(L / H)
$$

Thus the box model deposition velocity uncertainty is proportichal to the imprecision in the concentration measurement, with the constant of proportionality being inversely related to the fetch divided by the nixing layer height. For example, if the mixing layer height is $1 \mathrm{~km}$ and the fetch is $100 \mathrm{~km}$, then the uncertainty in the deposition velocity estimate is more than 15 times the imprecision in the concentration measurement. ' Figure 1 shows Eq. 6 for various values of the concentration measurement precision. Only for long fetches (>100 $\mathrm{km}$ ) and precise concentration measurements (<58) is the deposition velocity uncertainty less than 100\%. For the fetches existing over the Great Iakes $(\sim 100 \mathrm{~km})$ and the expected precision of the concentration measurements $(\sim 108)$, the uncertainty in the deposition velocity estimate could be 1508 . 


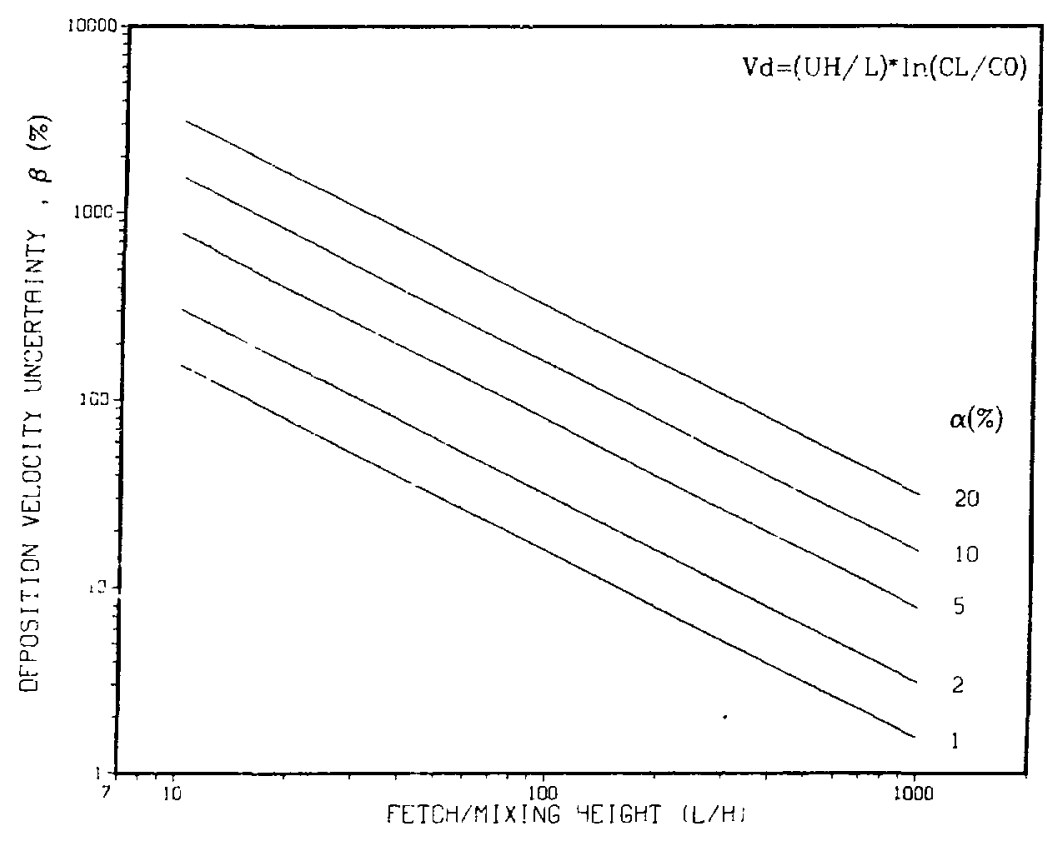

Figure 1. Variation of error in deposition velocity estimate with fetch/height ratis and the concentration measurement error.

Obviously very little confidence can be placed in individual deposition velocity estimates made under such conditions. However, since precision improves with the square root of the number of observations, the overall uncertainty can be reduced to an acceptable level (less than 508) with a sufficient number of independent observations.

Delumyea and Petel ${ }^{2}$ eliminated five measurements (out of 30 ) because the downstream concentration exceeded the upstream. This need not have been due to local sources as they stated, but was more likely due to imprecision in the concentration measurements. If so, these measurements were just as valid as the other 25 measurements and should be included on the overall average deposition velocity estimate. In addition, there may well be meteorological situations in which real upward fluxes occur.

\section{References}

1. Delumyea, R. G. and R. L. Petel, wet and dry deposition of phosphorus into Lake Huron, Water, Air, Soil Pollut. 10, 187-198 (1978).

2. Delumyea, R. and R. L. Petel, Deposition velocity of phosphorus-containing 
particles over southern Lake furon, April-october 1975, Atmos. Environ. 13, 387-394 (1979).

3. Fingleton, D. J. and J. A. Fobbins, Trace elements in air over Lake Michigan near Chicago, J. Great Lakes Res. 6, 22-37 (1980). 
A MODEL FOR THE DRY DEPOSITION OF PARTICLES ON NATURAL WATER SURFACES*

R. M. Williams

Background and scope

Atmospheric dry deposition is an important factor in the process by which particulate matter and associated pollutants are introduced into natural water surfaces. The rate of deposition of particles is of special concern in the evaluation of mass budgets and subsequent prediction of water concentration trends. This paper presents a model of particulate dry deposition which delineates the relative significance of the parameters controlling the deposition rate (commonly expressed as "deposition velocity"). The ultimate goal of this work is to determine a reasonable formulation for the deposition velocity in terms of fairly easily determined parameters, which can be used in detailed mass budget models and in pollutant flux monitoring networks.

\section{Progress in 1980}

The model presented here separates the atmospheric boundary layer over water into two layers. Particulate transfer through the upper layer is governed by turbulent transfer and gravitational cettling. Transfer through the lower layer can follow two parallel paths in addition to gravitational settling. One path is controlled by transfer resistance f-om the air to the smooth water surface. The other path allows the water surface to become broken with the formation of spray and bubbles. The fractional surface area that is broken is parameterized in terms of the wind speed. In addition, gravitational settling in the lower layer is adjusted for particle growth due to high relative humidity.

The model input parameters are wind speed, air-water temperature difference (atmospheric stability), particle dry diameter, lower layer relative humidity, and the broken surface conductance. The model results indicate that the deposition velocity can be strongly affected by the lower layer relative humiaity for particles with diameters between 0.1 and $1.0 \mu \mathrm{m}$. The degree of this effect is, in turn, largely determined by the wind speed

«Abstract of paper presented at Environmentrics 81, Alexandria, Virginia, 8-10 April 1980. 
and broken surface conductance. Stability effects appear to be small except at very low wind speeds. 
AIR QUALITY CHANGES OVER SOUTHERN LAKE MICHIGAN: 1973-1974 COMPARED WITH 1978-1979

G. T. Tisue, D. J. Fingleton,* J. A. Robbins,t R. Allison, and S. Barr

Background and Scope

In 1973, one of us (D.J.F.) began making daily high volume collections of airborne particulate matter at Chicago's 68th Street water intake structure. Sampling continued with few interruptions for about one year. Detailed meteorological measurements were not attempted, but a reasonably complete record of wind speed and direction was made by crib personnel during working hours.

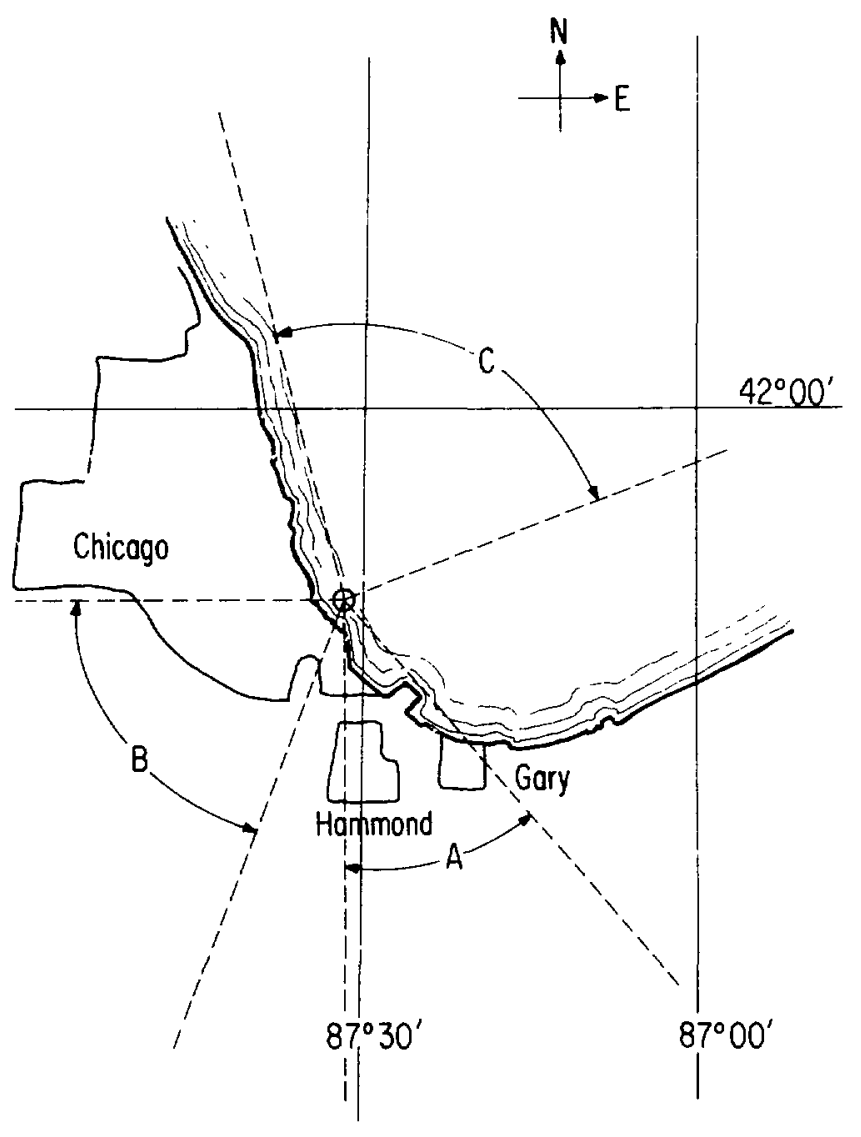

Figure 1. Map showing relationship of sampling sectors to major physiographic features. The sampling location is about 3 $\mathrm{km}$ offshore.

*Energy and Environmental Systems Division, Argonne National Laboratory. +National Oceanographic and Atmospheric Administration, Great Lakes Environmental Research Laboratory, Ann Arbor, Michigan. 
In 1978, members of the Physical Transport group in this Section installed a high-volume sampling system at this same location, along with a complete array of continuous recording meteorological sensors. Their system, which has been described previously,l consisted of three samplers, each operating when the wind direction lay within a prescribed sector. Accordingly, one sampler "viewed" the Chicago conurbation (Sector B), one the Gary-Hammond industrial complex (Sector A), a third the long fetch of the lake (Sector C)(Figure 1). Filters were changed approximately weekly.

\section{Progress in 1980}

In the year past, we completed analyses of all these samples for a suite of major, minor, and trace elements using x-ray fluorscence spectrometry (XRFS). Additionally the 1973-1974 samples were analyzed by instrumental neutron activation analysis (INAA) by personnel at the University of Michigan's Phoenix Laboratory, whose contribution to this work is thankfully acknowledged. Part of these data appeared in an earli $r$ report. ${ }^{2}$ The XRFS technique provided concentrations of $\mathrm{K}, \mathrm{Ca}, \mathrm{S}, \mathrm{Cl}, \mathrm{Ti}, \mathrm{V}, \mathrm{Cr}, \mathrm{Mn}, \mathrm{Fe}, \mathrm{Ni}, \mathrm{C}$, $\mathrm{Zn}, \mathrm{As}, \mathrm{Br}, \mathrm{Rb}$, and $\mathrm{Pb}$ (see Figures 2-3 for represientative results; data for the other elements listed are also available in ihis format). Comparisons between the two methods for a number of elements are currently underway.

The sheer volume of information represenced by these results prevents including them here in their entirety. Insteac ws wlll highlight only two of the many ways in which the data can be used. First anil most obviously, these results reveal trends in air quality occurring in the jive years between the two sampling periods. This interval roughly corresponded to the tine of enactment and implementation of national air quality standards and source emission controls, including the widespread introfuction of unleaded motor fuels.

Figures 4-6 show changes in the annual mean airborne concentrations for particulate forms of $\mathrm{S}, \mathrm{Zn}$, and $\mathrm{Pb}$ by sector. To make these comparisons, the 1973-1974 data were sorted according to the mean wind direction on each sampling date, then assigned to the corresponding 1978-1979 sector. If the mean wind direction fell outside these sectors, that date was excluded from the averaging. These comparisons show clearly that mean concentrations of these three elemenis remained the same (S), or decreased ( $\mathrm{Pb}, \mathrm{Zn})$, in Sector 

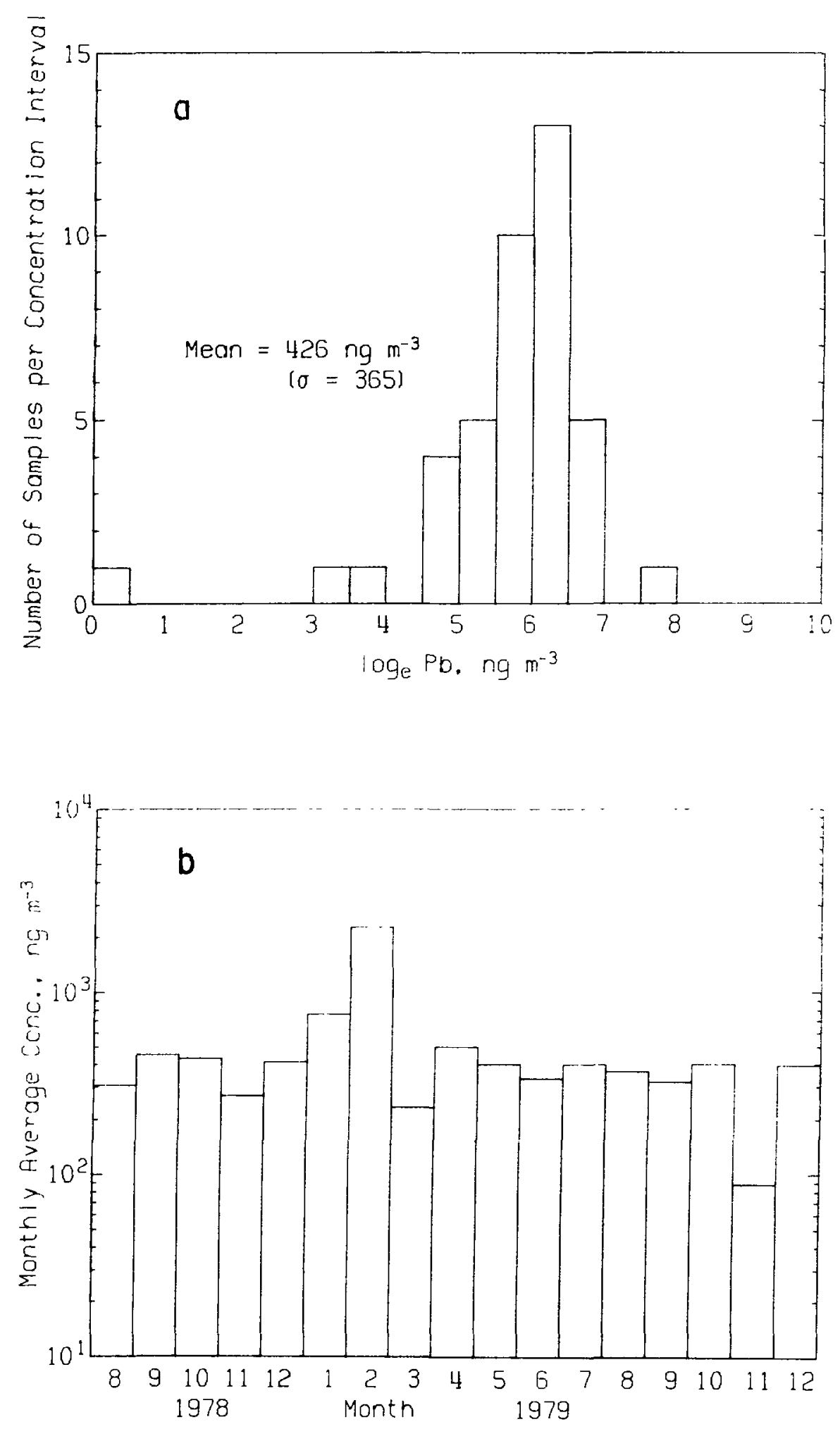

Figure 2. (a) Frequency distribution and (b) seasonal variation of airborne $\mathrm{Pb}$ concentrations in sector $\mathrm{A}$ for 1978-79. 

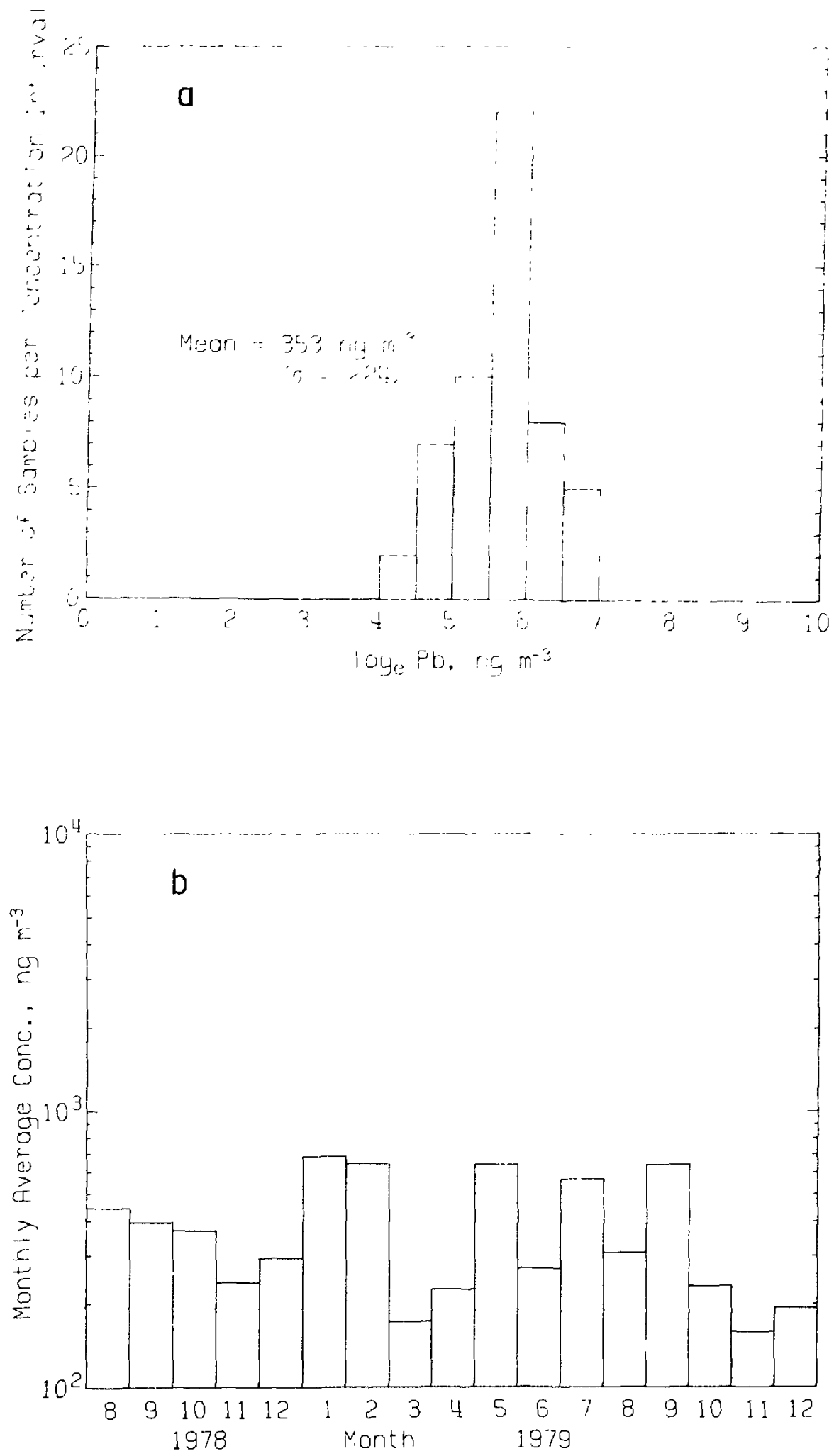

Figure 3. (a) Frequency distribution and (b) seasonal variation of airborne $\mathrm{Pb}$ concentrations in sector $\mathrm{B}$ for 1978-79. 

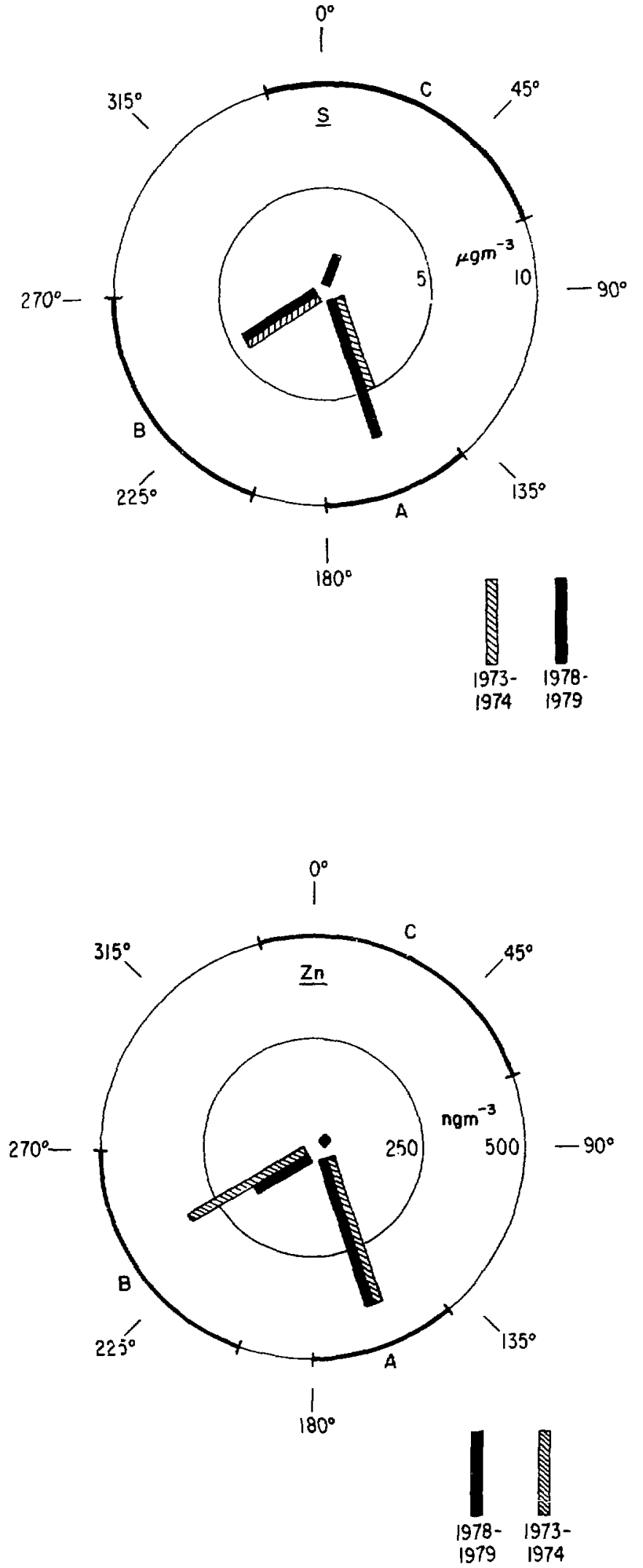

Figure 4. Annual mean concentrations of particulate forms of $S$ in the air at the 68th Street water intake structure, by sector, in 1973-74 and 1978-79.

Figure 5. Annual mean concentrations of particulate forms of $\mathrm{Zn}$ in the air at the 68th Street water intake structure, by sector, in 1973-74 and 1978-79. 
B, while in sector A (the "industrial" sectox), they $\epsilon$ ither rose (S), or did not change significantly $(\mathrm{Pb}, \mathrm{Zn})$.

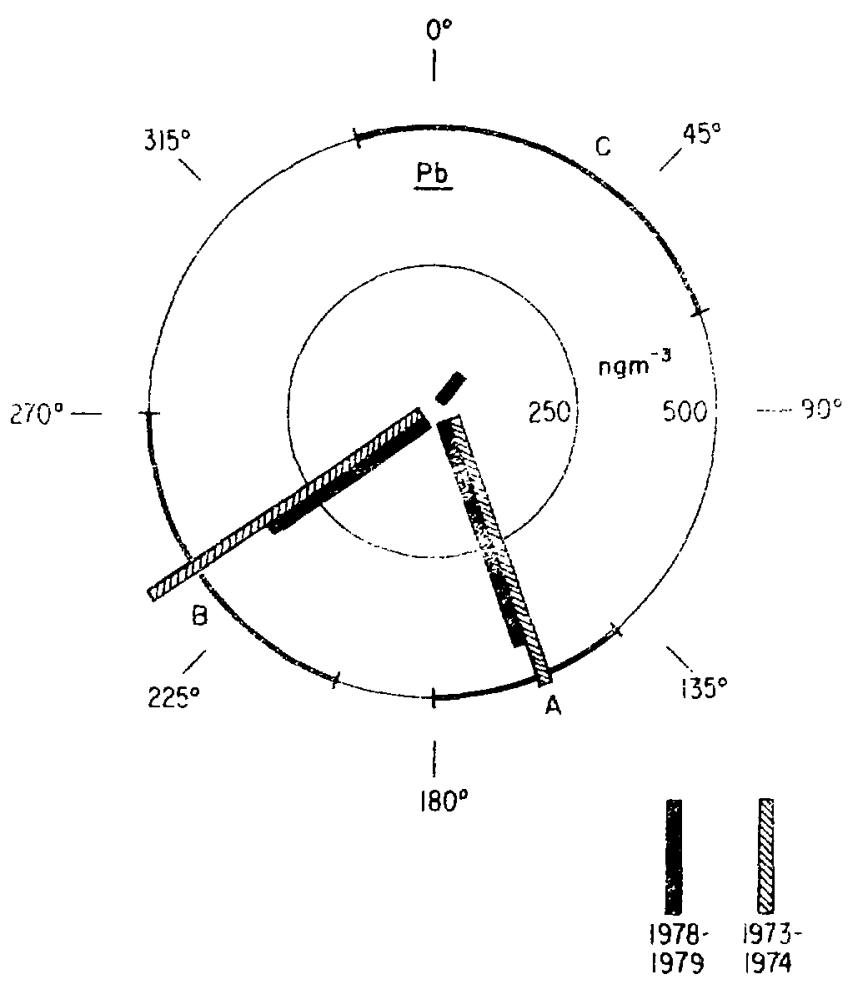

Figure 6. Animal nean concentrations of particulate forms of $\mathrm{Pb}$ in the air at the $68 \mathrm{th}$ street water intake structure, by sector. in 1973-74 and 1978-79.

The difference in behavior for $\mathrm{Pb}$ in sector $\mathrm{A}$ compared to sector $\mathrm{B}$ is illustrative of another way in which these data may be viewed. In the interval between 1973-1974 and 1978-1979, the Fb concentration in the "urban" sector (B) dropped significantly ( twofold). We attribute this decrease to the spreading use of unleaded automotive fuels. But in sector $A$ ("industrial") over the same interval, there was little if any significant change. A tentative explanation of this observation is that a change occurred in the $\mathrm{Pb}$ source characteristics in the A Sector. Table 1 supports this notion by showing that the relationship between $\mathrm{Pb}$ and $\mathrm{Br}$ concentrations also changed dranutically over this interval. In 1973-1974 in both sectors A and $\mathrm{B}, \mathrm{Pb}$ and $\mathrm{B} \ddot{\mathrm{i}}$ concentrations were highly corxelated, as expected for automotive sources. ${ }^{3}$ This correlation beccmes insignificant in sector A for 1978-1979, but not in B. In sector $\mathrm{A}$ it is replaced by a significant correlation between $\mathrm{PB}$ concentration and the $\mathrm{Pb} / \mathrm{Br}$ ratio. We interpret this as pointing to the emergence in sector A of a strong non-automotive source of $\mathrm{Pb}$, whose contribution is made more obvious by decreases in the automotive source term. 
We expect that additiona: work will reveal similar changes in source strengths and characteristics for other elements.

Table 1. Changes in atmospheric lead source characteristics in the interval from 1973-74 to $1978-79$.

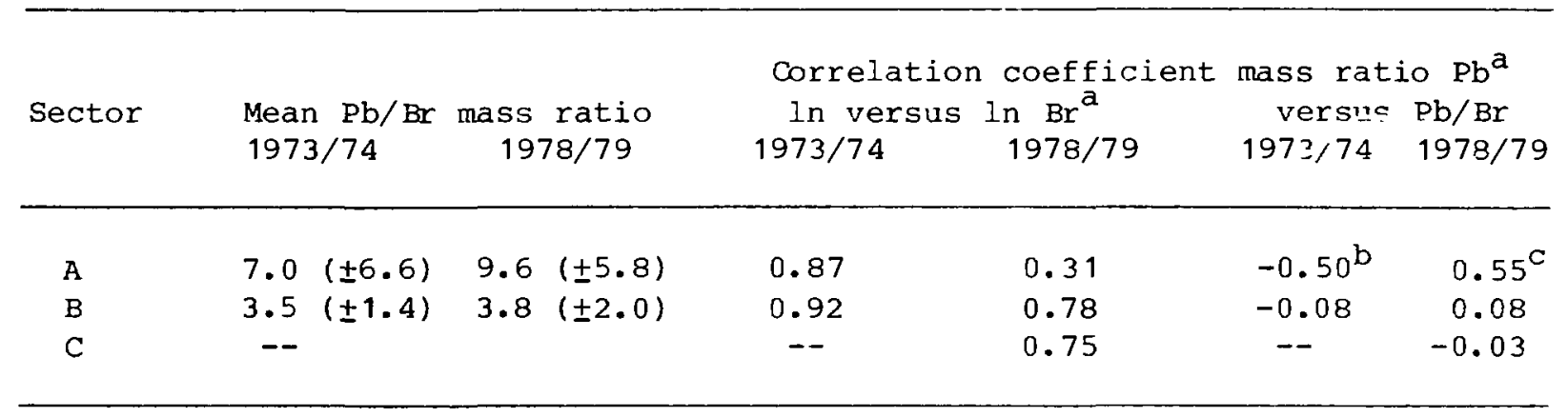

$a_{n g ~} m^{-3}$

$b(\underline{p}(t) \cong 0.01)$

$\underline{(\underline{P}}(t)<0.01)$

\section{References}

1. Williams, R. M. and R. V. White, A wind direction controlled air sampling system, to be published.

2. Fingleton, D. J. and J. A. Robbins, Trace elements in air over Lake Michigan near Chicago during September 1973, J. Great Lakes Res. 6, 22-37 $(1980)$.

3. Hammerle, R. H. and W. R. Pierson, Sources and elemental compositon of aerosol in Pasadena, California, by energy-dispersive x-ray fluorescence, Environ. Sci. Techno. 9, 1058-1068 (1975). 
RESULTS OF LAB AND FIELD TESTS OF AN ORGANICS AIR SAMPLER

R. J. Wingender

Background and scope

In conjunction with the inorganic air sampling program conducted over jakes Michigan and Huron, the commitment was made for the sampling of airborne arganic pollutants. The inorganics sampler was at first modified to accommodate XAD-2 resin as an adsorbant for organics in the vapor state. As a result of the efforts to optimize the sampling and analytical procedures, a different sampler utilizing Florisil® as an adsorbant was designed.

As the requirements for monitoring trace levels of contaminants in water became more demanding, techniques were developed which selectively removed the organics from water, concentrating them on a collection medium. The collection media most widely employed were porous polymer resins and porous polyurethane foam plugs. 2 The use of Tenax-GC, a diphenyl-phenylene oxide resin was limited to the more volatile contaminants on EPA's Priority pollutant List designated as "purgeable" compounds, whereis the styrenedivinyl benzene resins and polyurethane foam plugs were more appropriate for adsorbing and releasing PCBs and pesticides.

The increasing interest in the role of the atmosphere as a pathway for transport of toxic organics such as PCBs has generated a need to determine their atmospheric concentrations. Analysis of the low concentration of PCBs in the atmosphere necessitated a preconcentration/isolation step, and both porous polymer resins ${ }^{3,4}$ and polyurethane foam plugs ${ }^{5}$ were adopted for this purpose.

We chose to use Rohm and Has Amberlite XAD-2 resin, since it is one of the most widely used resins. It is a low-polarity styrene-divinylbenzene copolymer possessing the macroreticular characteristics essential for high sorptive capacity and it could easily be incorporated in our modified sampler.

The XAD-2 resin obtained from Eastman was soxhlet extracted in batch quantities with acetonitrile. After drying, 12 to $14 \mathrm{~g}$ of the resin was packed in the stainless steel (ss) collection tubes and further cleaned by sequential Soxhlet extractions with acetone, methylene chloride, and petroleum ether. After drying, the tubes were mounted in the sampler. Following 
exposure, the resin was soxhlet extracted with petroleum ether for 18 to 20 $\mathrm{hr}$. The extract was reduced in volume to $\sim 1 \mathrm{~mL}$, subjected to Florisil cleanup, and the volume reduced to $0.1 \mathrm{~mL}$. A $2 \mu \mathrm{L}$ aliquot was injected into the gas chromatograph.

Among the large number of compounds detected by the electron capture detector (ECD) were observed patterns of PCBs, especially that for Arochlor 1254. Polychlorinated terphenyls (PCTs) were also detected in some samples from Lake Huron. The flame ionization detector (FID) tracing showed peaks due to $\mathrm{C}_{20}$ to $\mathrm{C}_{37}$ straight chain alkanes. Surprisingly, the EC and FID tracings for the extract of the blank (unexposed to the atmosphere) XAD-2 resin were almost identical to those observed from the extract of the exposed resin. While the PCBS probably were collected from the air, the other uridentified compounds and the alkanes could have originated from the lubricating fluids and electronic components used in the sampler as well as from the air. Furthermore, one sampling run comparing the quantity of organics collected by XAD-2 in a stainless steel tube mounted in the modified sampler with one connected directly to a pump indicated that the amount of material collected by the former was approximately 258 thar collected by the latter. Clearly the tubes should have been sealed before ard after sampling to insure exposure only to the atmosphere, and the seals made during collection must be improved.

In addition to these problems, it was also observed that the XAD- 2 resin could not be cleaned completely with the petroleum ether soxhlet extraction, and a build-up of organics on the resin resulted. Also, even though our collections were made using low volume pumps ( 3 to $8 \mathrm{~L} / \mathrm{min}$ ), the scrubbing efficiency of the XAD-2 was apparently not adequate to prevent breakthrough. Examination of the extract of the resin from tubes placed in series indicated that almost $50 \%$ carryover from the first tube to the second occurxed.

In consideration of these problems, a different adsorbant was selected which could be utilized in a sampler designed to eliminate the possibility of exposure of the adsorbant except to the atmosphere at the prescribed time interval. The adsorbant chosen was Florisil@, a synthetic magnesium silicate used extensively in trace analysis for column cleanup of extracts of environmental samples. ${ }^{6}$ More recently it has been shown to function well as a rapid and inexpensive method for adsorption of PCBs and phthalates from air. 7,8 Apparently the only drawback to its more widespread use is its fine 
particle size, which causes a large pressure drop when high volume sampling is attempted. ${ }^{4}$

I have made a number of samplings of air contaminated with PCBs using Florisil as the adsorbant with a good deal of success. The technique utilizes about $0.2 \mathrm{~g}$ Florisil topped with about $1 \mathrm{~g}$ anhydrous $\mathrm{Na}_{2} \mathrm{SO}_{4}$ held in a 3/8" O.D. heavy wall Pyrex tube with precleaned glass wool. Air is drawn through the tube at a rate of 1 to $3 \mathrm{~L} / \mathrm{min}$ for 24 to $48 \mathrm{hr}$. The PCBs are rapidly eluted from the Florisil with $8 \mathrm{~mL}$ petroleum ether. Rather than reuse the adsorbant, I cleaned and repacked the glass tube with fresh materials.

Several advantages are easily recognized in the use of Florisil: (1) compounds may be selectively eluted by virtue of their polarity, and collection and cleanup may be performed on the same adsorbant bed; (2) it is not prepared from organic materials as is XAD-2, and is therefore free of organic reaction by-products; and (3) it is a highly efficient adsorbant only 18 breakthrough was measured after $300 \mathrm{ng}$ of PCBs had been collected from the air.

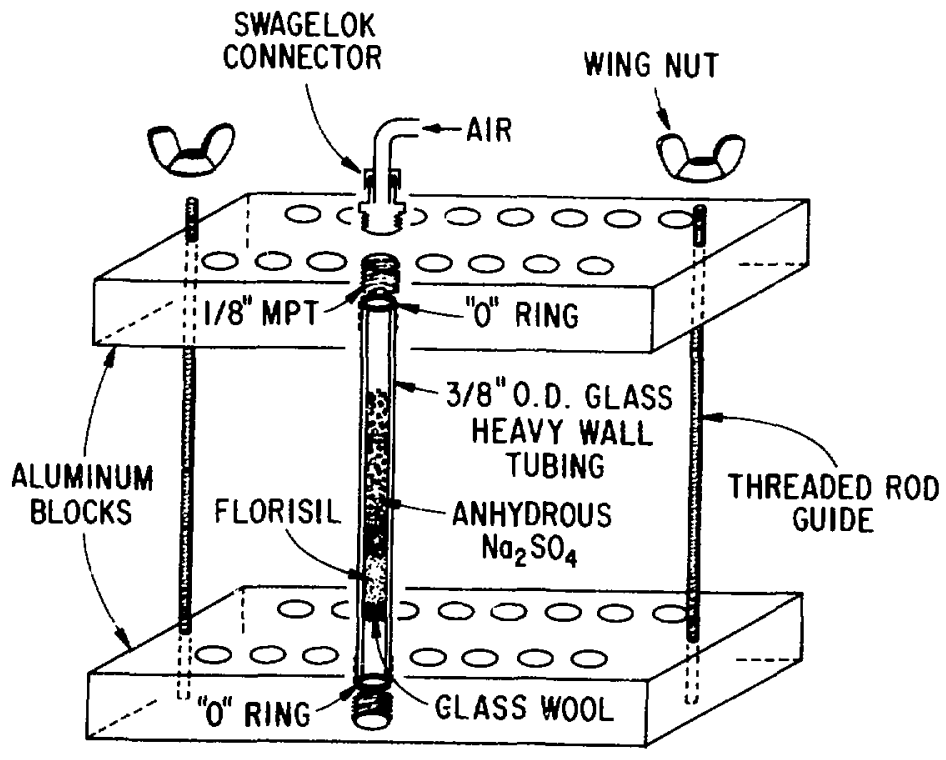

Figure 1. Proposed design of sample holder.

\section{Progress in 1980}

A preliminary design for a new sampler using Florisil has been made, 
employing the electronics developed for the modified sampler. The design includes a 34 port, 16 position, type ST multiposition chromatographic sampling valve manufactured by valco Instruments. This valve allows the inlet and outlet of each tube to be closed off except during sampling. Sixteen tubes containing Florisil will be positioned between two machined blocks as shown in Figure 1. Connections between the blocks and valve will be made using standard Swagelok fittings and Teflon tubing. Easy packing and removal of the tubes is accomplished by removing the two wing nuts and lifting off the top block.

\section{References}

1. Junk, G. A., J. J. Richard, M. D. Grieser, D. Witiak, J. L. Whitiak, M. D. Arguello, R. Vick, H. T. Svec, J. S. Fritz, and G. V. Calder, Use of macroreticular resins in the analysis of water for trace organic contaminants, J. Chromatogr. 99, 745-762 (1974).

2. Uthe, J. F., J. Reinke, D. H. Gesser, A. Chow, and F. C. Davies, The extraction and recovery of polychlorinated biphenyls (PCB) using porous polyurethane foam, Anal. Lett. $\underline{4}$, 883-886 (1971).

3. Pellizzari, E. D., J. E. Bunch, B. H. Carpenter, and E. Sawicki, collection and analysis of trace organic vapor pollutants in ambient atmospheres, Environ. Sci. Technol. 9, 552-555 (1975).

4. Doskey, P. V. and A. W. Andren, High-volume sampling of airborne polychlorbiphenyls with amberlite XAD-2 resin, Anal. Chem. 110, 129-137 (1979)

5. Stratton, C. L., S. A. Whitlock, and J. M. Allan, A method for the analysis of polychlorinated biphenyl in air, EPA Report No. EPA-600/4-78048 (August 1978).

6. Morley, H. V., Adsorbents and their application to column cleanup of pesticide residues, Residue Reviews 16, 1-29 (1966).

7. Giam, C. S., H. S. Chan, and G. S. Neff, Rapid and inexpensive method for detection of polychlorinated biphenyls and phthalates in air, Anal. Chem. 47, 2319-2320 (1975).

8. Williams, D. T., G. L. LeBel, and T. Furmanczyk, Polychlorinated biphenyl contamination in laboratory air, Chemosphere 9, 45-50 (1980). 
SEDIMENT RESUSPENSION PROCËSSES IN THE GREAT LAKES

B. M. Lesht, R. M. Williams, and R. V. White

Backgrouna ind Scope

There is little doubt that sediment resuspension is an important process in the recycling ind redistribution of pollutants and nutrients in the Great Lakes. Very little is known, however, about resuspension in these waters. This lack of knowledge has had a significant effect on attempts to develop numerical models that include the effects of particulate transport. Mocielers, for example, have been forced to use artificial parameter adjustments to calibrate their models when meteorological conditions (which cause resuspension) are different from the expected "average" year.1 Therefore, one immediate objective of this work is to luake enough direct observations of resuspension so that the relationship between resuspension and meteorological forcing can be understisod and incorporated into ecological models.

Progress in 1980

We conducted a month-long experiment (between 10 October and 8 November) in which our time-lapse camera system (TLCS) ${ }^{2}$ was deployed on Indiana Shoals, Lake Michigan, adjacent to our meteorological tower. In order to make more detailed observations we also mounted a two-axis electromagnetic current meter and four trar.smissometers on the tower. The current meter was positioned $1 \mathrm{~m}$ above the bottom and the transmissometers were placed at $0.5,2$, 5, and $8 \mathrm{~m}$. We recorded continuous 15-min ave;ages of the easterly and northerly currents during the experiment and average (15 $\mathrm{min})$ transmittance once per hour. The camera was set to expose one frame every $15 \mathrm{~min}$.

The film record shows 10 different sediment transport events ranging in intensity from gradual migration of the sand ripples to resuspension which completely obscures the bottom. These ten events occupy approximately 220 hrs of the total 670 urs of filming. Figure $1 a$ is a representation of the film in which the intensity of the observed sediment transport is assigned a numerical value $(0$ = no observed transport, 1 = ripple migration, 2 = resuspension).

The resuspension events are reflected in the transmissometer records. Figure $1 \mathrm{c}$ is the transmittance measured at $0.5 \mathrm{~m}$. It clearly shows the intense event at the beginning of the record and the shorter events between 
days 299-304. Unfortunately tihe transmissometers are subject to biological fouling, which is the cause of the steady decrease in transmissivity from day 299 to 311.
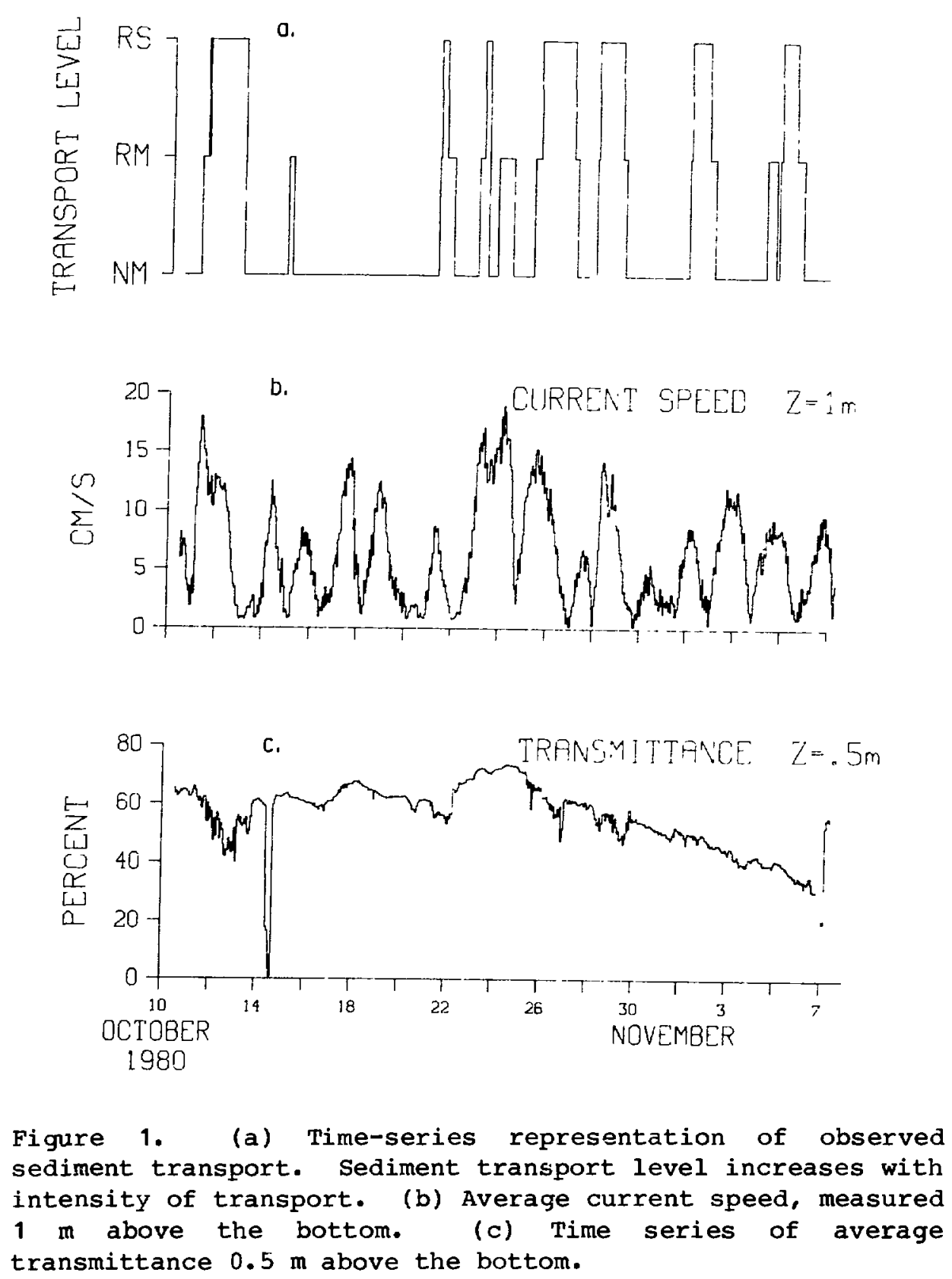

The concurrent record of current speed (Figure 1b) shows that although currents often exceed $0.15 \mathrm{~m} / \mathrm{s}$, the correlation between speed and resuspension is not particularly good. In our preliminary analysis we have found that the 
bottom currents are correlated with wind speed and direction and that resuspension is correlated with northerly winds. Thus we conclude that resuspension at Irdiana Shoals is primarily the result of surface waves. We are continuing our efforts to refine this conclusion.

\section{Prospects}

Analysis of the Indiana Shoals data will be continued, and further experiments will be conducted at this location. We intend to add a wave sensor to our instrumentation co verify the apparent correlation between resuspension and wave activity.

\section{References}

1. Podgers, P. W. and D. K. Salisbury, Modeling of water quality in Lake Michigan and the effect of the Anomalons Ice Cover of 1976-1977, Great Lakes Basin Commission, Ann Arbor, Michigan (1981).

2. Lesht, B. M. and R. V. White, Development of a time lapse camera for benthic research, Radiological and Environmental Research Division Annual Report, January-December 1979, ANL-79-65, Part III, pp. 6ti-79. 
LAKE MICHIGAN DATABASE ANALYSIS AND MODEL DEVELOPMENT

B. M. Lesht

\section{Background and Scope}

The U.S. Environmental Protection Agency conducted an extensive water quality surveillance program in Lake Michigan Juring 1976 anj 1977. This program consisted of measurements of 44 water quality parameters using samples taken at several depths at approximately 100 stations during each of 17 cruises. As part of our effort to implement and improve a numerical phytoplankton model of Lake Michigan, I am conducting a statistical analysis of this database.

The statistical analysis has two major objectives. The first is to identify subsets of the database which are appropriate for calibrating and verifying the phytoplankton model. The second objective is to extract enough detailed information from the database concerning the spatial and temporal variability of the measured parameters to enable us to design more efficient sampling schemes both for support of the model and for determination of longterm trends in water quality.

\section{Progress in 1980}

Since there are no well defined techniques for dealing with a data set of this type, most of my initial efforts have been experimental, aimed at gaining experience with the data and at designing the statistical procedures to be used in the analysis. I began by using a two-factor analysis of variance (ANOVA) model ${ }^{1}$ to determine the relative spatial and temporal variability of each of the measured parameters.

The two-factor model may be expressed by

$$
z_{i j k}=\mu+\alpha_{i}+\beta_{j}+\varepsilon_{i j k}
$$

in which $z_{i j k}$ is an observation of the parameter of interest (suitably transformed for an analysis of variance) made during cruise $i$ at station $j$. The term $\mu$ is the overall mean value of the parameter; $\alpha$ is the change in tie mean due to cruise $i ; \beta$ represents the effect due to station $j ;$ and $\varepsilon_{i j k}$ is the error or residual. This portion of the analysis is similar to the study 
of lake Ontario done by El-Shaarawi and Kwiatkowski. 2

An example of the result of this procedure is presented in Table 1, which shows the reduced analysis of variance tables for two parameters, epilimnion chloride and chlorophyll a (southern basin, 1976). I chose these two parameters to illustrate the extremes in variability that may be expected in the data. Table 1 shows that, for chloride, the variance due to cruise differences (i.e., temporal variability) is small and that station differences (i.e., spatial variability) are much more significant. on the other hand, the chlorophyll data show that both spatial and temporal variability are significant and that temporal variability is larger than spatial variability.

Table 1. Reduced ANOVA tables for (chloride) ${ }^{1 / 2}$ and In (chlorophyll a)(1976 southern basin).

\begin{tabular}{|c|c|c|c|c|}
\hline & Source & Degrees of freedom & Sum of squares & F value \\
\hline \multirow[t]{3}{*}{ Chloride } & Cruise & 5 & 0.04 & 5.10 \\
\hline & Station & 46 & 1.57 & 22.42 \\
\hline & Error & 942 & 1.43 & \\
\hline \multirow[t]{3}{*}{ Chlorophyll a } & Cruise & 5 & 45.43 & 35.63 \\
\hline & Station & 46 & 68.36 & 5.83 \\
\hline & Error & 860 & 219.32 & \\
\hline
\end{tabular}

I have also used a refinement of this technique to try to identify regions of the lake in which the parameters are alike. In this procedure, a single factor analysis of variance technique is used. The observations, $z_{i j}$, are expressed as the sum of a mean $\mu_{i}$ and an error term $\varepsilon_{i j}$, or

$$
z_{i j}=\mu_{i}+\varepsilon_{i j}
$$

The $\mu_{i}$ can be thought of as the lakewide average for cruise $i$, and the $\varepsilon_{i j}$ term is the residual due to stations and other differences. Figure 1 shows values of $\mu_{i}$ for epilimnion chlorophyll a calculated from several subsets of the 1976 southern basin data. This figure illustrates how the lakewide menn value changes as the subset excludes stations in shallow water. 


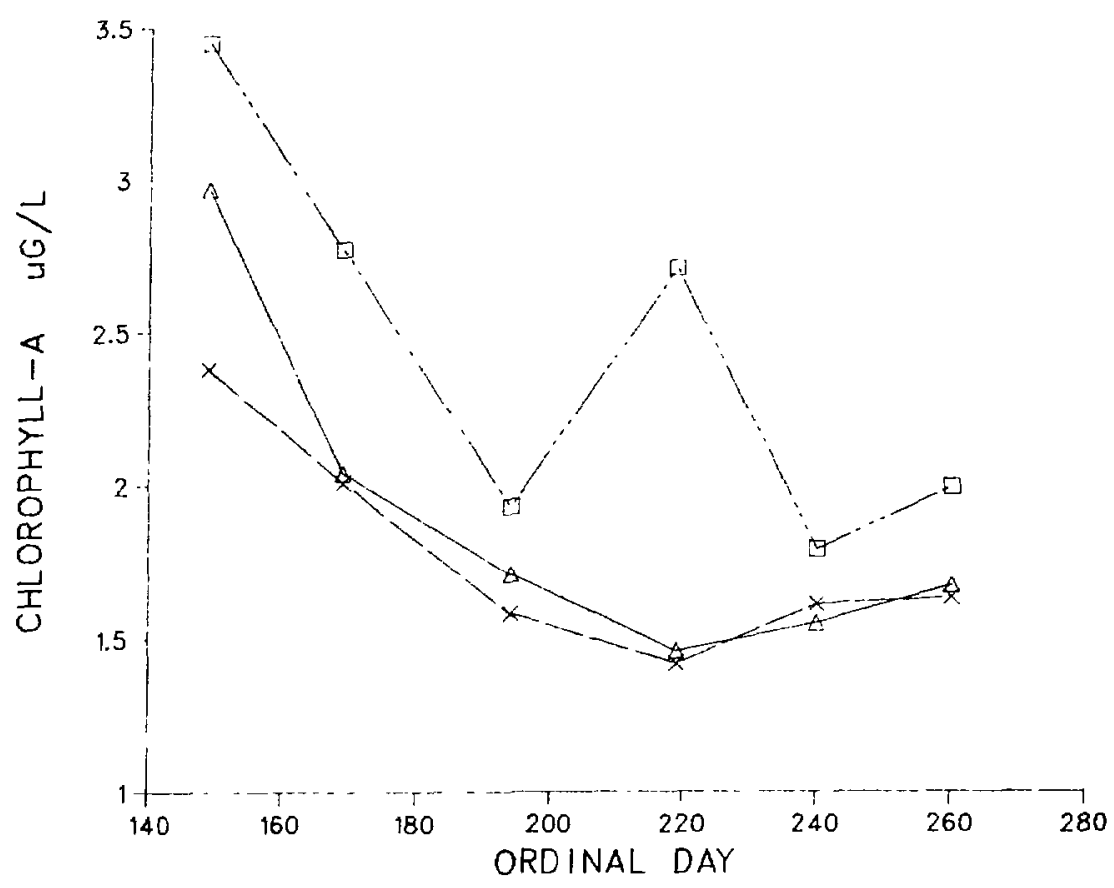

Figure 1. Predicted (mean) values of epilimnion chlorophyll a for the southern basin during 1976 plotted as a function of cruise date for several subsets of the data. Subsets are stations greater than $15 \mathrm{~m}$ depth, $\Delta$; stations sreater than $30 \mathrm{~m}$ depth, $x_{i}$ and inshore stations less than $15 \mathrm{~m}$ depth, $\square$.

When the lakewide means $\mu_{i}$ are subtracted from the individual observations $z_{i j}$, the residuals represent the difference between the observations made at a particular station and the lakewide mean for cruise i. If the residuals from $n$ cruises are considered as a set of random variables, then it is possible to determine which stations, on the average, are different from the lakewide mean. Figure 2 is an example of a control chart representation ${ }^{3}$ of the mean residuals for chlorophyll-a measured in the southern basin during 1976. The horizontal control lines are based on the $95 \%$ confidence limit.

\section{Prospects}

Determining which subset of the data is appropriate for calibrating the lake phytoplankton model will be an empirical process. Mean values for each of the parameters of importance in the model will have to be determined and 
the model will have to be adjusted to each set of parameters. This work should be completed in 1981.

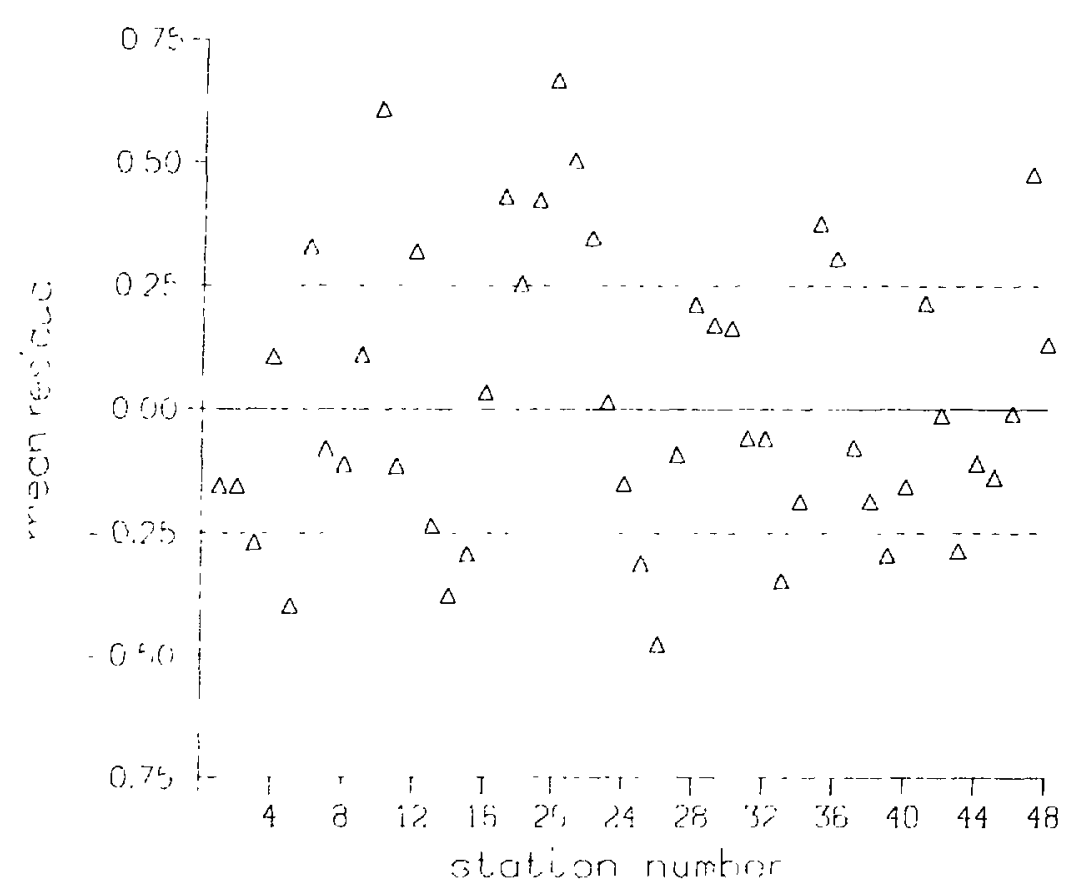

Figure 2. Control chart of mean residuals plotted as a function of station. Data are from epilimnion chlorophyll a values measured in the southern basin during 1976. Points within the horizontal dashed lines are not significantly different from the lakewide mean $(p=0.05)$.

Designing improved sampling schemes is more involved since the sampling strategy will depend on whether the lake mean or the lake variance is of importance. I plan to use the residuals of each parameter to determine which stations contribute most to the lake variance. This will be done using some form of stepwise regression procedure. 1

In addition, I will combine all the residuals into one data set, and use a clustering procedure ${ }^{4}$ to determine which stations look most alike for all of the parameters tested. This should allow us to eliminate redundant sampling and to identify homogeneous regions of: the lake. 


\section{References}

1. Neter, J. and W. Wasserman, Applied Linear Statistical Models, R. D. Irwin, Inc., Homewood, Illinois (1974).

2. El-Shaarawi, A. H. and R. E. Kwiatkowski, A model to describe the inherent spatial and temporal variability of parameters in Lake ontario 1974, J. Great Lakes Res. 3, 177-183 (1977).

3. Dixon, W. J. and F. J. Massey, Jr., Introduction to Statistical Analysis, McGraw-Hill, New York (1957).

4. Hartigan, J. A., Clustering Algorithms, Wiley \& Sons, New York, (1975). 
CONCENTRATIONS OF DISSOLVED AND PARTICULATE FORMS OF TRACE ELEMENTS IN LAKE MICHIGAN'S MAJOR TRIBUTARIES

G. T. Tisue, C. A. Seils, and D. A. Warner

\section{Background and scope}

A major goal of recent studies of trace elements in the Great Lakes has been the establishment of mass balance budgets. 1 These budgets are derived from estimates of element mass fluxes to and from the water column, including atmospheric and riverine inputs, and losses through sedimentation and outflow. We determined the flux of several trace metals borne into the lake in dissolved and particulate forms by major tributaries.

In the period 1977-1980 we sampled the twelve largest tributaries of Lake Michigan a total of 4 or 5 times, at periods of both high (late spring) and low (late autumn) flow. At the time of collection samples were filtered serially through stacked 5 and $0.45 \mu \mathrm{m}$ membranes. The concentrations of the elements $\mathrm{V}, \mathrm{Cr}, \mathrm{Fe}, \mathrm{Ni}, \mathrm{Cu}, \mathrm{Zn}, \mathrm{Mo}, \mathrm{Ag}, \mathrm{Cd}, \mathrm{Sn}, \mathrm{Hg}$, and $\mathrm{Pb}$ were subsequently determined in the filtrate that had been acidified and stored in polyethylene containers. For these analyses, we employed $x$-ray fluorescence spectrometry following preconcentration by precipitation with pyrrolidine-N-carbodithioic acid. 2

Elements retained on the membrane filters proved directly analyzable by $\mathrm{x}$-ray fluorescence spectrometry in the cases of $\mathrm{Al}, \mathrm{Si}, \mathrm{K}, \mathrm{Ca}, \mathrm{Ti}, \mathrm{V}, \mathrm{Cr}, \mathrm{Mn}$, $\mathrm{Fe}, \mathrm{Ni}, \mathrm{C}, \mathrm{Zn}, \mathrm{Rb}, \mathrm{Sr}$, and $\mathrm{Pb}$. In most samples, the concentrations of $\mathrm{Ag}$, $\mathrm{Sn}$, and $\mathrm{Hg}$ did not exceed blank values. We first prepared suitable standards to calibrate the instrument's response and to study potential interelement and mass absorption effects.

Progress in 1980

Semmler ${ }^{3}$ reported that properly prepared slurries of finely ground metal oxides could be standardized gravimetrically, then serially diluted and filtered to provide standards for $x$-ray fluorescence analysis. We have confirmed this report and applied the technique to standards for the elements $\mathrm{Al}, \mathrm{Si}, \mathrm{K}, \mathrm{Ca}, \mathrm{Ti}, \mathrm{Mn}, \mathrm{Fe}, \mathrm{C}, \mathrm{Zn}$, and $\mathrm{Pb}$. For optimum sensitivity in the $x$-ray fluorescence analyses, three secondary sources were employed: (1) Ti, for $\mathrm{Al}$ and $\mathrm{Si} ;(2) \mathrm{Cu}$, for $\mathrm{K}, \mathrm{Ca}, \mathrm{Ti}, \mathrm{V}, \mathrm{Cr}$, and $\mathrm{Mn}$; and (3) Mo, for $\mathrm{Fe}, \mathrm{Ni}$, 


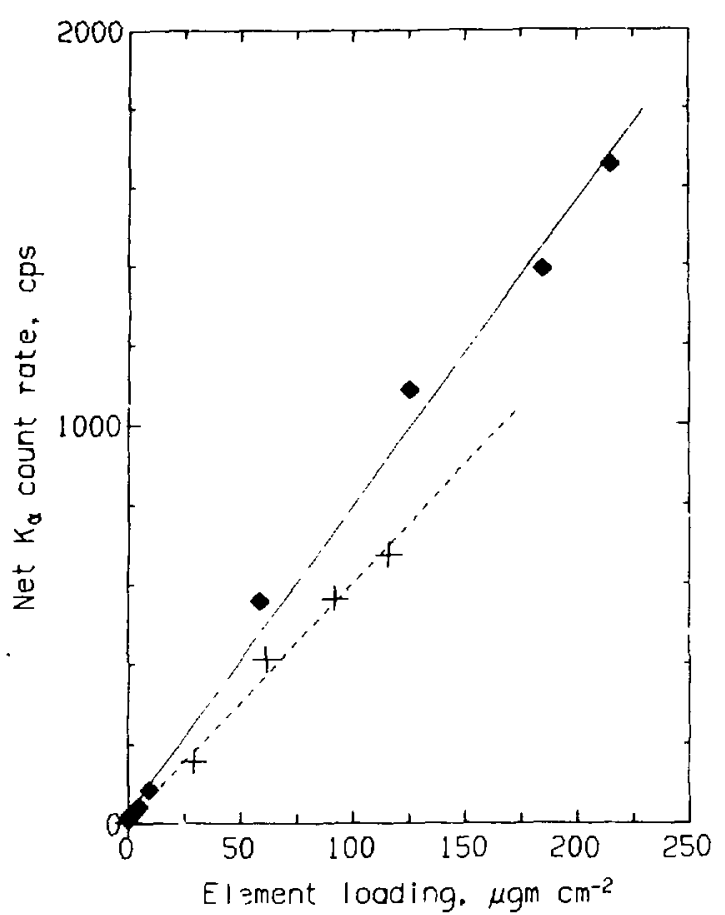

Figure 1. Calibration plots for Al $(+)$ and Si (\$) obtained from oxide standards on Nuclepore membranes using a Ti secondary source.

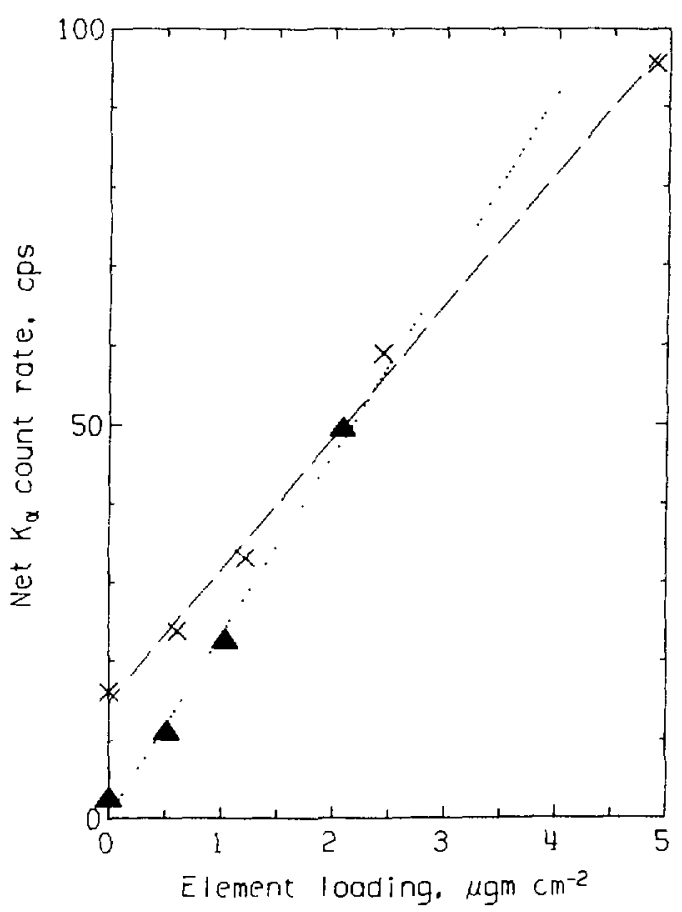

Figure 3. Calibration plots for $\mathrm{Fe}$ $(\mathrm{X})$ and $\mathrm{Pb}\left(I_{B}\right)(\Delta)$ using a Mo secondary source.

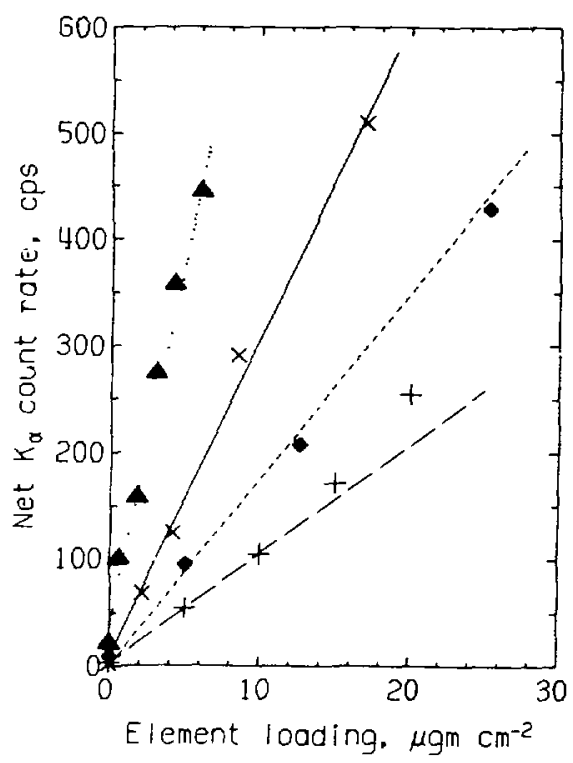

Figure 2. Calibration plots for $\mathrm{K}$ $(+), \mathrm{Ca}(\bullet), \mathrm{Ti}(\mathrm{X})$, and $\mathrm{Mn}(\mathbf{A})$, using a ou secondary source.

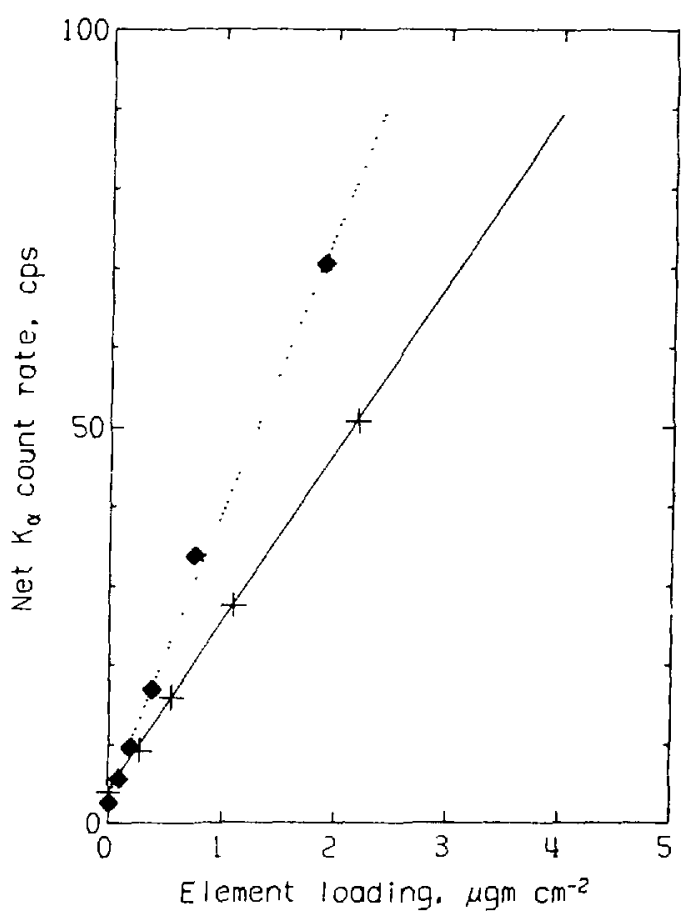

Figure 4. Calibration plots for $\mathrm{Cu}(+)$ and $\mathrm{zil}(\bullet)$, using a Mo secondary source. 
C., $\mathrm{Zn}$, and $\mathrm{Pb}$. Figures 1-4 show representative calibration plots for these elements. For elements with $z>25$ (Mn), tise single element calibration curves may be used directly. The lighter elements, especially Al and Si on heavily loaded filters, exhibit interelement and mass absorption effects that require appropriace corrections. We are currently studying aiternative data reduction procedures using multi-element standards that mimic the range of total mass loadings and relative proportions of elements observed in the actual samples. Calibration for elements for which standards have not been prepared is made by interpolation from the empirical relationship between observed sensitivity for various elements and the theoretical efficiency factor (absorption cross-section times fluorescent yield). This relationship is shown in Figure 5 .

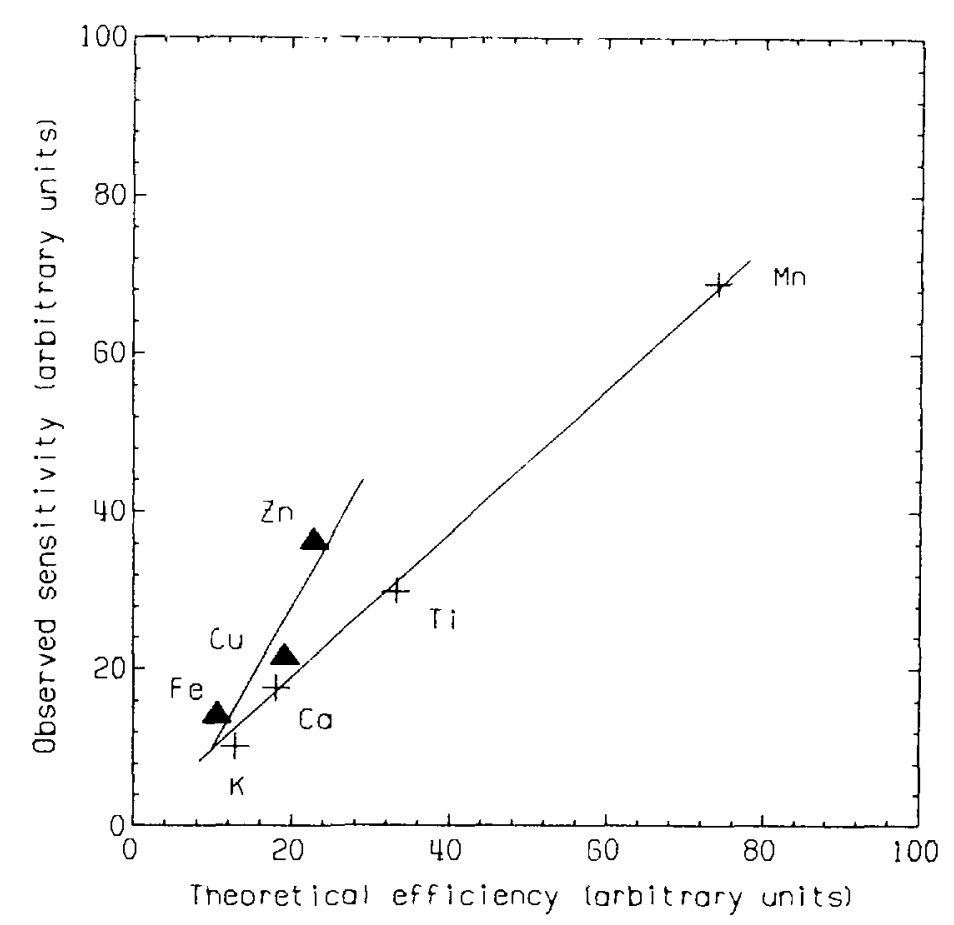

Figure 5. Relationship between observed sensitivity and theoretical efficiency factor (absorption cross-section $x$ fluorescent yield). (4) Mo secondary source; secondary source.

During 1980 we completed analyses of all tributary samples for the dissolved $(<0.45 \mu \mathrm{m})$ fractions of the target suite of trace metals. A key to our success with these samples was the development of a potassium peroxodisulfate digestion procedure to destroy interfering organic matter. 2 This pretreatment brought recoveries from actual samples to $>908$ for all the elements studied, as judged by the method of standard additions. Figure 6 shows a comparison of one such standard addition experiment with results 
obtained using standards prepared in deionized water. Table 1 presents typical recovery efficiencies observed for the principal elements investigated.

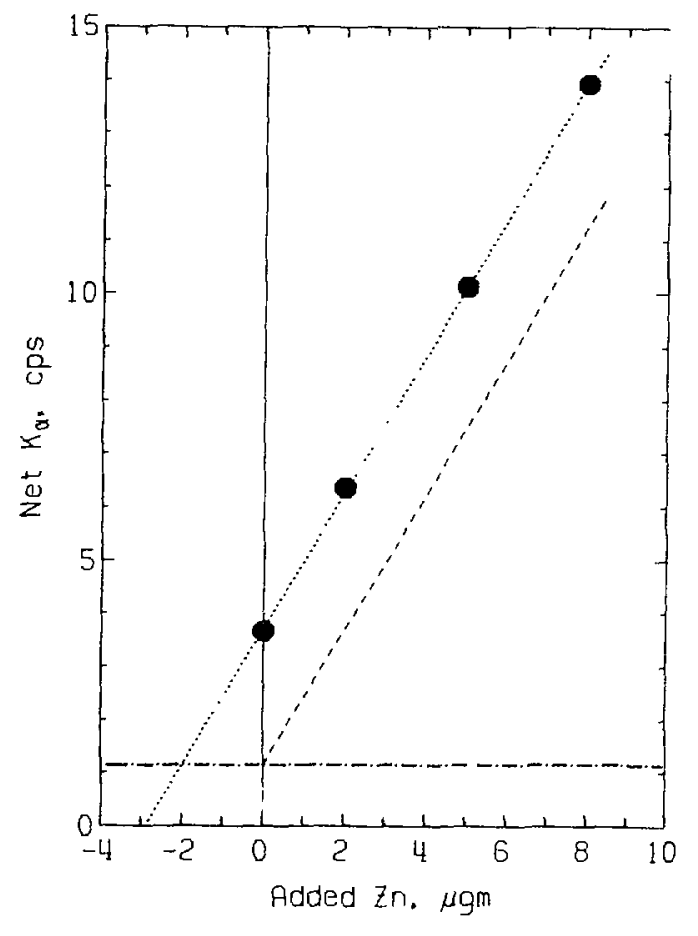

Figure 6. Standard additions of $\mathrm{Zn}$ to river water compared to calibration plot from standards in deionized water. (...) Muskegon River, 4/24/78; $(--)$ aqueous standards; $\left.\left(-^{\cdot}-\right)^{-}\right)$blank value.

Table 1. Recovery efficiencies from river waters.

\begin{tabular}{lr}
\hline & Typical recovery, 8 \\
\hline $\mathrm{V}$ & \\
$\mathrm{Fe}$ & 90 \\
$\mathrm{Ni}$ & 92 \\
$\mathrm{Cu}$ & 101 \\
$\mathrm{Zn}$ & 112 \\
$\mathrm{MO}$ & 100 \\
$\mathrm{Cd}$ & 96 \\
$\mathrm{Sn}$ & 95 \\
$\mathrm{Hg}$ & 91 \\
$\mathrm{~Pb}$ & 93 \\
\hline
\end{tabular}

The data on all elements determined in all the river samples is too 
Table 2. Concentrations of dissolved and particulate forms of zinc in Lake Michigan's major tributaries.

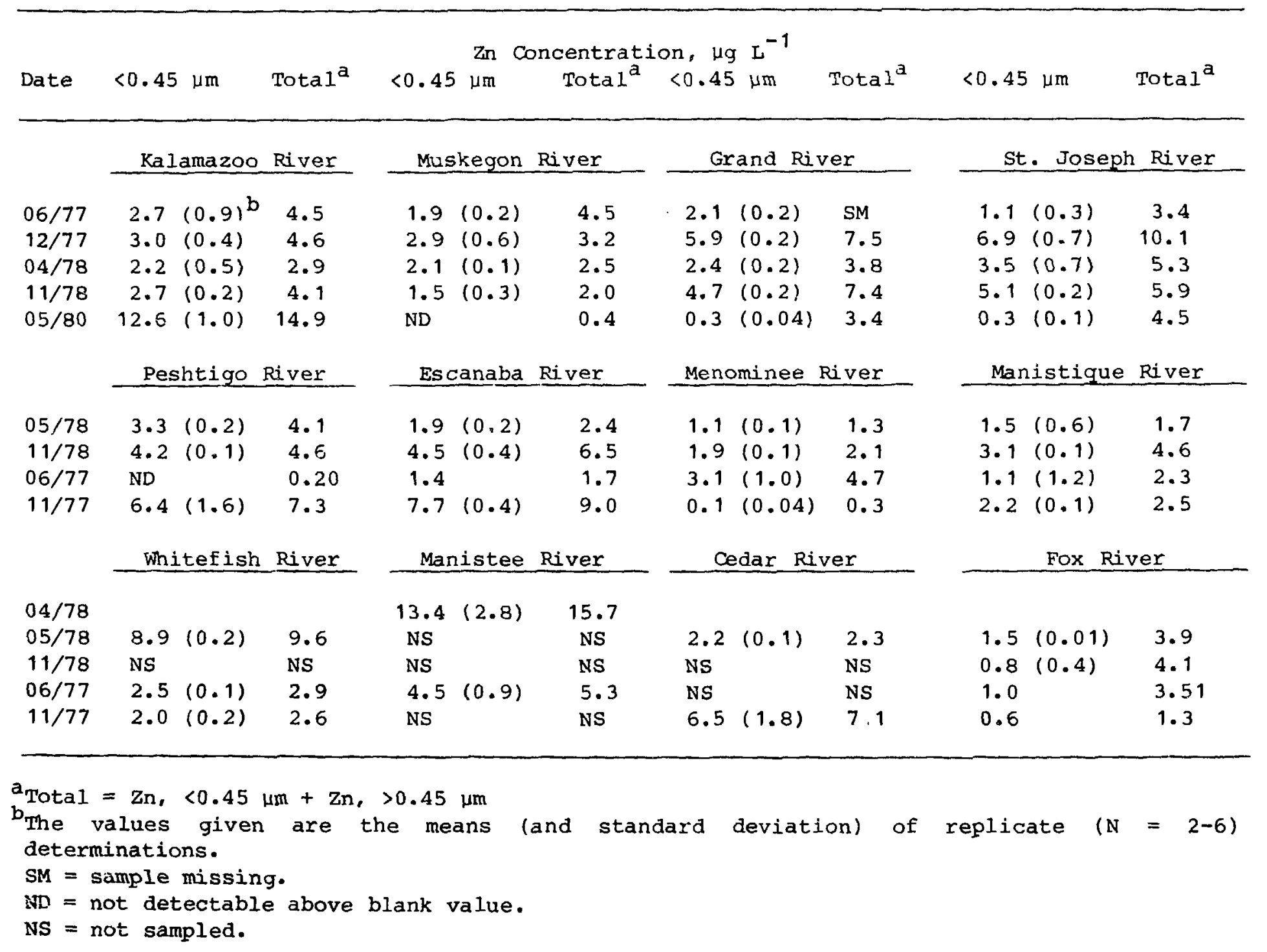




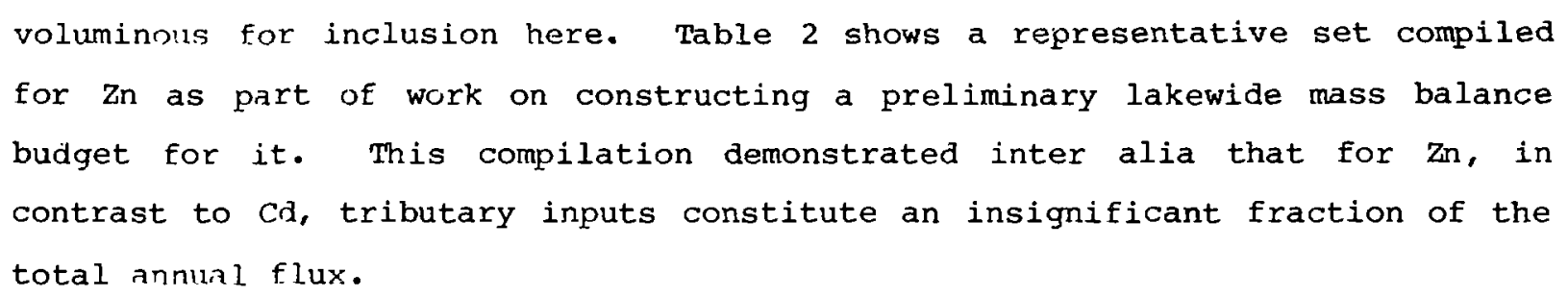

\section{References}

1. Muhlbaier, J. and G. T. Tisue, Cadmium in the southern basin of Lake Michigan, Water, Air, and Soil Pollut. 15, 45-59 (1981).

2. Tisue, G. T. and C. A. Seils, Pxeconcentration of nanomolar amounts of trace elements from natural waters for $x$-ray energy spectrometric analysis using pyrrollidine carbodithioic acid, 29th Ann. Conf. on Applications of X-Ray Analysis, Denver, 4-8 August 1980.

3. Semmler, R. A. and R. G. Draftz, Calibration standards for $x-r a y$ spectrometers used for pollution sample analysis, EPA Report 600/2-78-197 (September 1978). 
LAKE WATER CHEMISTRY AND ZINC TOXICITY TO PLANKTON COMMUNITIES - A PRELIMINARY REPORT

J. S. Marshall, D. M. Nelson, D. L. Mellinger, C. Lei, S. G. Lawrence*, and D. F. Malley ${ }^{*}$

Background and scope

According to the preliminary (1979) EPA water quality criterion for the protection of freshwater life, the maximum permissible 24-hr average zinc concentration is a function exclusively of hardness. 1 For waters witrhardnesses of those in Lake Michigan and Experimental Lakes Area (ELA) Lake 239, the calculated maximum permissible zinc concentrations are $\sim 50 \mu \mathrm{g} / \mathrm{n} / \mathrm{L}$ and $10 \mu \mathrm{g} \mathrm{Zn} / \mathrm{L}$, respectively. Hardness, a water quality index dependent primarily on $\mathrm{Ca}$ and $\mathrm{Mg}$ concentrations, is generally considered to be a dominant factor modifying zinc toxicity. 2 However, pH, other heavy metals, and various inorganic and organic metal-binding agents (dissolved, Farticulate, and colloidal) are also known to be important. $3^{-5}$

\section{$\underline{\text { Progress in 1980 }}$}

To assess the validity of the current zinc criterion for lakes with contrasting water hardness, two 2-week in situ experiments in Iake Michigan and two in ELA Lake 239 were conducted in July-August 1980. Hardness and other water quality parameters for these lakes are shown in Table 1. Experimental procadures were generally as described for recent in situ studies in Lake Michigan ${ }^{6}$ and ELA Lake $382 . .^{7}$

Responses of net plankton biomass, crustacean zooplankton biomass, and zooplankton community structure (as indicated by the percentage similarity index $^{6}$ for the plankton rotifer and crustacean communities) were much more pronounced in Lake Michigan than in ELA Lake 239 (Figure 1). Crustacean zooplankton biomass (Figure $1 \mathrm{~b}$ ) and percentage similarity for the rotifer community (Figure 1c) wexe significantly reduced by increased zinc concentrations as low as $15 \mu \mathrm{g} \mathrm{Zn} / \mathrm{L}$ in Lake Michigan, whereas neither was significantly reduced by concentrations as high as $60 \mu \mathrm{gn} / \mathrm{L}$ in ELA Lake 239.

\footnotetext{
*Department of Fisheries and Oceans, Freshwater Institute, Winnipeg, Manitoba, Canada
} 
Table 1. Chemical characteristics of ELA Lake 239 and Lake Michigan waters.

\begin{tabular}{|c|c|c|}
\hline Parameter & ELA Lake 239 & Lake Michigan \\
\hline 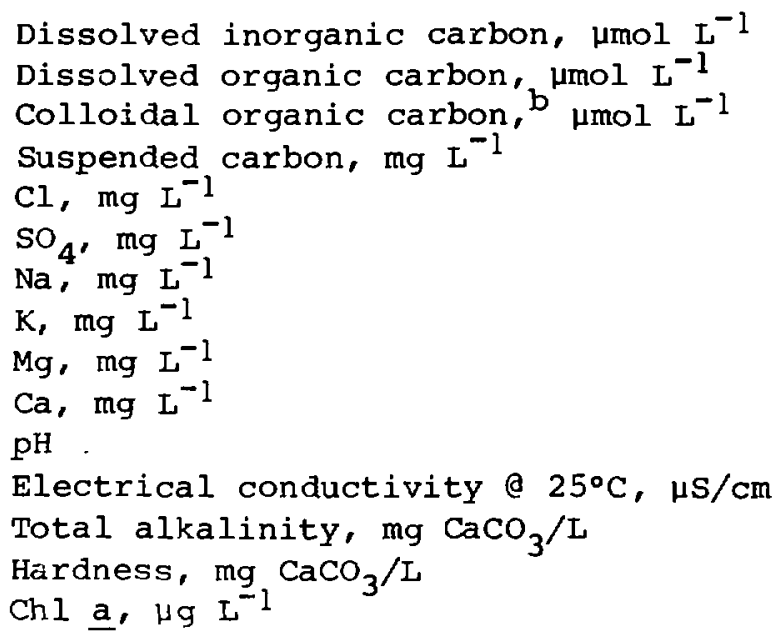 & $\begin{array}{l}100-140^{\mathrm{a}} \\
500-570^{\mathrm{a}} \\
\sim 420 \\
0.5-0.3^{\mathrm{a}} \\
0.6-0.8^{\mathrm{a}} \\
5.3-6.0^{\mathrm{a}} \\
1.2-1.4^{\mathrm{a}} \\
0.6-0.8^{\mathrm{a}} \\
0.8-0.9^{\mathrm{a}} \\
2.5-2.7^{\mathrm{a}} \\
6.4-7.3^{\mathrm{a}} \\
31-33^{\mathrm{a}} \\
\sim 13^{\mathrm{d}} \\
10-11^{\mathrm{e}} \\
1.6-4.0^{\mathrm{a}}\end{array}$ & $\begin{array}{l}1000-1200 \\
200-250 \\
\sim 80 \\
0.3-0.5 \\
6-10^{C} \\
15-30^{C} \\
4-6^{C} \\
1-2^{C} \\
10-20^{C} \\
30-40^{C} \\
8-9^{C} \\
250-290^{C} \\
\sim 110^{C} \\
\sim 135^{C} \\
0.6-4.0^{\mathrm{f}}\end{array}$ \\
\hline
\end{tabular}

a Prokopowich, J. and G. Lindsey. 8

$\mathrm{b}_{\text {Molecular weight greater than } 1000 .}$

Correy, M.s.9

d Hesslein, R. H, 10

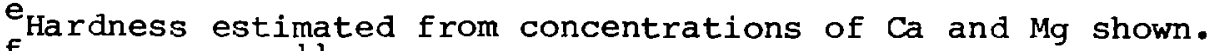

f Parker, J. I. 11

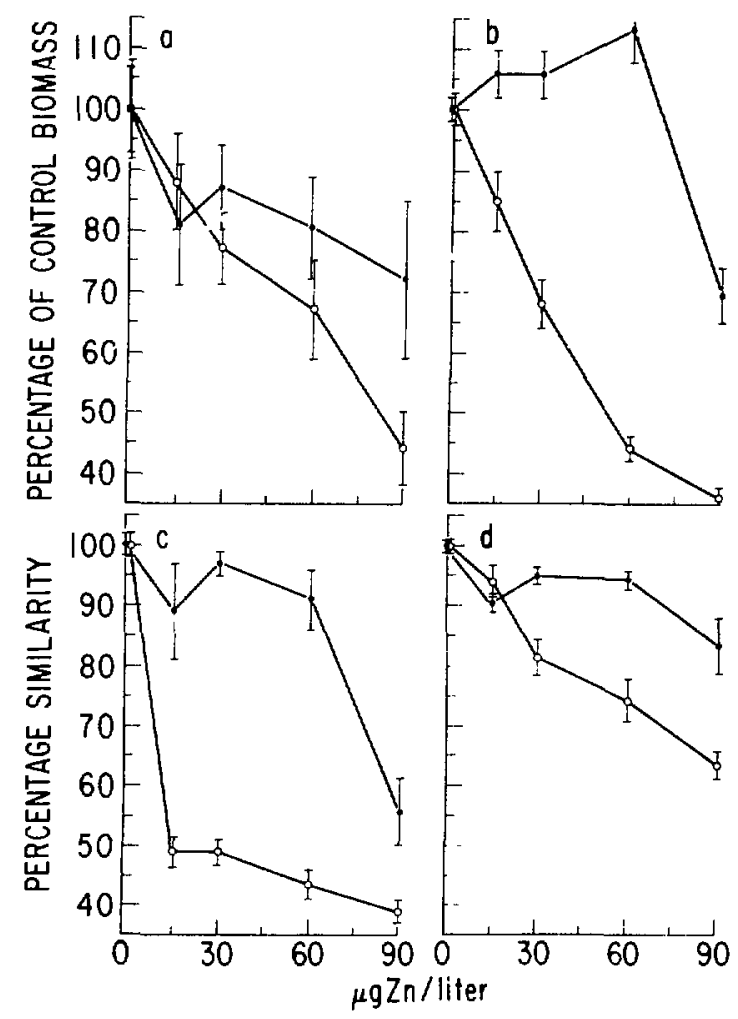

Figure 1. Effects of increased zinc concentrations on (a) net plankton biomass, (b) crustacean zooplankton biomass, (c) percentage similarity for plankton rotifer communities, and (d) percentage similarity for crustacean zooplankton communities after 2-wk in situ incubations in small enclosures in Lake Michigan (bottom curve) and ELA Lake 239 (top curve). Mean values shown for ail indices ( $t$ standard error bars) are expressed as percentages of mean values for controls. 


\begin{abstract}
These results suggest that the current zinc criterion may be too permissive for protection of freshwater life in Lake Michigan and too restrictive for other lakes. The results also indicate that hardness was clearly not the dominant factor responsible for the observed differences in plankton community responses to increased zinc concentrations in Lake Michigan and ELA Lake 239 waters. In view of the differences in the concentrations of dissolved organic carbon (DOC) and especially colloidal organic carbon (COC) in these lakes (Table 1), we suspect organic complexing may be the dominant factor responsible for the difference in zinc toxicity. This difference may be accounted for by a difference in bioaccumulation of zinc. Davies and sleep 12 have shown that zinc toxicity to phytoplankton is more closely related to the concentration of zinc in the organisms themselves (bioaccumulation) than to its concentration in the water.
\end{abstract}

\title{
Prospects
}

Although zinc toxicity to phytoplankton may be closely related to the concentration of free zinc ions, 13 we suspect that zinc toxicity to natural plankton communities (including zooplankton) is more closely related to the concentration of zinc in the organisms themselves than to any single water quality parameter. To test this hypothesis, we are continuing investigations of zinc distribution and the effects of increased zinc concentrations on natural plankton communities in lakes with diverse chemical characteristics.

\section{References}

1. U.S. Environmental Protection Agency, Ambient water quality criterion for zinc, report PB-296807, National Technical Information Service, Springfield, Va. 22161 (1979).

2. Weatherly, A. H., P. S. Lake, and S. C. Rogers. Zinc pollution and the ecology of the freshwater environment, zinc in the Environment. Part I. Ecological Cycling, J. O. Nriagu, Ed., John Wiley \& Sons, New York, pp. $337-418(1980)$.

3. Florence, T. M*, Speciation of zinc in natural waters, zinc in the Environment. part I. Ecological Cycling, J. o. Nriagu, Ed., John Wiley \& Sons, New York, pp. 199-277 (1980).

4. Bi.esinger, K. E., R. W. Andrew, and J. W. Arthur, Chronic toxicity of NTA (Nitrilotriacetate) and metal-NTA complexes to Daphnia magna, J. Fish. 
Res. Board Can. 31, 486-490 (1974).

5. Wilson, D. E., An equilibrium model describing the influence of humic materials on the speciation of $\mathrm{Cu}^{2+}, \mathrm{Zn}^{2+}$, and $\mathrm{Mn}^{2+}$ in Ereshwaters, Limnol. Oceanogr. 23, 499-507 (1978).

6. Marshall, J. S., D. L. Mellinger, and J. I. Parker, Combined effects of cadmium and zinc on a Lake Michigan zooplankton community, J. Great Lakes Res., in press.

7. Marshall, J. S., J. I. Parker, D. L. Mellinger, and S. G. Lawrence, Effects of cadmium and mercury on the plankton community of a Precambrian Shield lake in northwestern Ontario, to be published.

8. Prokopowich, J. and G. Lindsey, Freshwater Institute, Winnipeg, Manitoba, unpublished data (1980).

9. Torrey, M. S., Chemistry in Lake Michigan, Argonne National Laboratory report ANL/ES-40, Vol. 3 (1976).

10. Hesslein, R. H., Freshwater Institute, Winnipeg, Manitoba, personal communication (1980).

11. Parker, J. I., Argonne National Laboratory, unpublished data (1980).

12. Davies, A. G, and J. A. Sleep, Inhibition of carbon fixation as a function of zinc uptake in natural phytoplankton assemblages, J. Mar. Biol. Assoc. U.K. 59, 937-949 (1979).

13. Allen, H. E., R. H. Hall, and T. D. Brisbin, Metal speciation. Effects on aquatic toxicity, Environ. Sci. Technol. 14, 441-443 (1980). 
SORPTION OF ${ }^{65}$ Zn AND ${ }^{109} \mathrm{Cd}$ BY SESTON IN SOUTHERN LAKE MICHIGAN

J. I. Parker, K. A. Stanlaw, and C. W. Kennedy

\section{Background and Scope}

The recent sediment in Lake Michigan contains 2 to 3 times more zinc and cadmium than the precultural sediment, $l$ indicating an increase in the input rates in recent times. Rain water collected over Lake Michigan contains concentrations of zinc and cadmium at least 2 orders of magnitude higher than does the lake water, ${ }^{2}$ indicating the potential for increasing concentrations in the iake water. Plankton community bioassay experiments with zinc and cadmium show that increasing the ambient concentrations by factors of 5 or 10 resilts in adverse effects on algal primary productivity and zooplankton abundance. ${ }^{3}$ These observations suggest the potential fur adverse environmental impacts of zinc and cadmium on the Lake Michigan ecosystem.

\section{Progress in 1980}

The potential for increasing zinc and cadmium concentrations in the lake water is dependent primarily on the capacity of seston to sorb and transport zinc and cadmium to the bottom by sedimentation, and subsequent release from the sediment. We investigated the sorptiun of zinc and cadmium by seston collected at offshore stations in southern Lake Michigan. We conducted timeseries experiments during different phases of the plankton successional cycle to evaluate the sorption kinetics under conditions of varying particle abundance and physiological condition of the plankton. Glass carboys (13 L) were filled with lake water that was collected at the depth of the epilimnetic chlorophyll maximum. The carboys were treated with standardized concentrations of ${ }^{65} \mathrm{Zn}$ and ${ }^{109} \mathrm{Cd}$ of high specific activity and incubated in a deck incubator at epilimnet.c lake water temperatures and ambient daylight conditions. Sorption of ${ }^{65} \mathrm{Zn}$ and ${ }^{109} \mathrm{Cd}$ was determined by gamma spectrometry. The data are presented as a percentage of the radioisotope addition.

Thus far, three experiments have been conducted that provide preliminary information on the sorption of zinc and cadmium by seston in Lake Michigan. The sorption of ${ }^{65} \mathrm{Zn}$ and ${ }^{109} \mathrm{Cd}$ by total seston $(>0.45 \mu \mathrm{m})$ reached an apparent equilibrium in $\sim 1$ to 2 days. The uptake kinetics follow an adsorption 
isotherm of the form $c_{t}=c_{\infty}\left(1-e^{k t}\right)$, where $c_{t}$ is the uptake at any given time, $C_{\infty}$ is the uptake at equilibrium, and $t$ is the elapsed time in hours. $C_{\infty}$ for ${ }^{65} \mathrm{Zn}$ in the three experiments ranged from $\sim 2$ to 158 of the ${ }^{65} \mathrm{Zn}$ added, while that for cadmium was $\sim 5$ to 128 of the ${ }^{109} \mathrm{Cd}$ added (Figure 1). The level of zinc sorption appeared to be related to phytoplankton abundance, with maximal uptake occurring during the sumner chlorophyll maximum. In contrast, cadmium sorption appeared to be inversely related to chlorophyll concentration, but was positively related to the concentration of total suspended solids (TSS).

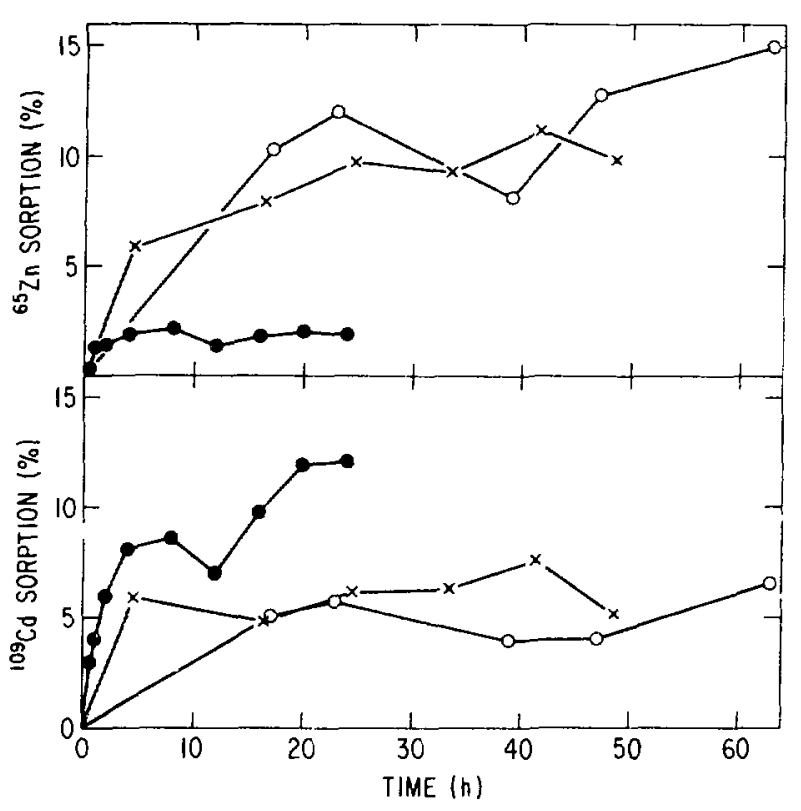

Figure 1. Sorption of ${ }^{65} \mathrm{Zn}$ and $109 \mathrm{C}$. by seston $(>0.45 \mu \mathrm{m})$ between 11 and 13 September 1978, when phytoplankton abundance was minimal (o), between 1 and 3 May 1979, when phytoplarikton abundance was about onehalf the spring maximum $(x)$, and during the phytoplankton bloom maximum 6-9 June 1979 (•) .

Fractionation of the total seston into selected particle sizes showed that most of the ${ }^{65} \mathrm{Zn}$ and ${ }^{109} \mathrm{Cd}$ uptake was accounted for by particles $<28 \mu \mathrm{m}$ in effective diameter. Sorption of ${ }^{109} \mathrm{Cd}$ resided almost exclusively with these small particles, and showed little distributional difference among particle size fractions during the three experiments. However, 958 of the ${ }^{65} \mathrm{Zn}$ resided on $<28 \mu \mathrm{m}$ particles when the chlorophyll concentration was low, but only $\sim 508$ resided on these particles when phytoplankton were abundant. This suggests that zinc sorption by seston is more strongly controlled by living organisms among the seston than is cadmium. Furthermore, zinc uptake was higher in clear carboys than in opaque ones, while no difference in cadmium uptake was observed between the light and dark carboys. This suggests 
that zinc uptake by seston in the water column of Lake Michigan is seasonally dependent, upon the abundance of phytoplankton, while cadmium sorption appears more responsive to non-living particles.

\section{Prospects}

Following the completion of further experiments to document the sorption of zinc and cadmium under variable regimes of TSS and plankton abundżnce, a model will be developed to predict the annual clearance capacity for zinc and cadmium $-\mathrm{n}$ the water column of Lake Michigan. This model will be coupled with estimates of the annual input of zinc and cadmium. and its utility in predicting increasing water column concentrations of zinc and cadmium will be evaluated.

\section{References}

1. Robbins, J. A. and D. N. Edgington, The distribution of selected chemical elements in the sediments of southern Lake Michigan, Radiological and Environmental Research Division Annual Report, January-December 1976, ANL76-88, Part III, pp. 65-71.

2. Parker, J. I., G. T. Tisue, C. W. Kennedy, and C. A. Seils, Effects of atmospheric precipitation additions on phytoplankton photosynthesis in Lake Michigan water samples, J. Great Lakes Res. 7. 21-28 (1981).

3. Marshall, J. S., J. I. Parker, D. L. Mellinger, and C. Lei, Bioaccumulation and effects of cadmium and zinc in a Lake Michigan plankton community, in preparation. 
A THREE-YEAR STUDY ON THE EFFECTS OF ENCLOSURE ON ZOOPLANKTON IN A LARGE, CURTAINED BAY OF ELA LAKE 382

D. L. Mellinger, J. S. Marshall, and D. F. Malley*

\section{Background and Scope}

This project was initiated in May 1978 when a large ( 3 ha) bay of ELA Lake 382 was isolated from the rest of the lake by means of a sea curtain.1.2 The purpose of this enclosure was to provide an appropriate setting for a relatively large-scale experiment to study the filtes and effects of added pollutants on aquatic communities. Personnel of the Department of Fisheries and Oceans, Freshwater Institute, winnipeg, Manitoba, are in charge of this project.

Progress in 1980

The weekly sampling routine of 1980 was the same as that of 1979 with samples collected from 6 May through 21 October. Rotifers and Copepod nauplii were collected with $53 \mathrm{\mu m}$ nets, while crustacean zooplankton samples were collected with $153 \mathrm{\mu m}$ nets. The average densities of different catego=ies of rotifers for 12 dates are shown in Table 1. During June, large populations of Tropocyilops prasinus mexicanus and Bosmina longirostris developed in the curtained bay but not in the other areas. However, the means of total crustacean zooplankton in the three regions are rather similar (Table 1). The average densjties ( \pm standard errors) of rotifers and crustacean zooplankton for the three years do not indicate any obvious trends (Table 2), but, it is clear that it may be difficult to separate the effects of an added pollutant in the curtained bay from natural fluctuations of individual species of the zooplankton community.

\footnotetext{
* Department of Fisheries and Oceans, Freshwater Institute, Winnipeg, Manitoba, Canada
} 
Table 1. Average densities of different categories of rotifers and crustacean zooplankton (\#/L) in open lake 382 (SL), uncurtained bay (UB), and curtained bay $(\mathrm{CB})$ for 12 sampling dates during May-October $1980 .^{\mathrm{a}}$

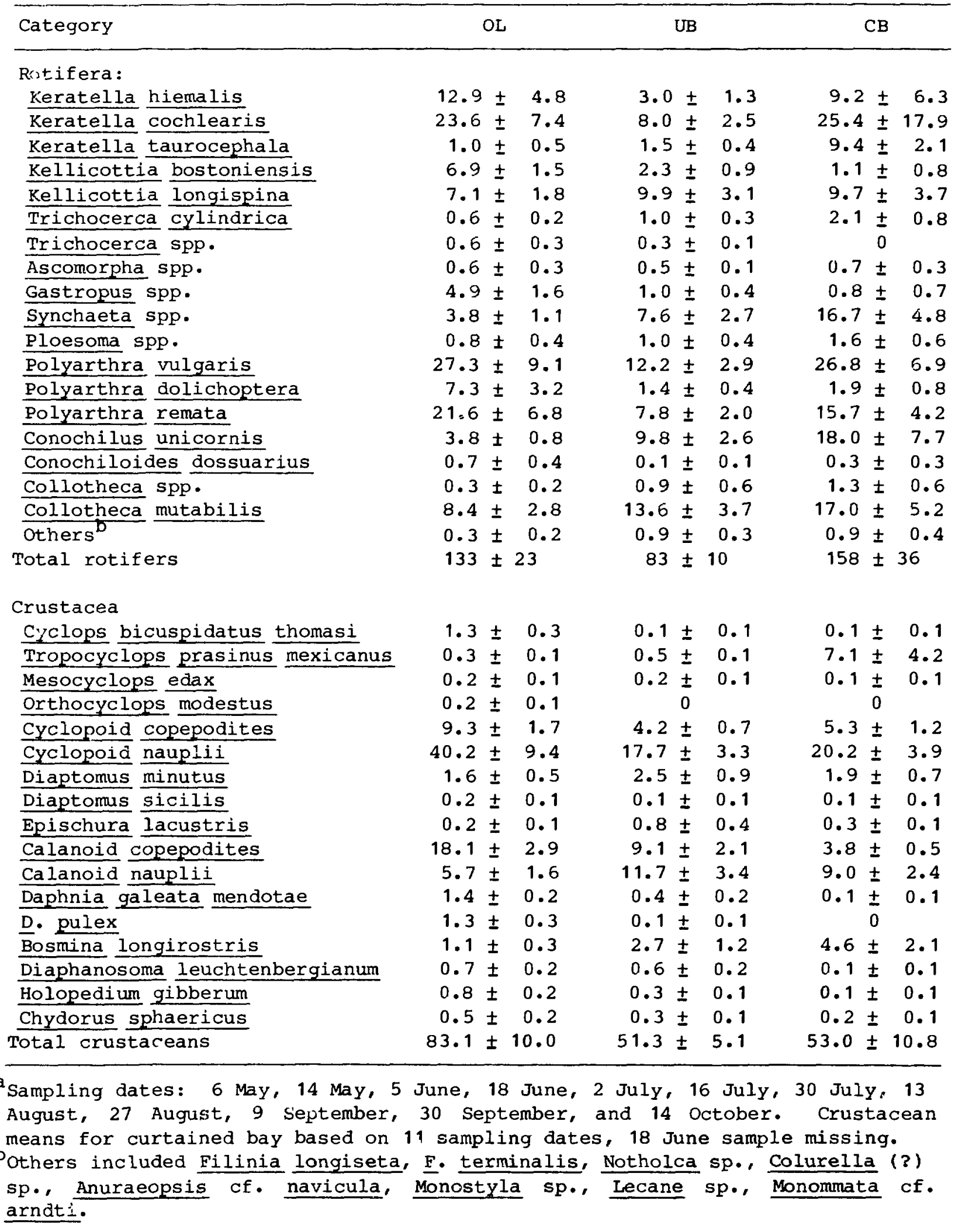


Table 2. Average densities for crustacean zooplankton and rotifers (\#/L) in open lake 382 (OL), uncurtained bay (UB), and curtained bay (CB) during MayOctober $1978-80$.

\begin{tabular}{|c|c|c|c|c|c|c|}
\hline & \multicolumn{3}{|c|}{ Rotifers } & \multicolumn{3}{|c|}{ Crustaceans } \\
\hline & 1978 & 1979 & 1980 & 1978 & 1979 & 1980 \\
\hline OL & $119 \pm 18$ & $128 \pm 31$ & $133 \pm 23$ & $51 \pm$ & $52 \pm 4$ & $83 \pm 10$ \\
\hline UB & - & $139 \pm 32$ & $83 \pm 10$ & - & $74 \pm 18$ & $51 \pm 5$ \\
\hline $\mathrm{CB}$ & $236 \pm 49$ & $144 \pm 31$ & $158 \pm 36$ & $55 \pm 10$ & $45 \pm 11$ & $53 \pm 11$ \\
\hline
\end{tabular}

\section{References}

1. Mellinger, D. I. and J. S. Marshall, Effects of enclosure on zooplankton in a large bay of ELA 382, Radiological and Environmental Research Division Annual Report, January-December 1978, ANL-78-65, Part III, p. 49.

2. Mellinger, D. L., J. S. Marshall, and D. F. Malley, Seasonal variations of zooplankton populations in an isolated bay and open area of ELA 382 during 1978 and 1979, Radiological and Environmental Research Division Annual Report, January-December 1979, ANL-79-65, Part III, pp. 21-24. 
MEASUREMENT OF THE SPATIAL AND TEMPORAL DISTRIBUTIONS OF CHLOROPHYLL AND TOTAL SUSPENDED SOLIDS IN SOUTHERN LAKE MICHIGAN BY FLUOROMETERY AND NEPHELOMETRY, RESPECTIVELY

J. I. Parker, C. W. Kennedy, and K. A. Stanlaw

Background and scope

Modeling the fate and potential effects of toxic contaminants in the Great Lakes is dependent on the knowledge of the spatial and seasonal distributions of piankton and total suspended solids (TSS). Acquisition of the large quantity of data needed to illustrate these trends effectively is constrained by time consuming sample collection and analysis. An automated approach to measuring phytoplankton chlorophyll by in situ continuous-flow fluorometry was described by Lorenzen. 1 Likewise, an automated approach to measuring TSS by in situ continuous-flow rephelometry was described by Stephens $^{2}$ and APHA. ${ }^{3}$ We have developed shipboard capability in these two techniques, and tested them simultaneously in Lake Michigan for the past two years; and we have documented some seasonal and spatial trends of phytoplankton chlorophyll and TSS in southern Lake Michigan.

Progress in 1980

We sampled sirface water along transects and depth profiles at offshore stations in the southern basin of Lake Michigan. In 1979, we conducted 24 cruises along a transect from chicago to an offshore station $\left(E_{1}\right)$ located at $42^{\circ} 02^{\prime} \mathrm{N}$ and $87^{\circ} 27.5^{\prime} \mathrm{W}, 21 \mathrm{~km} \mathrm{NE}$ of Chicago. The depth at station $\mathrm{E}_{1}$ is 35 m. In 1980, we conducted 24 cruises over the same transect to a new offshore station $\left(E_{2}\right)$ located at $42^{\circ} 10^{\prime} \mathrm{N}$ and $87^{\circ} 21^{\prime} \mathrm{W}, 32 \mathrm{~km} \mathrm{NE}$ of Chicago. The depth at station $E_{2}$ is $60 \mathrm{~m}$.

The nephelometer apparatus was a Turner Designs Model 10-035 fluorometer fitted with a high-pressure continuous-flow nephelometry kit (meeting the specifications recommended by the American Public Health Association ${ }^{3}$ ). The fluorometer for chlorophyll determination was a Turner Designs Model 10-000R, fitted with a continuous-flow cuvette system and an R446 infrared sensitive photomultiplier. The excitation lamp and filter were an F4T5 and a corning 560, respectively. The emission filter was a corning 2-64. The fluorometers were rack mounted in the laboratory of the $\mathrm{R} / \mathrm{V}$ Ekos. 
Lake water for surface transecting was pumped from a through-hull fitting located $\sim 1 \mathrm{~m}$ below the lake surface. A submersible pump was lowered at $2 \mathrm{~m}$ depth incremerts over the side of the ship for depth profiling at the station. The flow rates were $\sim 8 \mathrm{~L} / \mathrm{min}$. The water passed from the pumps through opaque rubber hose to the top of a bubble trap, and exited at the bottom of the trap through two parallel hose lines, one supplying each fluorometer.

The fluorometers do not measure the concentrations of TSS or chlorophyl? directly, but proviaje a measure of the relative intensities of light scattering due to TSS and fluorescence due to chlorophyll. The baseline intensity for each fluorometer was established and checked periodically throughout the study by passing $0.2 \mu \mathrm{m}$ flltered Lake Michigan water through the fluorometers and adjusting the relative signal strength near 0 on the most sensitive measurenent scale. Regular cleaning of the flow-through cuvettes controlled baseline drift. During lake sampling the relative signal strength from both fluoromeiers was recorled on a dual pen strip-chart recorder. CLoran coordinates and depth of sampling were recorder manually on the stripchart recording.

Since the instiunents do not measure the variables rirestly, 1 to $2 \mathrm{~L}$ lake water samples vere collected daily from the waste streams of each fluorometer for analysis of TSS and chlorophyll, to calibrate the flucrometric measurements. TSS was dutermined by filtering 1 to $2 \mathrm{~L}$ of lake water through washed and weighed $47 \mathrm{~mm}$ jlass fiber filters, drying the filter and residue to constant weight at $60^{\circ} \mathrm{C}$, and reweighing. Chlorophyll was measure water samples by sicandard acetone extraction techniques. ${ }^{4}$

The measurements of rSS and chlorophyll in lake water samples were compared with the synoptic light scattering and fluorescence measurements by least squares regression analysis. The data from calibration samples collected in 1979 and 1980 were pooled. These analyses showed the relationships between light scattering and TSS and between chlorophyll and fluorescence were linear over the ranges observed in Lake Michigan. The equation for predicting TSS $(\mathrm{Y})$ from light scattering $(\mathrm{X})$ was $\mathrm{Y}=-1.07+$ $0.07385 \mathrm{x}$, where $\mathrm{r}^{2}=0.93$ and $\mathrm{N}=54$. The equation for predicting chlorophyll (Y) from fluorescence $(X)$ was $Y=-0.0337+0.03265 X$, where $Y^{2}=0.89$ and $N=$ 76. These equations were used to estimate the TsS and chlorophyll 
concentrations from data recorded on the strip charts.

Chlorophyll concentrations in the surface water consistently showed an exponential decline with increasing distance from shore. The annual average chlorophyll concentration measured at $1.6 \mathrm{~km}$ intervals from the shore out to the offshore station illustrates this trend (Figure 1). In both years chlorophyll declined from a mean of $\sim 2 \mu \mathrm{g} / \mathrm{L}$ inshore to a relatively uniform mean concentration of $\sim 0.8 \mu \mathrm{g} / \mathrm{L}$ at $\sim 20 \mathrm{~km}$ offshore. Since the distance to both stations $E_{1}$ and $E_{2}$ exceeds $20 \mathrm{~km}$ it is likely these stations are representative of the offshore phytoplankton community.

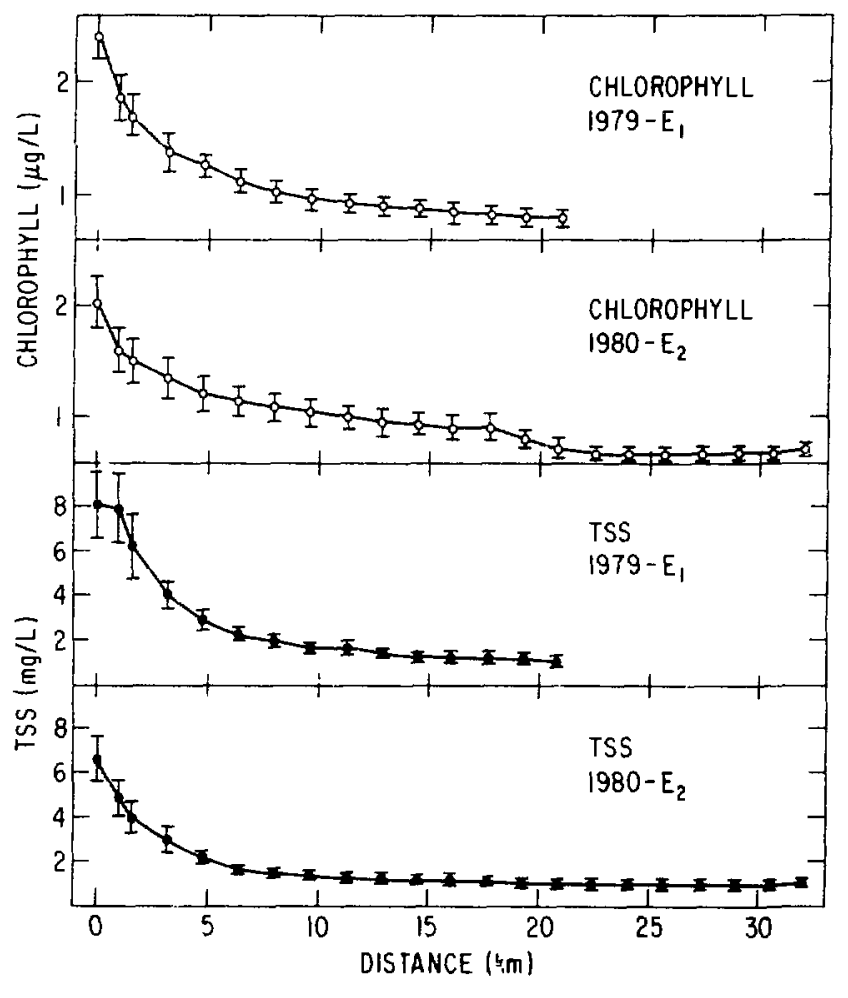

Levels of TSS in the surface water showed an exponential decline with increasing distance from shore similar to those of chlorophyll (Figure 1). In 1973 and 1980 TSS declined to an annual average of $\sim 1 \mathrm{mg} / \mathrm{L}$ at $\sim 20 \mathrm{~km}$ offshore. The decline of TSS with increasing distance offshore was more abrupt than for chlorophyll. Inshore TSS levels averaged $\sim 6$ to $8 \mathrm{mg} / \mathrm{L}$ and declined by half at $\sim 3 \mathrm{~km}$ offshore. In comparison the chlorophyll concentration reached half the inshore value at $\sim 7$ to $10 \mathrm{~km}$ offshore. 
The concentration of chlorophyll in the euphotic zone at the offshore station $E_{1}$ in 1979 and $E_{2}$ in 1980 were not significantly different. In 1979, the values at $E_{1}$ ranged from 0.5 to $3.4 \mu \mathrm{g} / \mathrm{L}$ and in 1980 at $E_{2}$ the range was from 0.3 to $5.3 \mathrm{\mu g} / \mathrm{L}$. Because of this high variability, selecting concentrations representative of the seasonal trends was difficult. Consequently, the depth profiles for each sampling date were integrated over the euphotic zone depth $(30 \mathrm{~m})$ to provide estimates of the chlorophyll concentration per unit of lake surface area. These estimates best illustrate the seasonal trends of chlorophyll concentration in the offshore phytoplankton community.

The integrated-euphotic zone chlorophyll estimates illustrate a bimodal pattern of phytoplankton abundance for both years at the offshore stations (Figure 2). In 1979, chlorophyll gradually increased from an annual minimum of $\sim 15 \mathrm{mg} / \mathrm{m}^{2}$ in early March to an early summer maximum of $\sim 80 \mathrm{mg} / \mathrm{m}^{2}$ in June. This blonm was abruptly at.tenuated in late June and July and chlorophyll levels ranged between 40 and $50 \mathrm{mg} / \mathrm{m}^{2}$ throughout the summer. A further decline was observed in late september, and by October chJorophyll concentrations were $\sim 30 \mathrm{mg} / \mathrm{m}^{2}$. In late fall a second phytoplankton bloom developed and chlorophyli levels increased to $\sim 70 \mathrm{mg} / \mathrm{m}^{2}$ by mid-December. A similar bimodal pattern was observed at $E_{2}$ in 1980 with seasonal maxima in summer and late fall. However, in 1980 the s'mmer bloom maximum of $\sim 90 \mathrm{mg} / \mathrm{m}^{2}$ occurred in early July, $\sim 1$ month later than in the previous year. This bloom was also abruptly attenuated in late July, and by early October chlorophyll declir.əd to $\sim 20$ to $25 \mathrm{mg} / \mathrm{m}^{2}$. In November a fall phytoplankton bloom developed a maximum chlorophyll concentration of $\sim 50 \mathrm{mg} / \mathrm{m}^{2}$, preceding the 1979 fall bloom by $\sim 3$ weeks. The 1980 fall bloom was attenuated to $\sim 25 \mathrm{mg} / \mathrm{m}^{2}$ by early December. Although January sampling was not conducted in either year data collected on 19 January 1981 showed $\sim 25 \mathrm{mg} / \mathrm{m}^{2}$ at station $\mathrm{E}_{2}$. This suggests that the late fall chlorophyll maximum observed in the two previous years is probably attenuated to winter minimum values by Janiary and remains low throughout most of the winter season.

The concentrations of TSS in the euphotic zone at the offshore stations for 1979 and 1980 were not significantly different. The time-series distribution of depth-integrated rSS at the two stations showed a seasonal trend quite difserent from that of depth-integrated chlorophyll. The TSS data 
showed no evidence of the bimodal distribution characteristic of the chlorophyll data. Instead, a unimodal pattern emerged. There was a relatively steady increase in total TSS in the euphotic zone from a seasonal minimum of $\sim 10 \mathrm{~g} / \mathrm{m}^{2}$ in late winter to a maximum of $\sim 75$ to $90 \mathrm{~g} / \mathrm{m}^{2}$ by late fal1, followed by an abrupt decline during winter (Figure 2). This pattern suggests that TSS accumulated in the euphotic zone until approximately tne occurrence of thermal overturn in late fall.

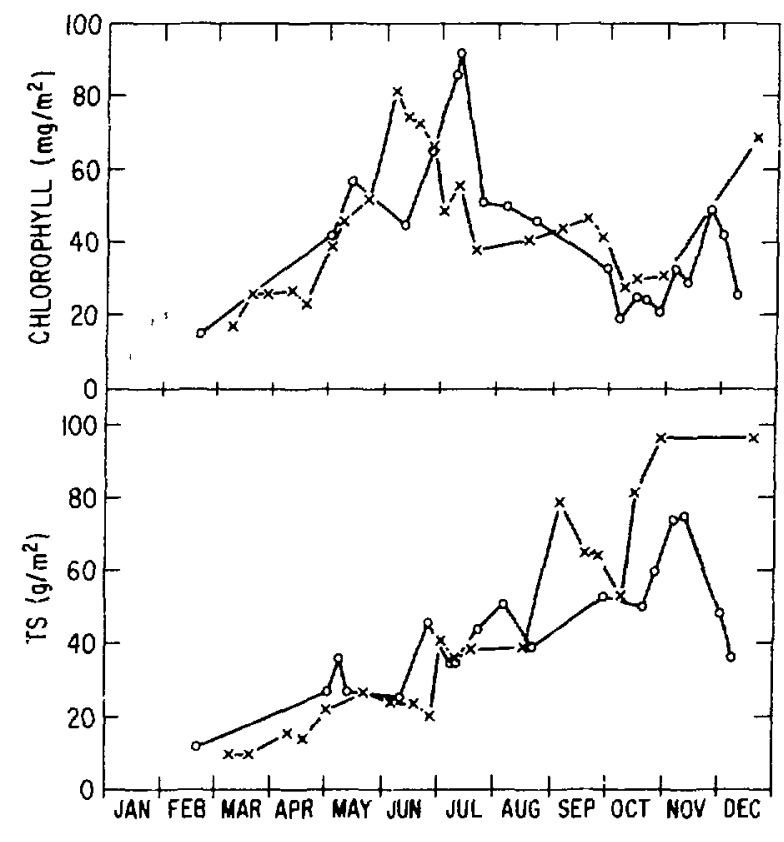

Figure 2. Annual time-series plot of integrated-euphotic zone $(30 \mathrm{~m})$ chlorophyll and TSS concentrations at stations $E_{1}$ in 1979 and $E_{2}$ in 1980 . $\mathrm{X}, 1979$; O, 1980.

These observations verify that continuous-flow nephelometry and fluorometry accurately estimate TSS and chlorophyll within the range of concentations measured in Lake Michigan. They also confirm the utility of these automated techniques in providing the quantity of data needed to document the seasonal and spatial trends.

\section{Prospects}

The time-series data sets of TSS and chlorophyll in the offshore water will be coupled with seasonal data on the sorption of zinc and cadmium by seston and plankton (obtained in simultaneous studies) to (1) model the fate of these toxic trace elements in the water and (2) to aid prediction of the potential for increasing water column concentrations of zinc and cadmium. 


\section{References}

1. Lorenzen, C. J., A method for the continuous measurement of in vivo chlorophyll concentration, Deep-Sea Res. 13, 223-227 (1966).

2. Stephens, K., Continuous measurement of turbidity, Deep-Sea Res. 14, 465467 (1967).

3. American Public Health Association, Standard methods for the examination of water and waste water, 14th Ed. (1976).

4. Strickland, J. D. H. and T. R. Parsons, A practical handbook of seawater analysis, Bull. Fish. Res. Board Can. 167, 185-194 (1972). 
PLANKTON MICROCOSM RESEARCH. RESPONSE OF NATURAL PHYTOPLANKTON COMMUNITIES TO ZINC TOXICITY - A PRELIMINARY REPORT

G. B. Hall

Background and scope

In 1976 Marshall and Mellinger ${ }^{1}$ developed an in situ method for toxicological studies on natural plankton communities using small-volume enclosures. Certain limitations of this procedure and interest by EPA's office of Toxic Substances in developing plankton community microcosms for testing toxic substances; provided the stimulus for construction of a laboratory incubator designed to maintain natural plankton communities under simulated in situ cunditions of temperature and photoperiod. ${ }^{2}$ The results reported here are prert of a more detailed investigation of zinc toxicity to natural plankton commities isolated from Lake Mlchigan and maintained in the laboratory incubator at ambient lake temperatures $\left(\sim 3^{\circ} \mathrm{C}\right)$.

\section{Progress in 1980}

Three laboratory microcosm experiments were conducted to determine the response of natural plankton communities isolated from Lake Michigan to additions of $z$ inc $(50 \mu \mathrm{g} \mathrm{Zn} / \mathrm{L})$ for periods of three weeks. Quantitative analyses of the phytoplankton communities in replicated control and zinctreated enclosures (15 L glass carboys) were made at intervals of 3, 7, 14, and 21 days. Phytoplankton samples for estimation of numbers (cells/mL) were preserved with Lugol's solution ${ }^{3}$ and stored in glass bottles in darkness until analyzed. Enumerations were made using a zeiss inverted microscope according to the Utermohl settling technique. ${ }^{4}$ Cell biovolume $\left(\mu \mathrm{m}^{3} / \mathrm{mL}\right)$ was calculated from mean cell dimensions and conformity of cell shape to geometric solids. 5 Bheophytin-corrected chlorophyll a concentrations were determined spectrophotomet $\leq i c a l l y \cdot{ }^{6}$ Primary productivity rates were estimated by a standard carbon-14 light and dark bottle technique. ${ }^{7}$ Aliquots of carbon-14 labelled samples were filtered onto 0.45 HM Satorious (cellulose acetate) nembrane filters and subsequently dissolved in $10 \mathrm{~mL}$ of $1: 2 \mathrm{v} / \mathrm{v}, 2-$ methoxyethanol:0.58 butyl PBD* $^{*}$ in toluene fluor. ${ }^{8}$ Carbon-14 labelled samples

$2 B D=[2-(4-t-B u t y l$ phenyl $)-5-(4-B i$ phenyl $)-1,3,4-$ oxadiazole $]$ 
were also fractionated without suction through $37 \mathrm{\mu m}$ pore size filters (Nitex netting). The fraction retained by the $37 \mu \mathrm{m}$ netting and the filtrate ( 37 $\mu \mathrm{m})$, as here defined, correspond to net plankton and nannoplankton productivity, respectively.

zinc became more toxic to phytoplankton communities with time, the most significant reductions in community activity occurring after 14 days (Figures 1 and 2). Densities and biomass in the $\mathrm{zn}$-treated microcosms were significantly lower than those for the controls at 14 days (Figure 1a,b). Subsequently, total standing crop increased in both control and zn-treated microcosms, corresponding to a significant increase in net plankton biomass (Figure 1c,d and Figure 2d). Primary productivity rates declined significantly in the zn-treated microcosms after 3 days, and remained significantly depressed throughout the incubation period (Figure 2a). Fractionated carbon-14 uptake studies showed that nannoplankton made the largest contribution to total community primary productivity (Figure $2 a-c$ ). Although net plankton species contributed less to total productivity, their contribution had increased by day 21. These data suggest that both nannoplankton and net plankton growth was initially stimulated by enclosure, but only net plankton standing crop showed a significant increase over initial values in both control and zn-treated enclosures (Figure 1c,d). It appears that these larger and metabolically less active species are more tolerant to zinc toxicity.

These findings show that zinc concentrations as low as $50 \mu \mathrm{g} / \mathrm{L}$ seriously affect natural phytoplankton communities, even at winter temperatures $\left(\sim 3^{\circ} \mathrm{C}\right)$. The calculated maximum permissible $24-\mathrm{hr}$ zinc concentration for Lake Michigan waters based on current U.S. EPA water quality criteria is $\sim 50 \mu g$ $\mathrm{Zn} / \mathrm{L}$. This indicates the need, as suggested by Marshall et al.,9 for reevaluation of the current criteria for establishing average concentration of heavy metals to protect freshwater life.

\section{Prospects}

The objectives of the plankton mic ocosm research are to develop a new method of maintaining natural plankton microcosms for toxicological studies and to obtain a better understanding of the responses of the plankton community to toxic stress. Preliminary research shows that we are meeting 

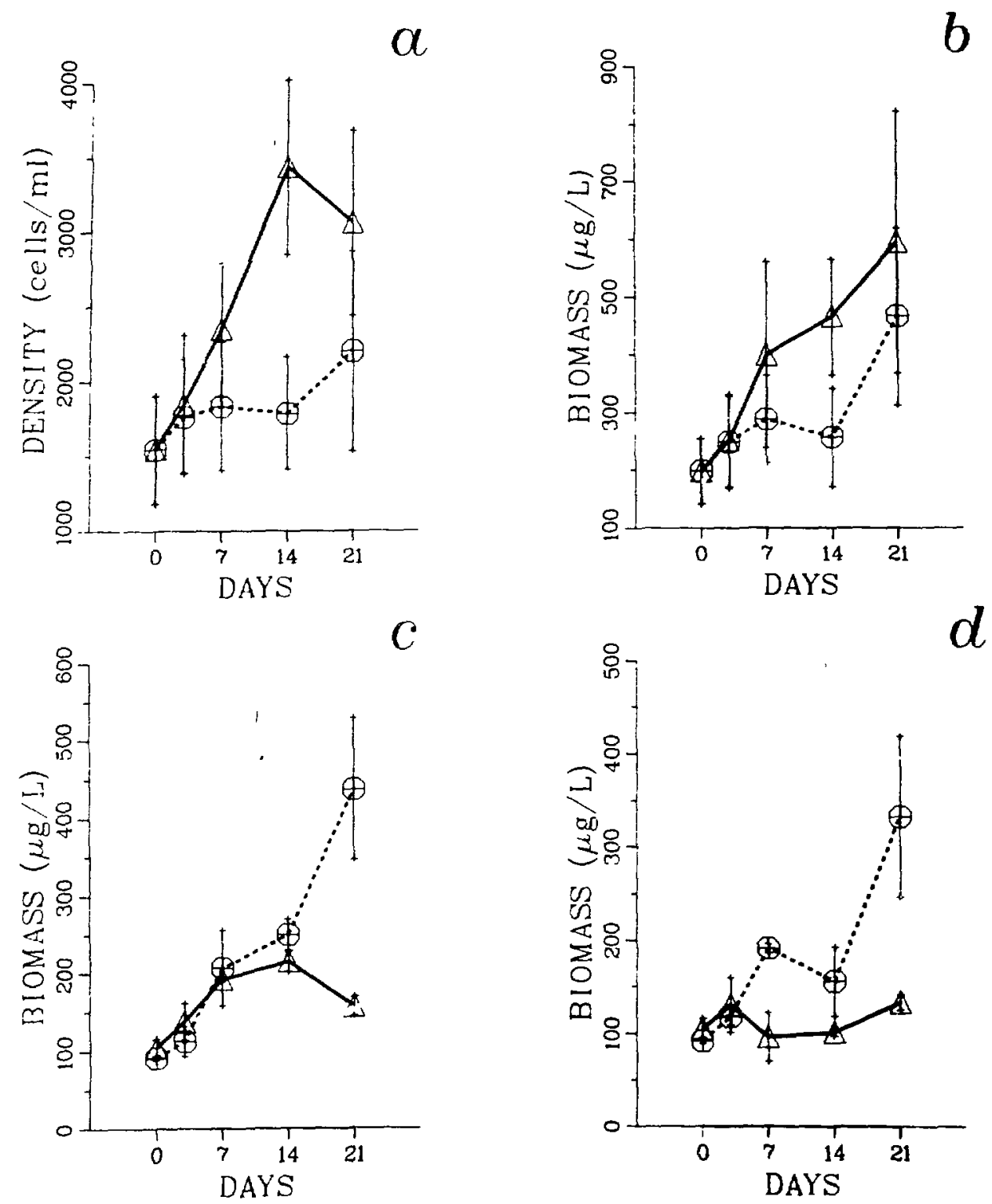

Figure 1. Effect of addition of $50 \mu \mathrm{\mu g} \mathrm{zh} / \mathrm{L}$ on (a) phytoplankton density (cells/mI) and (b) biomass ( $\mu$ g fresh weight/L) after laboratory incubation of 3 to 21 days $(\Delta$, control; $\oplus$, treated). Biomass of nannoplankton, $\Delta$, and net plankton, $\theta$; (c) control, (d) treated. 

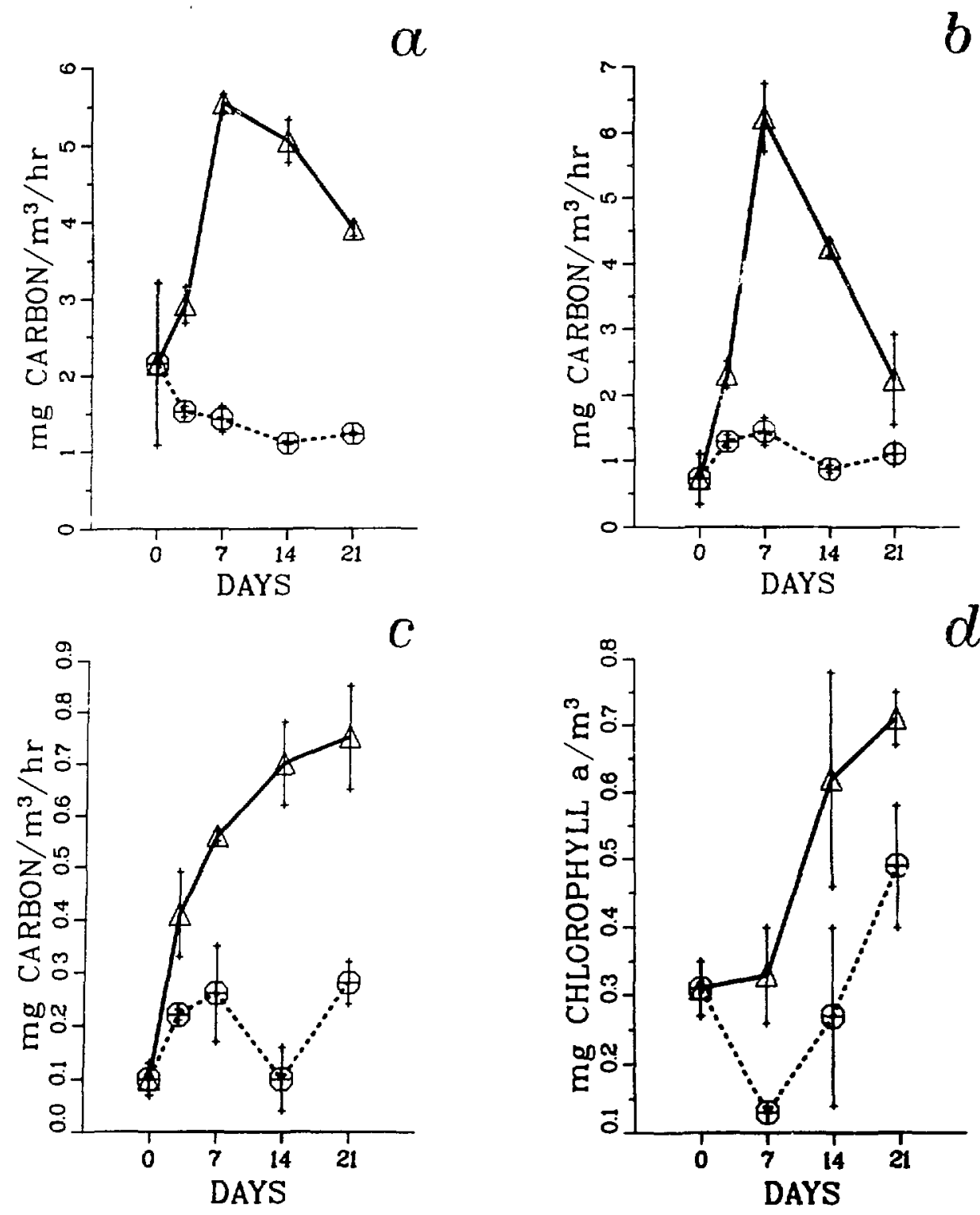

Figure 2. Effect of addition of $50 \mu \mathrm{g} \mathrm{zn} / \mathrm{L}$ on primary productivity of (a) total, (b) nanno, (c) net phytoplankton and on pheophytin-corrected chlorophyll a, and (d) after laboratory incubation of 3 to 21 days. Control, $\Delta ;$ treated, $\bar{\theta}$. 
these objectives and suggests the applicability of the plankton incubator procedure to a screening protocol for potentially hazardous materials.

During 1981, experiments will be conducted to evaluate enclosure effects of the plankton microcosms and continue toxicological studies with zinc. Subsequent experiments will evaluate the effects of 15 and $30 \mu \mathrm{gn} / \mathrm{L}$ on natural plankton communities during two week incubatior periods.

\section{References}

1. Marsha1l, J. S. and D. L. Mellinger, An in situ experimental method for toxicological studies on natural plankton communities, Aguatic Toxicology, J. G. Eaton et al., Eds., ASTM Publication STP 707, pp. 27-39 (1980).

2. Prepejchal, W., J. S. Marshall, G. B. Hall, and M. M. Thommes, A laboratory incubator for plankton microcosm research, this report.

3. Utermohl, H., Zur vervollkommnung der quantitativen PhytoplanktonMethodik, Mitt. Internal. Verein. Limnol. 9, 1-38 (1958).

4. Lund, J. W. G., C. Kipling, and E. D. Lecren, The inverted microscope method of estimating algal numbers and the statistical basis of estimations by counting, Hydrobiologia 11, 143-170 (1958).

5. Schwoerbel, J., Methods of Hydrobiology (Freshwater Biology), Fergamon Press, Canada (1970).

6. Strickland, J. D. H. and T. R. Parsons, A practical handbook of seawater analysis, 2nd Ed., Bull. Fish. Res. Board Can. 167 (1972).

7. Saunders, G. W., F. B. Trama, and R. W. Bachmann, Evaluation of a modified $\mathrm{C}^{14}$ techrique for shipboard estimation of photosynthesis in large lakes, Publ. No. 8, Great Lakes Res. Div., Univ. Michigan (1962).

8. Pugh, P. R., An evaluation of liquia scintillation counting techniques for use in aydatic primary production studies, Limnol. Oceanogr. 18, 310-319 (1975).

9. Marshall, J. S., D. M. Nelson, D. L. Mellinger, C. H. Lei, S. G. Lawrence, and D. F. Malley, Lake water chemistry and zinc toxicity to plankton communities - a preliminary report, this report. 
USE OF A COULTER COUNTER FOR SESTON ANALYSIS IN PLANKTON MICROCOSM RESEARCH

C. Lei and J. S. Marshall

\section{Background and Scope}

A large incubator capable of holding 10 glass carboys $(15.5 \mathrm{~L}$ capacity) has been constructed to allow the study of toxic effects of chemicals on natural plankton communities under simulated natural conditions of temperature, light intensity, photoperiod, and agitation in the laboratory. ${ }^{1}$ To follow seston dynamics in the incubator experiments (plankton microcosms), a rapid method of obtaining reliable data is needed. The coulter counter (Coulter Electronics, Hialeah, Florida) was originally designed for routine courting and sizing of red blood cells, but it is now used extensively in various fields which need routine counting and sizing of particulate materials. ${ }^{2}$ since this instrument has been used to determine phytoplankton biomass of unialgal cultures, ${ }^{3}$ mixed algal cultures, ${ }^{4}$ natural phytoplankton populations $5^{-7}$ and seston size distributions, 8 and has produced reliable and useful data, it seemed feasible to apply it for seston analysis in plankton microcosm studies.

\section{Progress in 1980}

A model TAII Coulter counter equipped with a population accessory was used to analyze the particle size distribution of seston in the second and third plankton microcosm studies (INC80-2 and INC80-3). A $200 \mu \mathrm{m}$ aperture tube was used to count and size individusl particles from 4 to $80 \mu \mathrm{m}$ in diameter. With a population accessory connected and after being properly calibrated against particles of standard size $(18.04 \mu \mathrm{m}$ polystyrene microspheres), this instrument can be used to count 13 size categories of particles simultaneously within the counting limit of a $200 \mu \mathrm{m}$ aperture tube (Table 1).

For seston analysis, a $200 \mathrm{~mL}$ sample of well mixed water was siphoned from each experimental carboy and strained through a Nitex filter-funnel with $80 \mu \mathrm{m}$ mesh to remove large particles. An aliquot of $100 \mathrm{~mL}$ well-mixed filtrate was then diluted with an equal amount of Isoton II solution which had been filtered 3 times through a membrane filter with $0.20 \mu \mathrm{m}$ pore size and poured into a $150 \mathrm{~mL}$ beaker for the analysis of size distribution of seston 
particles with a coulter counter. Three 100-second counts were made on each sample. This woula draw $48.78 \mathrm{~mL}$ of water through a $200 \mu \mathrm{m}$ aperture tube for sizing and counting seston particles. The total time needed for analyzing one sample from each experimental carboy was about 15 minutes. The number of particles in each size category was then converted to particle volume by multiplying by the geometric mean volumes in respective size categories (Table 1). The size spectrum of seston particles in each experimental carboy was expressed as particle volume $\left(10^{6} \times \mathrm{um}^{3} / \mathrm{L}\right.$ ) versus particle diameter (Figure 1), and the percent size distribution and the total particle volume (biovolume) were computed for each sample. To assess the toxic effects of zinc at a concentration of $50 \mathrm{\mu g} \mathrm{Zn} / \mathrm{L}$ on seston, an index of sample similarity was also calculated from the percent size distribution of seston for each experimental carboy.

Table 1. Size classes, diameters, and geometric mean volumes of spherical particles used for the analysis of particle size distribution of seston in plankton microcosm study.

\begin{tabular}{lll}
\hline Size class & $\begin{array}{c}\text { Diameter of spherical } \\
\text { particles, } \mu \mathrm{m}\end{array}$ & $\begin{array}{c}\text { Geometric mean volume } \\
\text { of particles, } \mu \mathrm{m}^{3}\end{array}$ \\
\hline 1 & $4.00-5.04$ & 47.39 \\
2 & $5.04-6.35$ & 94.78 \\
3 & $6.35-8.00$ & 189.6 \\
4 & $8.00-10.1$ & 379.1 \\
5 & $10.1-12.7$ & 758.3 \\
6 & $12.7-16.0$ & 1516 \\
7 & $16.0-20.2$ & 3033 \\
8 & $20.2-25.4$ & 6066 \\
9 & $25.4-32.0$ & $12.13 \times 10^{3}$ \\
10 & $32.0-40.3$ & $24.27 \times 10^{3}$ \\
11 & $40.3-50.8$ & $48.54 \times 10^{3}$ \\
12 & $50.8-64.0$ & $97.18 \times 10^{3}$ \\
13 & $64.0-80.6$ & $194.4 \times 10^{3}$ \\
\hline
\end{tabular}

Some results from recent studies are shown in Figure 1 and Table 2. After 21 days of incubation, size spectrum and percent size distribution of seston in two $\mathrm{Zn}$-treated microcosms showed a distinct difference from those in two untreated microcosms. Mean total particle volume $\left(10^{6} \times \mu \mathrm{m}^{3} / \mathrm{L}\right)$ was 


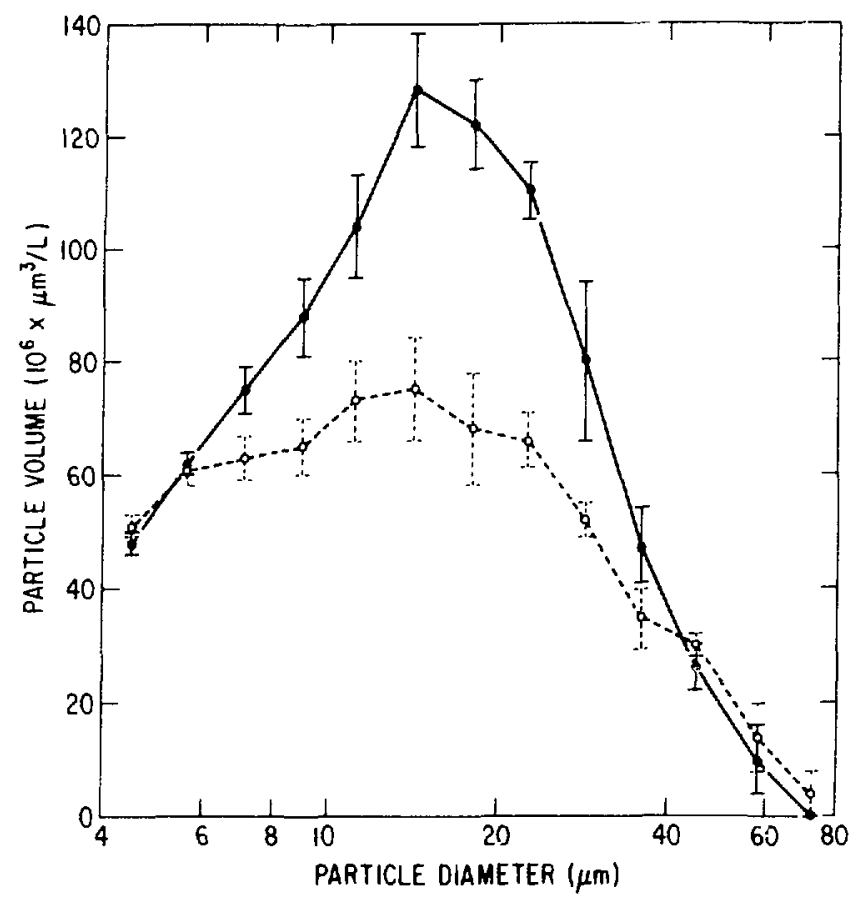

Figure 1. Size spectra of seston in plankton microcosms after 21 days of incubation under simulated Lake Michigan conditions of temperature and photoperiod during 27 October-24 November 1980 (INC802). Each point with bar represents mean \pm standard error for two samples. Solid line, control; dashed line, $50 \mu \mathrm{g} \mathrm{Zn} / \mathrm{L}$.

Table 2. Mean percent size distribution of seston particles in control and $\mathrm{Zn}$-treated $(50$ $\mu \mathrm{g} \mathrm{Zn} / \mathrm{L})$ plankton microcosms after 21 days of incubation under simulated Lake Michigan conditions of temperature and photoperiod during 27 October-24 November 1980.

\begin{tabular}{lrr}
\hline & \multicolumn{2}{c}{ Distribution } \\
\cline { 2 - 3 } Size class & \multicolumn{2}{c}{ Control } \\
\hline & & \\
1 & $5.4 \pm 0.2^{\mathrm{a}}$ & $7.8 \pm 0.4^{\mathrm{a}}$ \\
2 & $6.9 \pm 0.3$ & $9.3 \pm 0.4$ \\
3 & $8.4 \pm 0.1$ & $9.6 \pm 0.2$ \\
4 & $9.8 \pm 0.1$ & $10.0 \pm 0.1$ \\
5 & $11.5 \pm 0.2$ & $11.1 \pm 0.1$ \\
6 & $14.2 \pm 0.1$ & $11.4 \pm 0.4$ \\
7 & $13.6 \pm 0.1$ & $10.3 \pm 0.7$ \\
8 & $12.3 \pm 0.3$ & $10.1 \pm 0.2$ \\
9 & $8.8 \pm 0.9$ & $8.0 \pm 1.0$ \\
10 & $5.3 \pm 1.2$ & $5.3 \pm 0.5$ \\
11 & $2.9 \pm 0.2$ & $4.6 \pm 0.7$ \\
12 & $1.1 \pm 0.6$ & $2.1 \pm 0.8$ \\
13 & 0.0 & $0.6 \pm 0.6$ \\
\hline
\end{tabular}

$a_{\text {Mean }} \pm$ standard error for two samples (microcosms). 
reduced from $896 \pm 62(\bar{x} \pm S:)$ in untreated microcosms to $654 \pm 54$ in $\mathrm{Zn}-$ treated microcosms. The percentage similarity of seston was reduced from 98.08 in untreated microcosms to $90.1 \pm 0.38$ in $\mathrm{Zn-treated} \mathrm{microcosms.}$

\section{Prospects}

Although the coulter counter cannot distinguish living from dead particles and organic from inorganic particles, nor animals from plants or species from species of living organisms, its use in rapid assessment of toxic effects of chemicals on plankton communities is demonstrated by the experimental results. In future investigations we will continue to use the coulter counter as a means of assessing the toxic effects of chemicals on natural plankton communities.

\section{References}

1. Prepejchal, W., J. S. Marshall, G. B. Hall, and M. M. Thomes, A laboratory incubator for plankton microcosm research, this report.

2. Coulter counter Industrial Bibliography, Coulter Electronics Limited, England (1979).

3. El-Sayed, S. Z. and B. D. Lee, Evaluation of an automatic technique for counting unicellular organisms, J. Mar. Res. 21, 59-73 (1963).

4. Hasting, J. W., B. M. Sweeney, and M. M. Muliin, Counting and sizing of unicellular marine organisms, Ann. N.Y. Acad. Sci, 99, 280-289 (1962).

5. Mulligan, H. F. and J. M. Kingsbury, Application of an electronic particle counter in analyzing natural populations of phytoplankton, Limnol. Oceanogr. 13, 499-506 (1968).

6. Parsons, T. R., The use of particle size spectra in determining the structure of a plankton community, J. Oceanogr. Soc. Japan 25, 6-15 (1969).

7. Evans, J. H. and S. M. McGill, An investigation of the coulter counter in "biomass" determinations of natural freshwater phytoplankton populations, Hydrobiologia 35, 401-419 (1970).

8. Haffner, G. D. and J. H. Evans, Determination of seston size distribution with coulter counter model $A$ and $B$ and the two tube technique, Br. Phycol. J. 9, 255-260 (1974).

9. Marshall, J. S. and D. L. Mellinger, An in situ experimental method for toxicological studies on natural plankton communities, Aquatic Toxicology, J. G. Eaton et al., Eds., ASTM Publ. STP-7-7, pp. 27-39 (1980). 


\section{A LABORATORY INCUBATOR FOR PLANKTON MICROCOSM RESEARCH}

W. Prepejchal, J. S. Marshall. G. B. Hall and M. M. Thommes

\section{Background and Scope}

The need for a large laboratory incubator for toxicological studies on natural plankton communities ar se from certain limitations of our in situ method.1 The in situ method involves some risk of loss of experimental enclosures ( 8 to $50-\mathrm{L}$ glass or polyethylene carboys); also weather conditions and research vessel availability place restrictions on the frequency and time of sampling. Construction of an incubator designed to simulate in situ conditions of light, temperature, and mixing was a result of EPA's interest in developing plankton community microcosms for testing toxic substances.

\section{Progress in 1980}

The completed incubator system (Figure 1) provides control of light levels within the glass carboys up to $40 \mu \mathrm{E} / \mathrm{m}^{2} \mathrm{~s}$ and approximates the spectral distribution in a clear lake at 5 to $15 \mathrm{~m}$ depth as determined by Smith and Tyler. ${ }^{2}$ Bath temperature within the incubator, adjustable from 3 to $20^{\circ} \mathrm{C}$, is maintained by a recirculating refrigeration system that includes filtration to insure optical clarity in the bath. Thermal stratification within the tank is prevented by directed jets of chilled water and the rotation of the carboys. Sedimentation within the $15 \mathrm{~L}$ glass or $18 \mathrm{~L}$ plastic carboys is prevented by end over end rotation, and mixing is induced with a crossed-disc mixer (Figure 1) in each carboy. This incubator has a capacity of 16 carboys arranged in banks of four. If desired, separators can be inserted between banks so that the light level in each can be individually controlled.

In the course of three 3-week experiments conducted in this incubator, rotator drive problems were discovered and corrected. 


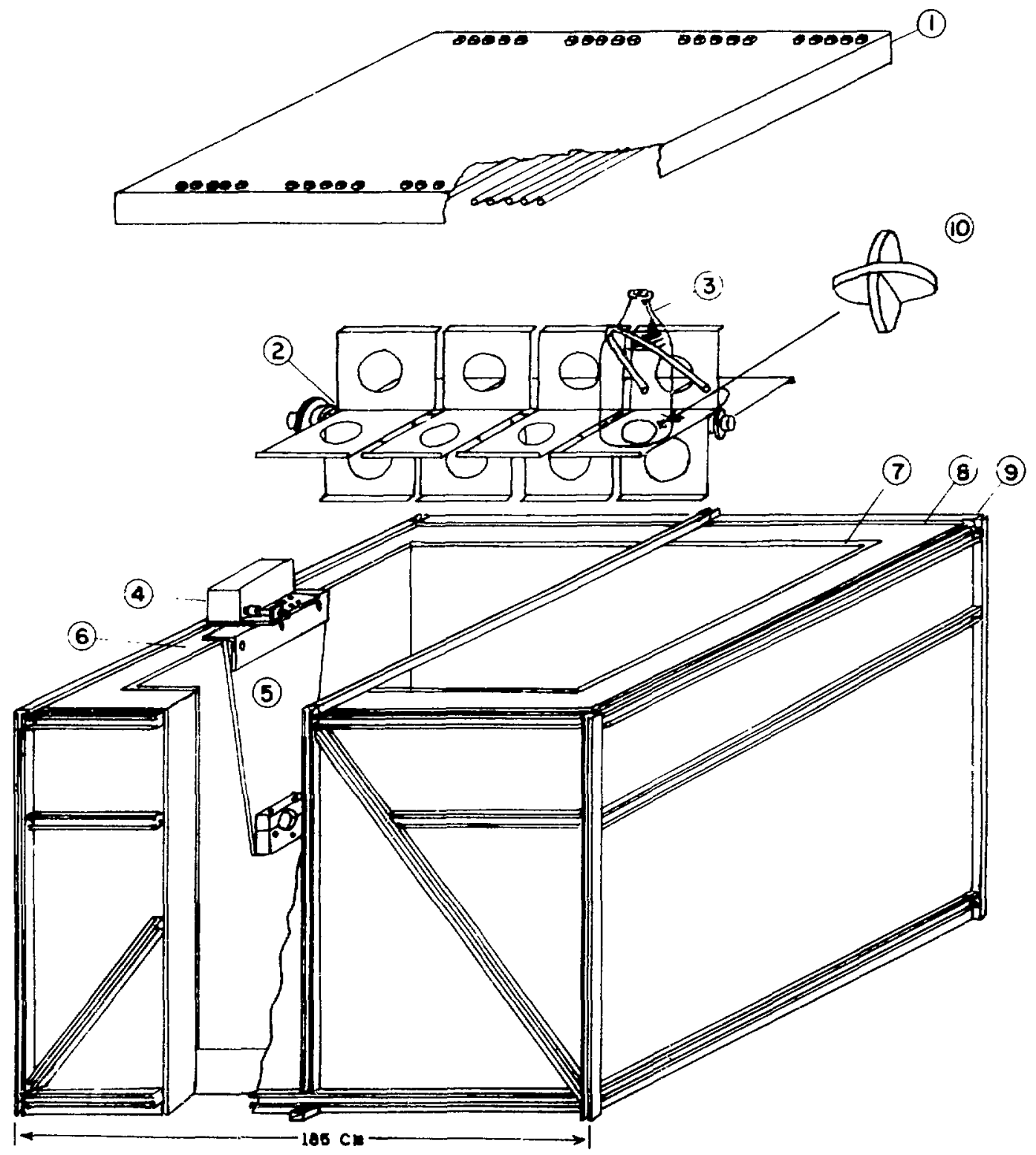

Figure 1. Incubator detail showing: (1) light source mounting twenty $40 \mathrm{w}$ daylight fluorescent lamps; (2) axle and carboy carrier assembly; (3) mounted carboy; (4) drive motor and shaft support bearing; (5) axle mount and bearing; (6) 4" Styrofoam insulation; (7) aluminum inner tank; (8) plywood covering; (9) Unistrut exoskeleton; and (10) Lucite mixers. 


\section{References}

1. Marshall, J. S. and D. L. Mellinger, An in situ experimental method for toxicological studies in natural plankton communities, Aquatic Toxicology, J. G. Eaton et al., Eds., ASTM Publ. STP 7071, pF, 27-39 (1980).

2. Smith, R. C. and J. E. Tyler, Optical properties of clear natural water, J. Opt. Soc. Am. 57, 589-601 (1967). 
CONSTRUCTION OE A PORTABLE IACUBATOR FOR PHYTOPLANKTON PRIMARY PRODUCTIVITY STUDIES

W. Prepejchal and G. B. Hall

\section{Background and scope}

The development of in $\mathrm{situ}^{1}$ and laboratory ${ }^{2}$ procedures for toxicological studies on natural plankton commanities dictated the need for a portable incubator to allow comparisons of primary productivity rates between field and laboratory experiments. In order to validate such comparisons, it is essential to duplicate the incubation environment.

\section{Progress in 1980}

In designing this incubator, our primary concerns were to develop a durable portable system, which would duplicate the lighting, cooling, and mixing characteristics of our laboratory incubator. ${ }^{2}$ The latter criterion is an attempt to minimize enclosure effects and optimize the measurement of physiological rate parameters.

Various practical congiderations have lead to the design (F'igure 1) which has a maximum capacity of twenty-one 300-mL B.O.D. bottles, thirty-two 150-mL bottles, or fifty $60-m L$ bottles. The smaller bottles are glass stoppered pyrex reagent bottles. Details of the bottle carriers, which affis to the rotatable axle, are shown in Figure 2. Bottle rotation is end over end, and mixing is induced with a scaled version of the cross-disc mixer used in the laboratory incubator. 2

In order to minimize spillage during shipboard operation and maximize available light levels, the light source, a sealed Lucite box, fits into the incubator and sits directly on the bath water surface. A self-contained blower, separator plate, intake and exhaust chimneys are required to remove lamp and ballast heat.

Incubator bath temperature during four experiments completed to date has been maintained by flowing lake water (field) or chilled water (laboratory) through the tank. Future efforts will be directed toward developing a selfcontained cooling system, a requirement for remote field conditions. 

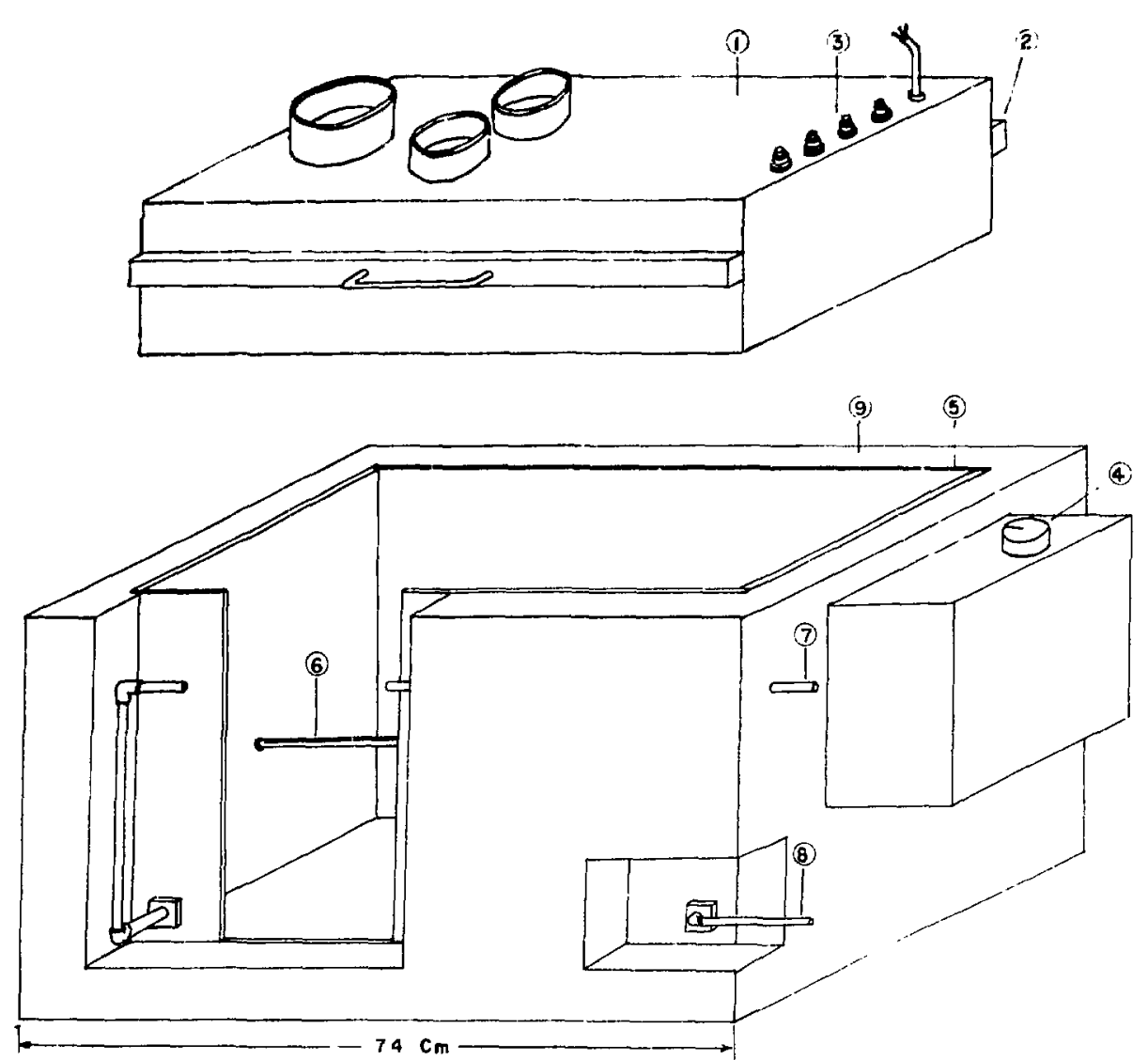

Figure 1. Portable incubator showing: (1) light source; (2) stops; (3) light and fan controls; (4) drive motor and control; (5) welded aluminum tank; (6) axle; (7) bath water exhaust; (8) bath water inlet; and (9) 2" styrofoan tank insulation.

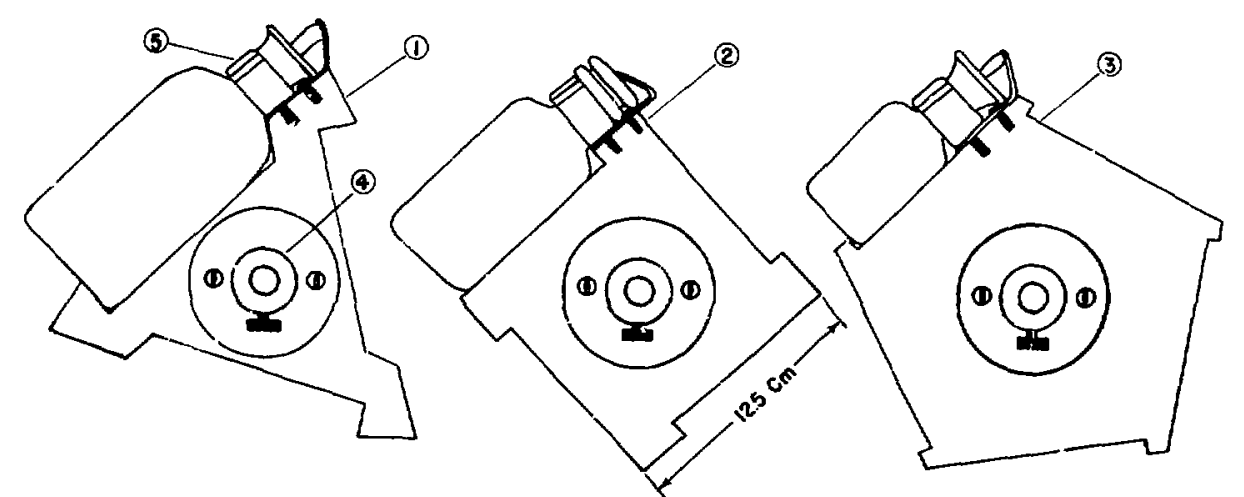

Figure 2. Sample bottle carriers showing $0.9 \mathrm{~cm}$ Incite carrier for (1) 300-mi, B.O.D. bottles, (2) $125 \mathrm{~mL}$ bottles, (3) $60 \mathrm{mr}$ bottles, (4) brass axle attachment, and (5) bottle clamps fabricated from aluninum battery holders. 


\section{References}

1. Marshall, J. S. and D. L. Hellinger, An in aitu experimental method for toxicological studies in natural plankton communities, Aquatic Toxicology, J. G. Eaton et al., Eds., ASTy Publ. STP 7071, pp. 27-39 (1980).

2. Prepejchal, W., J. S. Marshall, G. B. Hall, and M. M. Thommes, A laboratory incubator for plankton microcosm research, this report. 


\section{HETEROTROPHY IN A SEDIMENT-WATER MICROCOSY}

P. A. Szczepanik-Van Leeuwen and w. R. Penrose

\section{Backgy ound and Scope}

Segments of ecosystems (microcosms) removed to a laboratory often continue to represent the behavior of the source ecosystem for some time. Because inputs can be controlled and outputs measured, they are useful for studying properties of their sources, particularly such perturbations as pollutant atress. We have proposed that they also be used for screening newly-manufactured chemicals for environmental acceptability under the Toxic Substances Control Act of 1976.

We employed a sediment-water microcosm defined by Parker.l These were relatively undisturbed cores taken from high-deposition areas of Lake Wichigan and extruded, along with overlying water, into a plastic cylinder. These maintained superficial resemblances to the Lake Michigan benthic community for up to ten months. 2

The potential usefulness of these microcosms as screening tests depends on the ability to integrate the complex functioning of the benthic ecosystem into a few easily measured functional parameters, such as carbon flow, secondary production, and phosphorus and nitrogen turnover. They must also be reasonably reproducible and yield results qualitatively independent of, or correctible for, source and season.

\section{Progress in 1980}

This project was initiated late in the year with an August trip on the R/V Ekos. A number of 5 -inch cores were taken from Lake Michigan in an area of high sediment deposition, about $16 \mathrm{~km}$ WNW of Benton Harbor, Michigan. These were extruded into $35-\mathrm{cm}$ tubes capped at both ends and transported in ice to Argonne. They were then maintained at $4^{\circ} \mathrm{C}$.

Initial experiments were designed to develop and validate analytical procedures and to identify measurements that would reflect the activity of the enclosed ecosystems. A carbon tracer, in the form of ${ }^{14} \mathrm{C}$-labelled amino acids, was added to the water phase. Potential parameters measured were (a) respiration rates, as ${ }^{14} \mathrm{CO}_{2}$ production; (b) incorporation into the particulate 
organic carbon pool (DOC), as filtrable ${ }^{14} \mathrm{C}$, (C) benthic bioturbation activity, as depth of penetration into the sediment; and (d) detritus cycle activity, as rate of attachment of labelled bacteria to glass surfaces and labelling of meiofauna.

Both total carbon (including $\mathrm{CO}_{2}$ fixed with $\mathrm{BaCl}_{2}$ ) and "non-acid volatile" (NAV) carbon (after $\mathrm{CO}_{2}$ was removed with acid and heat) were assayed in terms of labelled carbon. The single most useful measurement proved to be the non-acid volatile carbon. The disappearance of the NAV carbon from the water phase followed first-order kinetics after a 24-hr period of stabilization. This decay appeared to have two components: respiration las $\mathrm{CO}_{2}$ ), and incorporation into biomass in the sediment phase. Estimation of the production of radioactive carbon dioxide either by headspace sampling or as $\mathrm{BaCl}_{2}$-fixed $\mathrm{CO}_{2}$ proved to be unreliable. Extraction and counting of the sediment-bound carbon allowed measurement of bloturbation observable as increased movement of hydrolyzable radioactivity into the sediment. This movement was found to be slight after the first 20 days and to increase dramatically by 33 days. The growth of microbial detrivores by colonization of bactèria on the surface of suspended vials was also shown to be measurable.

In one experiment, several microcosms were stressed with a low concentration of a typical toxic chemical $(2,4$-dichlorophenol). The rate of disappearance of the NAV carbon was significantly reduced in these microcosms. The test level of the toxicant also caused the death of all visible animals in the microcosms within three days, indicating that the concentration causing toxicity to the benthic community is much lower than previously supposed.

Future experiments will be directed at finding whether the change in NAV carbon loss rate is due to the meiofauna or to the microbial part of the detritus cycle, at determining whether the introduction of chemical toxicants affect all measurable parameters in a predictable manner, and at measuring the actual toxic level $\left(\mathrm{LC}_{50}\right)$ of the chemicals in the benthic community.

\section{References}

1. Parker, J. I., Radiological and Environmental Research Division, Rrgonne National Laboratory, unpublished (1980).

2. Parker, J. I., Predation by Mysis relicta on Pontoporeia hoyi: A food 
chain link of potential importance in the Great Lakes, J. Great Lakes Res. 6. $164-166(1980)$ 
EFFECTS OF ZINC AND CADMIUN ON PHYTOPLANKTON PRIMARY PRODUCTIVITY IN SOUTHERN IAKE MICHIGAN

J. I. Parker, K. A. Stanlaw, and J. S. Marshall

\section{Background and scope}

Recent research has confirmed that wet atmospheric deposition over southern Lake Michigan contains concentrations of zinc and cadmium 2 to 3 orders of magnitude higher than does the lake water, and that additions of as little as 108 rainwater to lakewater samples suppressed phytoplankton primary productivity. 1 The suppression is probably due to the toxic effects of zinc and cadmium in the rainwater, but do not rule out the possibility of other important pollutants. These findings lllustrated the potential for increasing zinc and cadmium concentrations in the lake water and prompted the derelopment of a series of phytoplankton community-bioassay experiments to document the toxic effects of zinc and cadmium additions on phytoplankton primary productivity in Lake Michigan water samples.

\section{Progress in 1980}

We conducted five effects experiments during the exponential growth phase and two during the senescence phase of the summer phytoplankton bloom at an offshore station in southern Lake Michigan. Two short-term (4 hr) productivity experiments were conducted using serial additions of rainwater as treatinents, 1 during the growth phase, and two short-term (4 hr) productivity experiments using zinc and cadmium additions were conducted simultaneously. One additional zinc and cadmium addition experiment was conducted during the senescence phase. Two, 2-week in situ enclosure experiments ${ }^{2}$ were conducted using zinc additions of $15,30,60$, and $90 \mu \mathrm{g} / \mathrm{L}$, one curing the exponential growth phase and one during the senescence phase.

The objectives of these experiments were to determine (1) the concentrations of zinc and cadmiun that can affect phytoplankton primary productivity and (2) the sensitivity of primary productivity to zinc and cadmium stress during different phases of the phytoplankton growth cycle.

The summer phytoplankton bloom in 1980 occurred retween mid-June and midJuly (Figure $1 A$ ). The serial additions of rainwater had little effect on phytoplankton primary productivity during the early portion of the exponential 
growth phase. However, additions of 25 and 50 ralnwater significantly reduced algal productivity during the ateepent portion of the growth phase (Figure 1B). Based on the zinc and cadnilua concentrations in the rainwater treatment used in this experiment, the 50 treatment was equivalent to additions of $\sim 10 \mathrm{\mu g} \mathrm{zn} / \mathrm{L}$ plus $0.15 \mathrm{\mu g} \mathrm{Cd} / \mathrm{L}$. The simultaneous experiments using zinc and cadmium additions produced sinilar results, with phytoplankton being most sensitive duxing the exponential growth phase, while showing little sensitivity at the onset of the exponential growth phase (Figure 1C). In these experiments primary productivity was significantly reduced at zinc or cadmium concentrations of $\sim 10 \mu \mathrm{g} / \mathrm{L}$ and $0.2 \mu \mathrm{g} / \mathrm{L}$, reepectively. Zinc plus cadmium treatments also reduced productivity, but not significantly more than the zinc or cadmium treatments alone; there was no evidence of synergism.

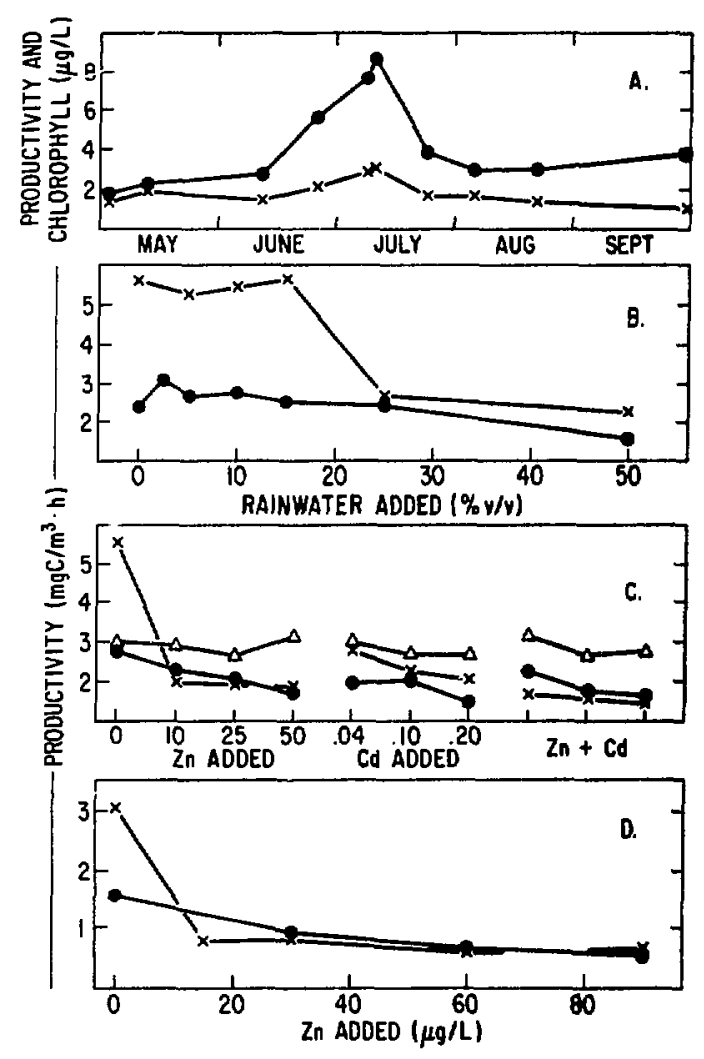

Figure 1. A. Primary productivity (e. mg $C / \mathrm{m}^{3} \cdot h$ ) and chlorophyll concentration $\left(x, \mathrm{mg} / \mathrm{m}^{2}\right)$ in the offshore phytoplankton community during the summer bloom in 1980. B. Effects of incremental additions of atmospheric precipitation on primary productivity during 11 June 1980 (o) and 25 June 1980 (x). C. Eefects of $\mathrm{zn}$ and $\mathrm{Cd}$ additions $(\mu \mathrm{g} / \mathrm{L})$ alone and in combination $(10 \mu \mathrm{g} \mathrm{zn}+$ $0.04 \mu \mathrm{g} \mathrm{Cd} / \mathrm{L}_{i} 25 \mathrm{\mu g} \mathrm{Zn}+0.10 \mu \mathrm{g}$ $\mathrm{Cd} / \mathrm{L} ; 50 \mathrm{\mu g} \mathrm{zn}+0.02 \mu \mathrm{g}(\mathrm{Cd} / L)$ on primary productivity during 11 June $(0), 25$ June $(X)$, and 5 August $(\Delta)$. D. Effects on primary productivity of $\mathrm{Zn}$ additions during two-week exposure test5, initiated on $10 \mathrm{July}$ $(\oplus)$ and 5 suguat $(x)$.

The first 2-week in situ enclosure experiment was initiated on $10 \mathrm{July}$ 
1979 at the phytoplankton bloom peak. The lowest zinc treatment $(30 \mu \mathrm{g} / \mathrm{L})$ reduced phytoplankton primary productivity by about half, while higher additions caused no further reductions (Figure 1D).

During the senescence phase, the third short-term zinc/cadmium addition experiment failed to show detectable effects on phytoplankton primary productivity either in separate or combined additions. However, the second in situ enclosure experiment showed a significant reduction of phytoplankton primary productivity after two weeks' exposure to $15 \mu \mathrm{g} / \mathrm{L}$ zinc (Figure 1D). Apparently, a longer exposure period was required to detect effects on primary productivity in senescent algal populations. This may have resulted from reduced sorbtion of zinc from the water by the senescent algal cells. ${ }^{3}$ Recent work by Davies and sleep $^{4}$ has shown that the toxic effects of zinc on marine phytoplankton productivity are directly related to cellular sorbtion levels.

These observations indicate (1) that the sensitivity of phytoplankton primary productivity in Lake Michigan to zinc and cadmium stress may be dependent on the physiological condition or growth phase of the organisms, and (2) that zinc and cadmium concentrations of $\sim 15 \mu \mathrm{g} / \mathrm{L}$ and $0.2 \mu \mathrm{g} / \mathrm{L}$, respectively, can significantly reduce primary productivity in Lake Michigan phytoplankton. This work further suggests that the EPA Water quality criteria of $\sim 50 \mathrm{\mu g} \mathrm{zn} / \mathrm{L}$ for Lake Michigan may not provide adequate protection for aquatic life. 5

\section{Prospects}

During the 1981 spring phytoplanktor bloom a series of improved toxicity tests will be completed and coupled with ${ }^{65} \mathrm{Zn}$ and ${ }^{109} \mathrm{Cd}$ radiotracer studies to determine the effects on primary productivity per unit of sorbtion. These data will be pooled with similar information obtained during the 1980 fall phytoplankton bloom to develop an annual model of effects.

\section{References}

1. Parker, J. I., G. T. Tisue, C. W. Kennedy, and C. A. Seils, Effects of atmospheric precipitation additions on phytoplankton photosynthesis in Lake Michigan water samples, J. Great Lakes Res., in press.

2. Marshall, J. S. and D. L. Mellinger, An in situ experimental method for toxicological studies on natural plankton commanities, Aquatic Toxicology. 
ASTM Publ. STP 707, Pp. 27-39 (1980).

3. Parker, J. I., K. A. Stanlaw, and C. W. Kennedy, Sorption of ${ }^{65} \mathrm{zn}$ and ${ }^{109} \mathrm{Cd}$ by seston in southern Lake Michigan, this report.

4. Davies, A. G. and J. A. Sleep, Inhibition of carbon fixation as a function of zinc uptake in natural phytoplankton assemblages, J. Mar. Biol. Assoc. U. K. 59, 937-949 (1979).

5. U.S. Environmental Protection Agency, quality Criteria for water, Office of Water and Hazardous Materials, Mashington, D. C. (1977). 
THERMAL EXPERIENCE OF BRONN TROUT RESIDING NEAR HEATED DISCHARGES

S. A. Spigarelli, M. M. Thommeg, W. Prepejchal, and R. M. Goldstein*

Background and Scope

Many ectothermic animals normally experience aiel thermocycles as the result of vertical or horizontal migrations. Considerable effort has been expended to evaluate the adaptive significance of such behavior.1,2 Normally, brown (Salmo trutta) and rainhow (Salmo gairdneri) trout inhabit inshore waters of La e Michigan and do not experience large diel temperature fluctuations. However, when encountering heated discharges, these species thermoregulate to the extent that integrated thermal dose ${ }^{3}$ and selected temperature ${ }^{4}$ are intermediate between maximum and minimum available temperatures, indicating two possible "strategies" for thermoregulation: (1) selection and acclimation to a particular preferred temperature or (2) partitioning of time between heated and cool waters to obtain an intermediate thermal dose. These preliminary findinge led to a three-year study to determine temperature-orientation behavior of trout residing near thermal discharges. Radiotelemetric techniques developed by $\mathrm{ANL}^{5}$ were employed to monitor internal body temperature and temperature of waters occupied by brown and rainiow trout. This report discusses the variations in temperature experienced by brown trout and some possible explanations for the observed behavior.

Progress in 1980

Over 15,528 telemetric observations of temperature orientation by 44 brown trout $(1$ to $7 \mathrm{~kg})$ residing near a thermal outfall were reduced and analyzed to determine the patterns of temperature exposure and the effects of season, sex, and size. Since trout were tracked under highly variable water temperature ranges (seasonal shifts), an index of attraction (equilibration index) to maximum available temperature was calculated:

$$
\text { E.I. }=\frac{T_{F}-T_{a}}{T_{d}-T_{a}}
$$

*Environmental Impact Studies Division, Argonne National Iaboratory. 
where $\mathbf{T}_{\mathbf{F}}, \mathbf{T}_{\mathbf{a}}$, and $\mathbf{T}_{\mathbf{d}}$ are the observed temperatures for $\mathbf{f i s h}$, ambient and discharge, respectively. This index allows relative comparisons of "attraction" to discharges among fish and time periods.
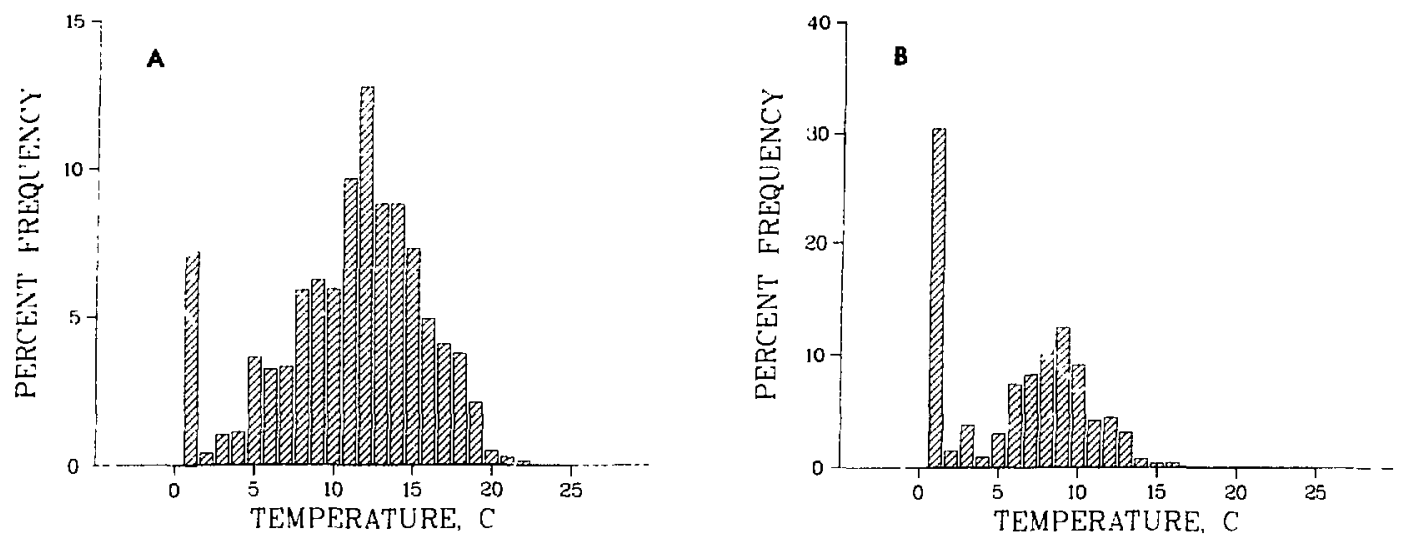

Figure 1. A. Annual frequency distribution of hourly mean body temperatures for all 44 brown trout. B. Corresponding distribution of ambient temperatures $(N=2326)$.

Annual temperature experience by brown trout in thermal psume areas is represented by a frequency distribution of observed body temperatures (Figure $1 \mathrm{~A}$ ). The modal body temperature is $12^{\circ} \mathrm{C}$ (mean $=11.1^{\circ} \mathrm{C}$ ) which approximates the optimum metabolic temperature of brown trout. ${ }^{6}$ The distribution of corresponding ambient temperatures (Figure $1 \mathrm{~B}$ ) shows modes at $1^{\circ}$ and $9^{\circ} \mathrm{C}$ (mean $=6.1^{\circ} \mathrm{C}$ ), indicating that on the average, brown trout select temperatures $5^{\circ}$ righer than ambient. Also, these distributions indicate that brown trout do not venture into thermal plumes when ambient temperatures exceed $17^{\circ} \mathrm{C}$.

Seasonal and monthly distributions of fish body temperatures are quite variable, and typically are skewed or bimodal. Most distributions, however, show relatively high peaks near $12^{\circ} \mathrm{C}$, indicating a tendency for brown trout to seek their optimum temperature every season and month, except November when the distributions were skewed to higher temperatures. The November response is thought to be a reflection of spaming-related attraction, e.g*, confusion of the discharge with a natal tributary. 
Comparisons of temperature selection between sexes indicate that males sellent higher temperatures than females every season except summer, but that this difference is offset hy males spending more time at lower temperatures, b.e.. tine sean temperature dose is similar between sexes but the selected temperatures differ. Although size effects on temperature belection are comonly noted, no size effect was found in this study, indicating that brown trout $>1 \mathrm{~kg}$ have similar thermoselection behavior.

Patterns of time spent in heated and ambient waters are shown in Figure 2. On an annual basis (Figure $2 A$ ) the distribution of equilibration indices shows that while resiaing in thermal plume areas, brown trout spent an average of $\sim 308$ of the time at ambient temperatures (E.I. = 0! and $\sim 708$ at plume iomperatures (E.I. $>0$ ). On a seasonal basis, time at ambient temperature was greatesi ( $\approx 378$ ) in spring (Figure $2 B$ ) and least $(\sim 22 \%$ ) in winter (Figure 2E). Time spent at maximum discharge temperature (E.I. $=1.0$ ) was highest ( 158) in fall (Figure 2D) when brown trout were seeking tributaries for spawning. In summer (Figure 2C: brown trout had a relatively high percentage time at plume temperatures $(\sim 688)$ while residing in the plume area, but tended to spend lttle time in the area, compared to oiher seasons.

It is apparent from these analyses that brown trout do not seek and acclimate to a particular temperature while occupying heated areas. Patterns of temperature experience were highly variable between individuals, but most fish selected temperatures (central tendency) between $11-14^{\circ} \mathrm{C}$ and partitioned time between heated and ambient waters. In some cases, there was evidence of diel patterns in the body temperature data; in others, no diel patterns were evident but the variations in temperature experience were equally high. Thus, it seems that brown trout are respording to a number of stimuli that may include: temperature preference and optima; endogenous diel rhythms in activity; and the skewed distribution of forage in thermal plume areas.

We investigated the possibilıty that forage distribution with temperature was a significant factor in the thermal distribution of brown trout. Observations of forage fish density and temperature ${ }^{7}$ were compared to frequency distributions of water temperatures experienced by brown trout. In general, temperatures selected by brown trout were those with intermediate to high densities of forage, but no significant relationship was found for a entire temperature gradient. Selected temperatures of brown trout ifrequency 

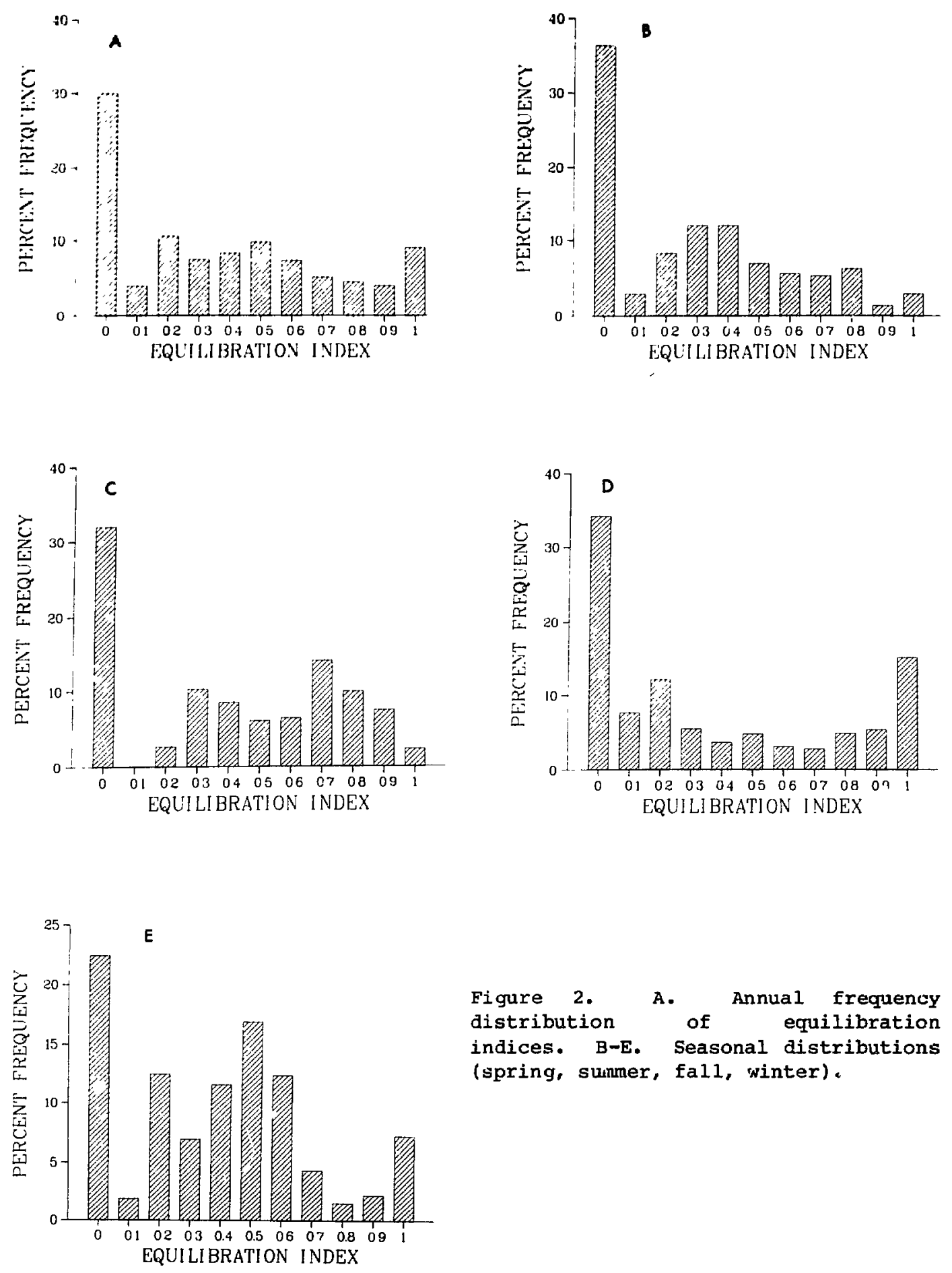

Figure 2. A. Annual frequency
distribution indices. B-E. Seasonal distributions (spring, sumer, fall, winter). 
modes) frequently occurred 1 to $2^{\circ} \mathrm{C}$ below plume temperatures where forage densities were greatest. Typically, forage fish densities are 1 to 2 orders of magnitude greater in thermal plumes in spring when alewife (Alosa pseudoharengus) are spawning, and equal or less than ambient densities at other times of the year. However, thermal plumes often have very skewed distributions of forage with temperature and localized densities that greatly exceed ambient densities. ${ }^{7}$ Thus, in most seasons, a relatively high density of forage is available somewhere in plume areas, and brown trout may be attracted to this abundant food supply.

\section{References}

1. Brett, J. R., Energetic responses of salmon to temperature. A study of some thermal relations in the physiology and freshwater ecology of sockeye salmon (Oncorinynchus nerka), Am. Zocl. 11, 99-113 (1971).

2. Biette, R. M. and G. H. Geen, Growth of underyearling sockeye salmon (Oncorhynchus nerka) under constant and cyclic temperatures in relarion to live zooplankton ration size, Can. J. Fish. Aquat. Sci. 37, 203-210 (1980).

3. Romberg, G. P. and W. Prepejchal, Thermal discharge residence by Lake Michigan salmonids, Radiological and Environmental Research Division Annual Report, January-December 1975, ANL-75-60, Part III, pp. 78-80.

4. Spigarelli, S. A. and M. M. Thommes, Temperature selection and estimated thermal acclimation by rainbow trout ( J. Fish. Res. Board Can. 36, 366-376 (1979).

5. Prepejchal, W., M. M. Thomes, S. A. Spigarelli, J. R. Haumann, and P. E. Hess, An automatic underwater radiotelemetry system to monitor temperature responses of fish in a freshwater environment, Argonne National Laboratory Report ANL/ES-108 (1980).

6. Elliott, J. M., The growth rate of brown trout (Salmo trutta) fed on maximum rations, J. Anim. Ecol. 44, 805-821 (1975).

7. Spigarelli, S. A., R. M. Goldstein, W. Prepejchal, and M. M. Thommes, Fish abundance and distribution near three heated effluents to Lake Michigan, to be published. 
EFFECTS OF CONSTANT AND FLUCTUATING TEMPERATURES ON ECTOTHERMS

S. A. Spigarelli, M. M. Thommes, W. Prepejchal, and A. Jensen*

Background and scope

Most research on the effects of environmental temperature on ectotherm physiology and behavior has followed the traditional approach of employing constant temperature treatments (acclimation). Consequently, the empirical and theoretical methods used to develop biological criteria and impact assessments are based on constant temperature relationships and the implicit assumption that ectotherm responses are similar under constant and fluctuating temperatures.

The validity of this approach and its assumptions are becoming more questionable as modern techniques provide the means to measure actual temperature exposures of $\mathrm{fish}$ in nature. There is increasing evidence to show that fish and other ectotherms do not select or acclimate to constant temperatures in nature, even over the short term. For many fishes, the normal tendency is to experience cyclic or highly variable temperatures on a diel basis: e.g., (1) sockeye salmon (Oncorhynchus nerka) ${ }^{1}$ and alewife (Alosa pseudoharengus $^{2}$ exhibit diel feeding migrations between cold hypolimnetic and warm epilimnetic waters; and (2) brown trout (salmo trutta) partition time between heated effluents and ambient temperatures. ${ }^{3}$

Based on observed thermal experience of brown trout residing near thermal effluents, we hypothesized that their increased temperature exposures (mean values) would affect metabolic rate, feeding, growth, and uptake of pollutants. Preliminary field efforts to test these hypotheses indicated that brown trout with thermal plume experience grew at faster rates, ${ }^{4}$ deposited more lipids in muscle, ${ }^{5}$ and accumulated more ${ }^{137} \mathrm{Cs}^{6}$ than fish residing at ambient temperatures. These indications led to an experiment designed to quantify the effects of observed thermal exposures on feeding, growth, lipid deposition, and pollutant uistake by brown trout in Lake Michigan. ${ }^{7}$ These factors were compared under three temperature treatments: (1) a simulation of the thermocyclic behavior of brown trout residing in thermal effluents during

*Scientist in Residence, Argonne's Division of Educational Programs; on. sabbatical leave from the University of Michigan. 
spring (mean $=12.5^{\circ} \mathrm{C}$ ); (2) a constant temperature of $13^{\circ} \mathrm{C}$, the optimum metabolic temperature for the species $^{8}$; and (3) amblent temperatures (mean $=$ $7.7^{\circ} \mathrm{C}$ ). Thus, the three treatments provided comparisons between two actual thermal regimes (thermocyclic and ambient) and between predicted (constant) and observed.
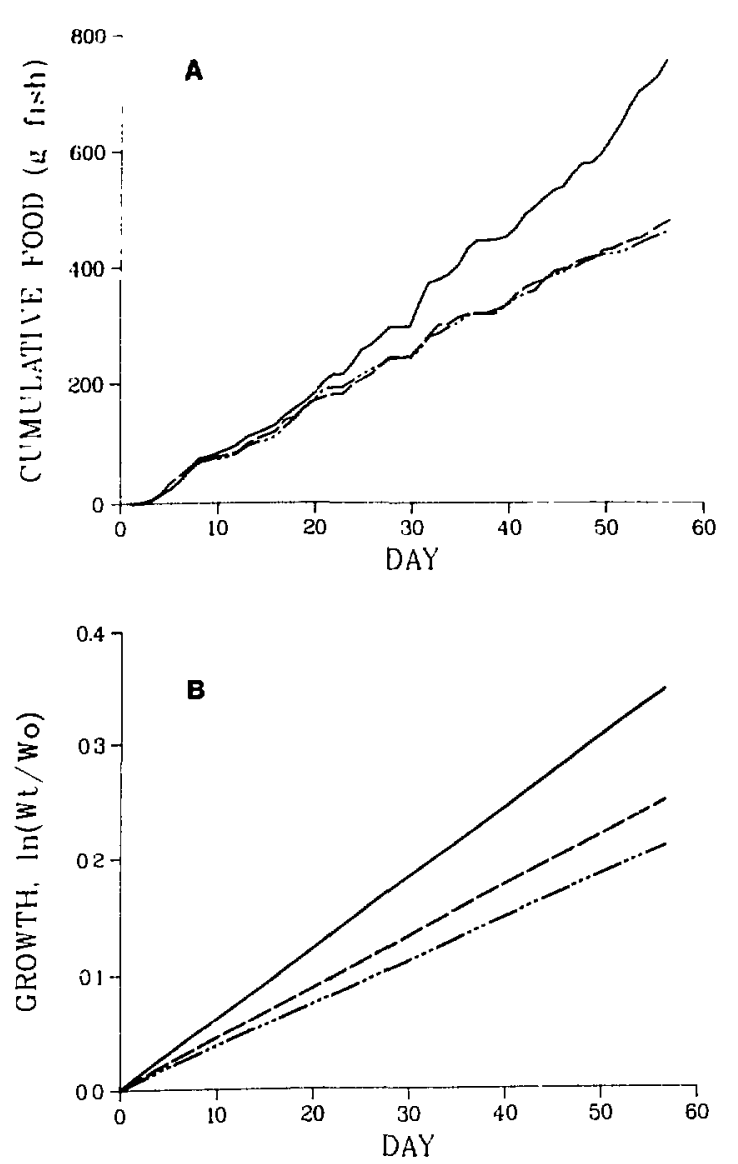

Figure 1. A. Mean cumulative food consumption by brown trout exposed to three temperature treatments. B. Growth of brown trout in each Ereatment: cyclic, $G=0.0+0.0061$ day; optimum, $G=0.0+0.0044$ day; ambient, $G=0.0+0.0037$ day. cyclic; ---, ambient; ---, optimum.

Progress in 1980

Brown trout exposed to the thermocyclic regime (plume residence simulation) consumed significantly more food than fish exposed to the constant temperature regime (Figure $1 A$ ). This result was anexpected since prevalent theory (based on constant temperature) predicted that food consumption would 
be approximately equal under a cyclic regime with a mean temperature equal to the constant temperature. ${ }^{8}$ The high level of food consumption under ambient conditions was even more surprising since predicted food consumption is considerably less than observed. The level of feeding by trout exposed to the constant optimum temperature was nearly identical to that predicted. These results indicate that feeding rate is not only dependent on absolute temperature but also on temperature variation, and that accepted theoretical constructs underestimate feeding rates under naturaliy fluctuating ternperatures.

Growth rates of brown trout were directly related to food consumption and fish exposed to the thermocyclic regime grew significantly faster than fish exposed to constant optimum or ambient temperatures (Figure 1B). Food conversion efficiencies were approximately equal among treatments, indicating no large energetic penalty for exposures to temperature fluctuations. Fluctuating temperatures also had a strong influence on lipid deposition and distribution by brown trout (Table 1). Total lipid contents (whole fish) and lipid deposition in dorsal muscle were highest for the fluctuating temperature regimes and lowest for the constant regime. The relatively high lipid aeposition by fish exposed to ambient and cyclic temperatures may indicate an "anticipatory" response characteristic in nature, but not under controlled laboratory (constant temperature) conditions.

Table 1. Lipid content ( 8 wet weight) of brown trout after 57 days.

\begin{tabular}{lccc}
\hline & \multicolumn{3}{c}{ Treatment } \\
\cline { 2 - 4 } & Cyclic & Optimum & Ambient \\
& & & \\
Whole fish & 12.2 & 7.6 & 12.9 \\
Muscle & 11.9 & 3.2 & 8.9 \\
Muscle/whole & 0.98 & 0.42 & 0.69 \\
g lipid whole/g lipid eaten & 0.46 & 0.28 & 0.67 \\
\hline
\end{tabular}

These results are very inportant since they indicate that natural fluctuations in temperature increase the rates of feeding, growth, and lipid deposition by brown trout over those predicted (based on constant 
temperature). This has significant implications regarding accepted fish growth models and applications of growth models for prediction of pollutant uptake. As previously reported, ${ }^{9}$ PCB uptake by brown trout in this experiment was greatest under the thermocyclic regime and least under the consicant temperature regime. PCB uptake was proportional to feeding rate, growth and lipid deposition, all of which are affected by temperature fluctuations.

\section{Prospects}

The curicis results of this experiment have led to the development of a simple pollutant uptake model that is based on fish energetics (1.e., growth and metabolic rates). The model is being applied to the experimental data and to PCB data from Lake Michigan, with great success. 10 It appears that much of the variability in $\mathrm{PCB}$ concentrations of Lake Michigan fishes is related to variable growth rates and lipid contents among individuals of the same species, and that this metabolic variation may, in turn, be rulated to temperature experience. Our first experiment indicates the importance of temperature fluctuations but does not allow definitive conclusions about the effects of amplitude and central tendency of temperature fluctuations on the critical parameters of feeding, growth, and lipid deposition. Future work should emphasize these relationships and their implications for toxicant uptake models.

\section{References}

1. Brett, J. R., Energetic responses of salmon to temperature. A study of some thermal relations in the physiology and freshwater ecology of sockeye salmon (Oncorhynchus nerka), Am. Zool. 11, 99-113 (1971).

2. Janssen, J. and S. B. Brandt, Feeding ecology and vertical migration of adult alewives (Alosa pseudoharengus) in Lake Michigan, Can. J. Fish. Aquat. Sci. $37,177-184$ (1980).

3. Spigarelli, S. A., M. M. Thommes, W. Prepejchal, and R. M. Goldstein, Thermal experience of brown trout residing near heated discharges, this report.

4. Spigarelli, S. A. and D. W. Smith, Growth of salmonid fishes from heated and unheated areas of Lake Michigan - measured by RNA-DNA ratios, Thermal Ecology II, G. W. Esch and R. W. McFarlane, Eds., ERDA Symp. Ser. CONF750425, pp. $100-105$ (1976). 
5. Spigarelli, S. A. and R. Holpuch, Plume residence and toxic material accumulation, Radiological and Envircrmental Research Division Annual Report, January-December 1975, ANL-75-60, Part III, pp. B1-83 (1975).

6. Spigarelli, S. A., Cesium-137 activities in fish residing in thermal discharges to Lake Michigan, Health Phys. 30, 411-413 (1976).

7. Romberg, G. P., W. Prepejchal, and M. M. Thommes, Field laboratory for in situ contaminant studies with fish, Radiological and Environmental Research Division Annual Report, January-December 1978, ANL-78-65, Part III, pp. 29-32 (1978).

8. Elliott, J. M., Number of meals in a day, maximum weight of food consumed in a day and maximum rate of feeding for brown trout (Salmo trutta), Freshwater Biol. 5 , 287-303 (1975).

9. Spigarelli, S. A., M. M. Thommes, W. Prepejchal, and D. A. Warner, Accumulation of toxic pollutants by brown trout exposed to various temperatures in Lake Michigan, Radiological and Environmental Research Division Annual Report, January-December 1979, ANL-79-65, Part III, pp. 36-40 (1979).

10. Jensen, A., S. A. Spigarelli, and M. M. Thommes, Modelling growth and PCB uptake of brown trout (Salmo trutta), this report. 
MODELLING GROWTH AND PCB UPTAKE OF BROWN TROUT (SALMO TRUTTA)

A. L. Jensent, S. A. Spigarelli, and M. M. Thommes

\section{Background and Scope}

It has been proposed that mathematical models be applied to routine identification of chemicals having a potential for environmental hazard.1.2 The economy of this approach is obvious. Success depends on availability or development of models that accurately predict transfer, fate, and bioconcentration. The objective of this study is to determine if PCB uptake by brown trout (Salmo trutta) can be accurately predicted using a bioenergetics uptake model. The model under study was developed for PCB and methyl mercury uptake by yellow perch (Perca flavescens)..$^{3}$

The model is being applied to predict $P C B$ uptake by brown trout in laboratory experiments and in Lake Michigan. In the laboratory uptake was examined under three different temperature regimes. ${ }^{4}$ The model describes uptake in terms of exposure, which is a function of food ration and volume of water passing the gills. These factors are functions of metabolism, which in turn is determined by animal size and growth rate. Several different models were applied to model growth as a function of temperature.

\section{Progress in 1980}

Development of the mathematical model, parameter estimation, development of computer progi 'ms, and preliminary data analyses have been completed. The model for change in body burden of: contaminant with respect to time is the mass balance equation

$$
\frac{d P}{d t}=e_{f} C_{f} R+e_{w} C_{w} V-k_{u} P W^{\xi},
$$

where

$$
\begin{aligned}
& P=\text { body burden of contaminant } \\
& e_{f}=\text { efficiency of toxicant uptake from food } \\
& C_{f}=\text { toxicant concentration in food }
\end{aligned}
$$

*Scientist-in-Residence, Argonne's Division of sabbatical leave from the University of Michigan. 


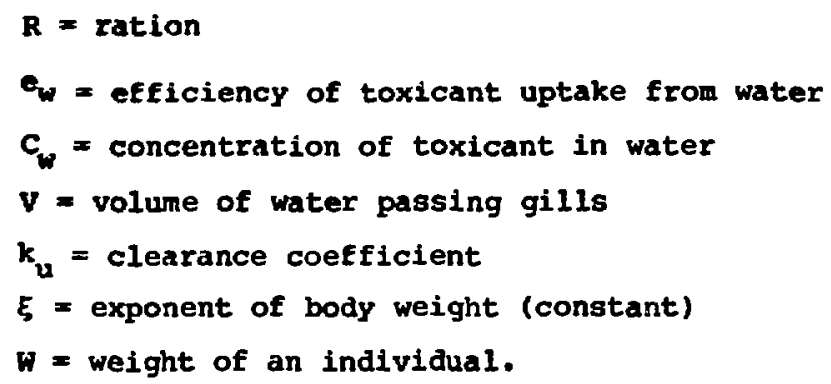

This equation states that the rate of change in body burden equals the rate of uptake from the water, $e_{w} c_{w} v$, plus the rate of uptake from the food, $e_{f} c_{f} R$, minus the rate of clearance, $k_{\mathfrak{u}} \mathrm{PW}^{5}$. Applying empirical terms for ration and volume of water passing the gills gives:

$$
\frac{d P}{d t}=\frac{e_{f} C_{f}}{e_{c f}}\left[\alpha W^{\gamma}+\beta \frac{d W}{d t}\right]-k_{u} P W^{\xi}+\frac{e_{w} C_{w}}{e_{o x} c_{o x} q_{o x}}\left[\alpha W^{\gamma}+\beta \frac{d W}{d t}\right]-k_{u} P W^{\xi},
$$

where

$$
\begin{aligned}
& \alpha=\text { low routine metabolism parameter } \\
& \gamma=\text { exponent of body weight } \\
& \beta=\text { coefficient relating growth to energy associated with growth } \\
& e_{o x}=\text { efficiency of oxygen uptake } \\
& C_{o x}=\text { concentration of oxygen in the water } \\
& q_{o x}=\text { caloric equivalent of oxygen } \\
& e_{C f}=\text { efficiency of assimilation of metabolizable enexgy from food. }
\end{aligned}
$$

The forcing functions of this uptake model are weight per individual and growth rate. To determine if growth could be predicted accurately under different temperature regimes the model was applied to growth under three different temperature regimes: constani $13^{\circ} \mathrm{C}$, ambient with a mean of $7.7^{\circ} \mathrm{C}$, and a cyclic regime with a mean of about $13^{\circ} \mathrm{C}$, period of 24 hours, and amplitude of $3^{\circ} \mathrm{C}$.

Several different growth models were investigated. ElIiott's 1976 growth equations were applied. 5 His model is of the form

$$
\frac{d w}{d x}=\left(a+b_{2} T\right) w^{1-b_{1}}
$$


$w(t)=\left[b_{1}\left(a+b_{2} T\right) t+w(0) b_{1}\right]_{1}^{\frac{1}{b_{1}}}$

where

$w(0)=$ initial weight

a. $b_{1}, b_{2}=$ parameters

$T=$ water temperature.

Elliott's model accurately predicted growth at constant cemperature, but it did not accurately predict growth under the ambient or cyclic temperatures. No model examined gave accurate predictions of growth under ambient or cyclic temperatures.

To apply the uptake model, growth equations were fitted separately to each experimental temperature regime and to Lake Michigan brown trout. These models accurately predict growth. The laboratory experiments were of relatively short duration (57 days) so the exponential growth equation was adequate. This model is of the form

$$
\begin{aligned}
& \frac{d W}{d t}=g W \\
& w(t)=w(0) e^{g^{t}},
\end{aligned}
$$

where

$g=$ growth constant

$w(0)=$ initial weight.

In the lake growth took place over a period of several years so von Bertalanffy's growth equation was applied, i.e.,

$$
\begin{aligned}
& \frac{d W}{d t}=3 W_{\infty} K e^{-K x}\left(1-e^{-K x}\right)^{2} \\
& w(t)=w_{\infty}\left(1-e^{-K x}\right)^{3},
\end{aligned}
$$

where

$W_{c o}=$ asymptotic individual weight

$\mathrm{K}=$ growth rate coefficient. 


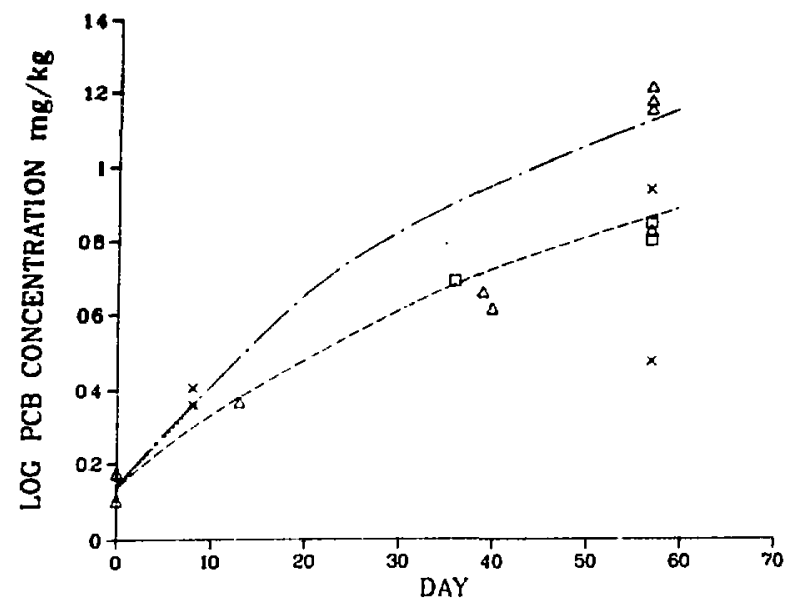

Figure 1. Uptake of $\mathrm{PCB}$ by brown trout exposed to $2.52 \mathrm{mg} / \mathrm{kg}$ in their food and $0.00001 \mathrm{mg} / \mathrm{kg}$ in the water. Rate of uptake depends on growth which is a function of temperature. $\Delta$, ol served cyclic; $x$, observed constant; $\square$, observed ambient, - - -, predicted cyclic; $\cdots$, predicted constant;

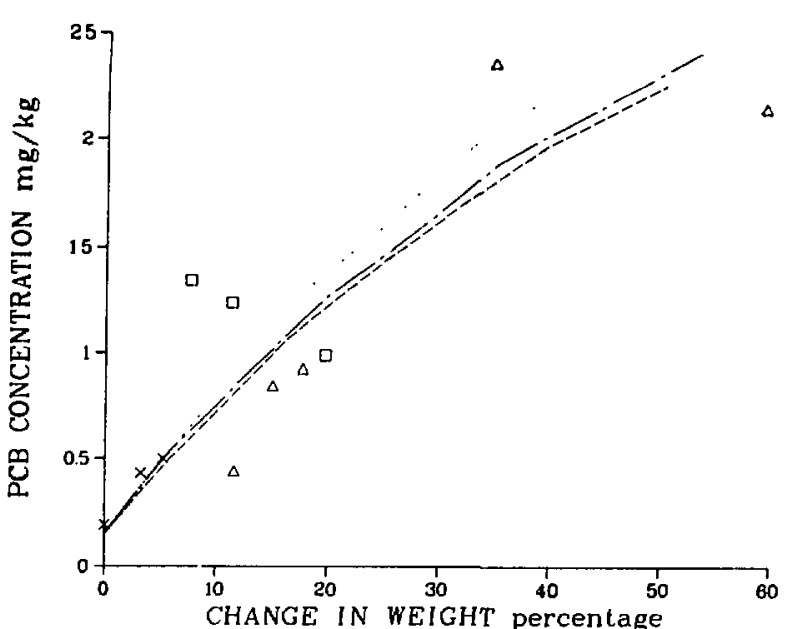

Figure 2. Relation between PCB concentration and increase in weight of brown trout in the laboratory. Symbols same as in Figure 1.

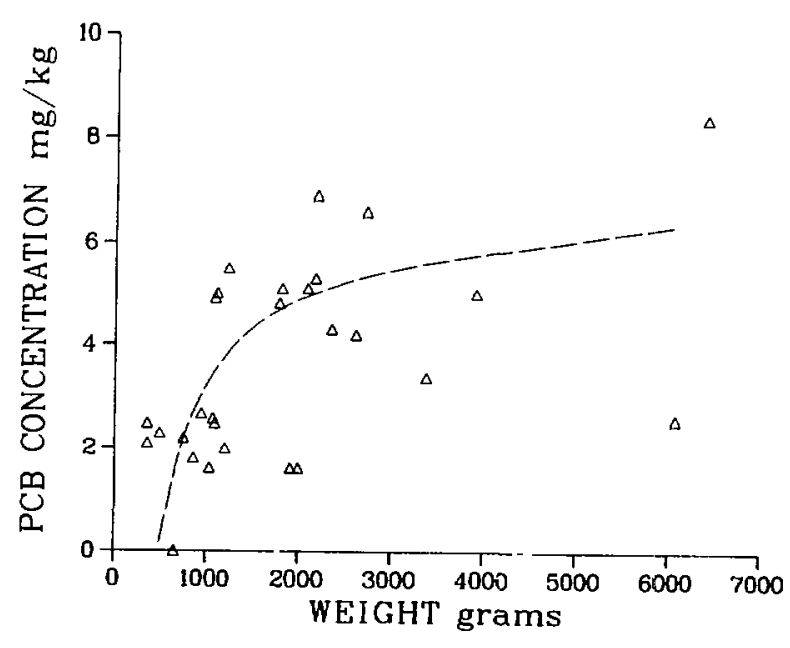

Figure 3. Relation between $\mathrm{PCB}$ concentration and weight of brown trout in Lake Michigan. 
Parameters of the growth equation were estimated from the data. All other parameters of the model were estimated using values reported in the literature. The observed uptake data were not applied to estimate model parameters or to adjust predictions.

The fit of the model to laboratory data is shown in Figures 1 and 2 and the fit to the Lake Michigan data is shown in Figure 3. The field observations were reported by the Wisconsin Department of Natural Resources. 6 There is considerable scatter in both the laboratory and the field observations, but the model describes well the trends in the observations. Increase in PCB concentration occurs rapidly during the period of high growth when fish are young. Uptake rates depend on temperature. High temperatures and fluctuating temperatures increase the growth rate 7 and the rate of toxicant uptake.

Although the model contains a large number of parameters, $f$ w of the parameters need to be estimated for evaluation of the poteitial for bioconcentration of a new material. For estimation of bioconcestration in brown trout only $e_{\mathrm{w}}$ and $e_{\mathrm{f}}$ need be estimated. Combination of the bioenergetic uptake model with a transfer and fate model such as EXAMs ${ }^{1}$ would provide a usefu .ool for predicting potential environmental hazards. ${ }^{8}$

\section{References}

1. Lassiter, R. R., G. I. Baughman, and L. A. Burns, Fate of toxic organic substances in the aquatic environment, State-of-the-Art in Ecological Modelling, Vol. 7, G. E. Jorgenson, Ed., Int. Soc. Ecol. Model., Copenhagen, pp. 211-246 (1978)

2. Baughman, G. L. and L. A. Burns, Transport and transformation of chemicals in the environment: A perspective, Handbook of Environmental Chemistry,

o. Hutziner, Ed., Springer Verlag, in press.

3. Norstrom, R. J., A. E. McKinnon, and A. I. W. deFreitas, A bioenergeticsbased model for pollutant accumulation by fish. Simulation of PCB and methylmercury residue levels in Ottawa River yellow perch (Perca Elavescens), J. Fish. Res. Board Can. 33, 248 (1976).

4. Spigarelli, S. A., M. M. Thommes, W. Prepejchal, and D. A. Warner, Accumulation of toxic pollutants by brown trout exposed to various temperatures in Lake Michigan, Radiological and Environmertai Research 
D1vision Annual Roport, January-December 1979, ANL-79-65, Part III, Pp. 36-40.

5. Elllott, J. M., The growth rate of brown trout (salmo trutta) fed on maximum rations, J. Anim. Ecol. 44, 805 (1975).

6. Scheffy, T. B., 1977 statur report on the PCB problem in wisconsin, Wreconsin Department of Natural Resources, Madison, Misconsin (1977).

7. Spigarell1, S. A., M. M. Thomes, w. Prepefchal, and A. Jensen, Effects of constant and fluctuating temperatures on ectotherms, this report.

8. Schnoor, J. I., Fate and transport of dieldrin in Coralv $+1 l e$ Reservoir: residues in fish aid water following a pestlcide ban, science 211, 840-842 (1981). 
PUDLICATEOSS BY THE STAFF OF THE EOOLOGICAL SCIENCES SECTION IN THE PERIOD JANUARY THFOMGH DECAMBR 1980

\section{Articles, Dok thap:ers, ete.}

J. J. Alberts, C. M. Bbula, and D. T. Farrax, A comparison of the distribution of industrially released ${ }^{238} \mathrm{Pu}$ and fallout $239,240 \mathrm{Pu}$ in soils of a temperate, northern United States watershed, J. Environ. gual. 9 , 592-595 (1980).

P. M. Irving and J. E. Miller, Field exposures of soybeans to $\mathrm{SO}_{2}$ and $\mathrm{NO}_{\mathrm{x}}$ in combination.... J. Air Pollut. Contr. Assoc. 30, 220 (1980).

P. R. Kamath and S. A. Spigarelli, Diseases and parasites of aquatic organisns, Envixonmental Effects of Dooling Systems, Proc. IAEA Research Coordination Committee on cooling Systems Ef fects, IAEA Technical Reports Series No. 202, International Atomic Energy Agency, Vienna, pp. 118-130 (1980).

B. M. Lesht, Benthic boundary layer velocity profiles: Dependerice on averaging period, J. Phys, Oceanogr. 10, 985-991 (1980).

J. S. Mrshall and D. I. Mellinger, An in situ experimental method for toxicological studies on natural plankton communities, ASTM Spec. Tech. Publ. 707, 27-29 (1980).

J. S. Marshall and D. I. Mellinger, Dynamics of cadmium-stressed plankton communities, Can. J. Fish. Aquat. Sci. 37, 403-414 (1980).

J. E. Miller, D. G. Sprugel, R. N. Muller, H. J. Smith, and P. B. Xerikos, Open-air funigation system for investigating sulfur dioxide effects on crops, Phytopathology 70, 124-1128 (1980).

W. Prepejchal, M. M. Thommes, S. A. Spigarelli, J. P Haumann, and P. E. Hess, An automatic underwater radiotelemetry system to monitor temperature responses of fish in a freshwater environment, Argonne National Labomatory Report ANL/ES-108 (November 1980).

C. A. Seils and G. T. Tisue, X-ray spectrometric determination of sulfate in natural waters, Adv. X-Ray Anal. 23, 133-141 (1980).

S. A. Spigarelli, Influence of temperature and other cooling system factors on fish behavior, Environmental Effects of cooling systems, Proc. IAEA Research Coordination Committee on Cooling Systems Effects, IAEA Technical Reports Series No. 202, International Atomic Energy Agency, Vienna, pp. $79-95(1980)$.

s. A. Spigarelli and C. C. Coutant, Ecosystem stress and cooling systems, Environmental Effects of Cooling Systems, Proc. IAEA Research Coordination Committee on Cooling Systems Effects, IAEA Technical Reports Series No. 202, International Atomic Energy Agency, Vienna, pp. 175-184 (1980).

S. A. Spigarelli, C. W. Voigtlander, and M. J. Schneider, Retrospective comments, Environmental Effects of Cooling Systems, Proc. IAEA Research 
Coordination comalttee on coling Systems effects, IAEA Technical Roports Series No. 202, International Atomic Energy Agency, Vienna, pp. 185-188 (1980).

D. G. Spragel, J. E. Miller, R. N. Muller, H. J. Smith, and P, B. Xerikos, sulfur dioxide effects on yield and seed quality in field-grown soybeans, Phytopathology 70, 1129-1133 (1980).

R. H. Williams, The exchange of particles and gases across water surfaces, Atmospleric Input of pollutants to Natural Maters, $C$. 4,5 . $J$. Eisenreich, Ed., Ann Arbor Science Publishers, Ann Arbor, Michigan, pp. 67-78 (1980).

\section{Contributions to Conference Proceedings and Miscellaneous Reports}

N. K. Derickson, S. A. Spigarelli, and M. M. Thommes, A computer simulation of the energetic effects on brown trout that reside in heated effluents, Abstract 110th Annual Meeting, American Fisheries Society, Iouisville, Kentucky, 21-24 September 1980.

R. M. Goldstein, S. P. Spigarelli, W. Prepejchal, and M, M. Thommes, Thermal and spatial distribution of fish in locally heated and unheated areas of Lake Michigan, Abstract 110th Annual Meeting, American Fisheries Society, Loulsville, Kentucky, 21-24 September 1980.

P. M. Irving and J. E. Miller, Response of field-grown soybeans to acid precipitation alone and in combination with sulfur dioxide, Abstract Int. Conf. Ecological Impact of Acid Precipitation, SNSF-Project, Sandefjord, Norway, 11-14 March 1980, p. 38.

P. M. Irving and J. E. Miller, Response of field-grown soybeans to acid precipitation alone and in combination with sulfur dioxide, Ecological Impact of Acld Precipitation, Proc. Int. Conf. Sandefjord, Norway, 11-14 March 1980, D. Drablos and A. Tollen, Eds., SNSF-Project, pp. 170-171 (1980).

R. M. Irving and J. E. Miller, Response of field-grown soybeans to acid precipitation alone and combination with sulfur dioxide, Abstract XXII AUA-ANL Biology Symp. Biological Aspects of Ecosystem Restoration, Argonne National Laboratory, 21-22 April 1980, No. 9.

A. I. Jensen and S. A. Spigarelli, Assessment of water intake impacts on alewife, rainbow smelt, and yellow perch populations in Iake Michigan, Abstract 5th Nat. Workshop on Entrainment and Impingement, San Francisco, 5-7 May 1980.

J. O. Karttunen, Cesium-137 in various Chicago foods, U.S. Dept. of Energy report EML-370, pp. III3-III6 (1980).

J. S. Marshall, D. L. Mellinger, and J. I. Parker, Effects of heavy metal stresses on the plankton community of a small Canadian lake, Abstract Winter Mtg., Aul. Soc. Limnology and Dceanography, Los Angeles, 31 January4 February 1980. 
J. I. Parker, T. Tisue, C. Kennedy, and C. Seils, effects of atmospheric preclpitation on primary productivity in Lake Michigan, Abstract Great Lakes 80, XXIII Conference, Kingston, Ontar10, 19-22 May 1980.

w. R. Penrose, J. S. Marshall, J. I. Parker, S. A. Splgarell1, G. T. Tiaue, and $R$. M. Williams, Unexpected sensitivity of Lake Michigan plankton to zinc, Environmental Research Contribution, ERB-80-01, Argonne National Laboratory (1980).

T. Tlsue, sulfate reduction in the interstitial fluids of Great Lakes sediments, Abstract Great Lakes 80, XXIII Conference, Kingston, Ontario, 19-22 May 1980.

T. Tisue, R. Williams, J. Muhlbaier, R. White, and R. Allison, Trace element concentrations in airborne particles over Lake Michigan, Abstract Great Lakes 80, XXIII Conference, Kingston, Ontario, 19-22 May 1980.

T. Tisue and C. Seils, Preconcentration of nanomolar amounts of trace elements from natural water for $x$-ray energy spectrometric analysis using pyrolliaine carbodithioic acid, Abstract 29th Annual z-Ray Conference, Denver, Oolorado, 4-8 August 1980.

G. T. Tisue, R. M. Williams, D. Fingleton, and J. A. Robbins, Trace elements in the atmosphere over southern Lake Michigan: Concentrations and sources, 1978, Abstract ACS National Mtg., American Chemical Society, San Francisco, September 1980. 